\title{
Viscosity Measurements of Three Base Oils and One Fully Formulated Lubricant and New Viscosity Correlations for the Calibration Liquid Squalane
}

\author{
Arno Laesecke ${ }^{1,2}$, Clemens Junker ${ }^{3}$, and Damian S. Lauria ${ }^{1}$ \\ ${ }^{1}$ National Institute of Standards and Technology, \\ Boulder, CO 80305, USA \\ ${ }^{2}$ retired from NIST
}

${ }^{3}$ Institut für Thermodynamik, Helmut-Schmidt-Universität/Universität der Bundeswehr Hamburg, Holstenhofweg 85, D-22043 Hamburg, Germany

ArnoR@Laesecke.US

junkerc@hsu-hh.de

damian.lauria@nist.gov

The viscosities of three pentaerythritol tetraalkanoate ester base oils and one fully formulated lubricant were measured with an oscillating piston viscometer in the overall temperature range from $275 \mathrm{~K}$ to $450 \mathrm{~K}$ with pressures up to $137 \mathrm{MPa}$. The alkanoates were pentanoate, heptanoate, and nonanoate. Three sensing cylinders covering the combined viscosity range from $1 \mathrm{mPa} \cdot \mathrm{s}$ to $100 \mathrm{mPa} \cdot \mathrm{s}$ were calibrated with squalane. This required a re-correlation of a squalane viscosity data set in the literature that was measured with a vibrating wire viscometer, with an estimated extended uncertainty of $2 \%$, because the squalane viscosity formulations in the literature did not represent this data set within its experimental uncertainty. In addition, a new formulation for the viscosity of squalane at atmospheric pressure was developed that represents experimental data from $169.5 \mathrm{~K}$ to $473 \mathrm{~K}$ within their estimated uncertainty over a viscosity range of more than eleven orders of magnitude. The viscosity of squalane was measured over the entire viscometer range, and the results were used together with the squalane correlations to develop accurate calibrating functions for the instrument. The throughput of the instrument was tripled by a custom-developed LabVIEW application. The measured viscosity data for the ester base oils and the fully formulated lubricant were tabulated and compared with literature data. An unpublished viscosity data set for pentaerythritol tetrapentanoate measured in this laboratory in 2006 at atmospheric pressure from $253 \mathrm{~K}$ to $373 \mathrm{~K}$ agrees with the new data within their experimental uncertainty and confirms the deviations from the literature data. The density data measured in this project for the three base oils deviate from the literature data in a way that is by sign and magnitude consistent with the deviations of the viscosity data. This points to differences in the sample compositions as the most likely cause for the deviations.

Key words: calibration; lubricants; measurements; oscillating piston viscometer; pentaerythritol tetraalkanoate esters; squalane; viscosity.

Accepted: December 13, 2018

Published: February 13, 2019

https://doi.org/10.6028/jres.124.002 


\section{Introduction}

Lubricants are needed in many industries for numerous tribological applications [1] and viscosity is their property of paramount importance [2]. A considerable chemical variety of lubricants exists [3], with esters from natural fats and oils having been used for almost four millennia [4]. Boyde and Randles summarized the various types of ester lubricants while Bohner et al. [5] focused on the little investigated polyester liquids (until 1962). Interest in pentaerythritol-derived polyester lubricants was renewed with the development of refrigeration and air-conditioning technology, when the transition from chlorinated fluorocarbons (CFCs) to hydrofluorocarbons (HFCs) in the time frame 1995 to 2010 entailed the need for new compressor lubricants, that were miscible with the HFCs and environmentally compatible [6-10].

In this project, the properties of three pentaerythritol tetraalkanoate esters and a fully formulated, MIL-PRF-23699-qualified sample were investigated as aviation lubricants. Thermal decomposition kinetics data and wide-ranging density data have been published previously $[11,12]$. This paper reports about the viscosity measurements that were carried out with an oscillating piston viscometer (OPV) in the overall temperature range from $275 \mathrm{~K}$ to $450 \mathrm{~K}$ with pressures up to $137 \mathrm{MPa}$ and in a viscosity range from $1 \mathrm{mPa} \cdot \mathrm{s}$ to $100 \mathrm{mPa} \cdot \mathrm{s}$. Modifications of the instrument with regard to thermal insulation, calibration, sample charging and pressurization, as well as automation and data acquisition are described.

This report continues with considerations of the molecular size, shape, and charge distribution of the three pentaerythritol tetraalkanoate esters and the related consequences with respect to the macroscopic properties of these compounds. The purity of the samples is also addressed. The viscometer is described here in greater detail to explain the unconventional calibration with squalane that was performed in this work. Comparisons of the measured viscosities with literature data for the three pentaerythritol tetraalkanoate esters conclude the paper.

\section{Sample Liquids}

\subsection{Molecular Considerations}

Macroscopic thermophysical properties of engineering interest arise from molecular size, shape, charge distribution, and polarizability. Thus, designing higher-performing lubricants requires an understanding of the effects of these molecular features. For a long time, the relation between molecular and macroscopic features was abstract and theoretical because molecular properties were rather inaccessible. The acceleration of computational processing has lowered the barrier to perform molecular mechanics and quantum chemical calculations. These give not only numerical results, but they also generate improved visualizations of chemical compounds that facilitate an intuitively more realistic understanding of the four features mentioned above for individual molecules as well as for the interactions between like and unlike molecules. Beyond improved static views, computational molecular science has made animations of molecular dynamics possible, which contribute to a much more realistic understanding of the timescales of molecular processes.

We have integrated molecular views in our viscosity studies for more than a decade. They are particularly valuable for more complex molecules such as those that were measured in this work. Figure 1 shows renderings of the three pentaerythritol tetraalkanoates: pentanoate $\left(\mathrm{C}_{25} \mathrm{H}_{44} \mathrm{O}_{8}\right.$, POE-5), heptanoate $\left(\mathrm{C}_{33} \mathrm{H}_{60} \mathrm{O}_{8}\right.$, POE-7), and nonanoate $\left(\mathrm{C}_{41} \mathrm{H}_{76} \mathrm{O}_{8}\right.$, POE-9). Their static shape resembles that of propellers with blades of different lengths. The renderings are based on ab initio calculations that were performed for POE5 and POE-7 with density functional theory at the B3LYP (Becke, three-parameter, Lee-Yang-Parr) level and with the 6-311++G** basis set [13]. For POE-9, the Hartree-Fock approximation with the 6-31G* basis set was used to keep computing time on a laptop to within a day. The three molecules are shown as electron density isosurfaces at a value of 0.002 electrons $\cdot \mathrm{au}^{-3}$, with 1 atomic unit $(\mathrm{au})=0.05292 \mathrm{~nm}$ being 
the Bohr radius of hydrogen. At that electron density, this isosurface encloses more than $99 \%$ of a molecule. The dots on the isosurfaces (visible in magnified view) indicate inaccessible areas ${ }^{1}$ that are not available for molecular interactions [14]. The electrostatic potential has been color-mapped onto the isosurfaces to indicate the local charge distribution in the molecules. The scale of the electrostatic potential is from red (negative charge, $-184.4 \mathrm{~kJ} \cdot \mathrm{mol}^{-1}$ for POE-9) to blue (positive charge, $111.9 \mathrm{~kJ} \cdot \mathrm{mol}^{-1}$ for POE-9). The double-bonded oxygens of the ester groups stand out as centers of negative charge. The intensity of the red color indicates clearly that the oxygens in POE-5 are less polarized than those in POE-7 and POE-9. The difference of its electrostatic potential compared to the above quoted value of POE-9 is $+18.1 \mathrm{~kJ} \cdot \mathrm{mol}^{-1}$. Figure 1 shows three views of each molecule. Frontal views in the top row are flipped forward in the middle row to show the flatness of the side aspects of the molecules and flipped forward again to show the back sides of the molecules in the bottom row. Note the crosswise distribution of the double-bonded oxygens on the front and on the back of the molecules. They can attract, at various electrostatic strengths, positive partial charges on other molecules and may eventually form associations via hydrogen bonds. Such attractions increase viscosities compared to nonpolar compounds. For instance, the very polar water molecule $\left(\mathrm{H}_{2} \mathrm{O}\right)$ is much smaller than the nonpolar decane $\left(\mathrm{C}_{10} \mathrm{H}_{22}\right)$ molecule, but its dynamic viscosity at $293.15 \mathrm{~K}$ and $0.1 \mathrm{MPa}$ is $1.0016 \mathrm{mPa} \cdot \mathrm{s}$ while that of decane is $0.91348 \mathrm{mPa} \cdot \mathrm{s}$ [15].The visualization of molecular charge distributions is a unique benefit of molecular mechanics and quantum chemical calculations that is not available with other molecular modeling methods. It facilitates a much more detailed understanding of the effects of local polarity that can influence macroscopic thermophysical properties significantly even if a molecule as a whole has no dipole moment, which is the conventional measure of polarity.

Besides the visualization, the $a b$ initio (from first principles) calculations provide quantitative information about the size and shape of the molecules. Table 1 lists surface areas, accessible surface areas, volumes, and ovalities of the isoelectron density surfaces that are shown in Fig. 1. Ovality is the surface area of an isoelectron density surface relative to the surface area of a sphere that has the same volume as the isoelectron density surface. The value of these geometric data lies in their relation to steric interactions between the molecules, providing estimates for close-packed densities that are of interest in free-volume models of densities and viscosities, and length scale parameters that can be used in collision integrals to estimate gas-phase transport properties.

Table 1. Calculated geometric properties of the isoelectron density surfaces of the pentaerythritol tetraalkanoate esters shown in Fig. 1.

\begin{tabular}{ccccc}
\hline Compound & $\begin{array}{c}\text { Surface Area } \\
\left(\mathrm{nm}^{2}\right)\end{array}$ & $\begin{array}{c}\text { Accessible Surface Area } \\
\left(\mathrm{nm}^{2}\right)\end{array}$ & $\begin{array}{c}\text { Volume } \\
\left(\mathrm{nm}^{3}\right)\end{array}$ & Ovality \\
\hline POE-5 & 5.7492 & 3.4914 & 0.55150 & 1.88 \\
POE-7 & 7.2386 & 4.2604 & 0.68878 & 2.02 \\
POE-9 & 8.8105 & 5.0857 & 0.84288 & 2.15 \\
\hline
\end{tabular}

For completeness it is noted here that a visualization of molecular size, shape, and charge distribution of the calibration liquid squalane $\left(\mathrm{C}_{30} \mathrm{H}_{62}\right)$ was contributed by one of us (A. L.) to the publication of Bair and Yamaguchi [16].

\footnotetext{
${ }^{1}$ A region on an electron density isosurface is designated as inaccessible if a sphere of radius $0.1 \mathrm{~nm}$ centered on a line normal to the surface and touching a point in the middle of the region, impinges on any other regions of the surface.
} 
Volume 124, Article No. 124002 (2019) https://doi.org/10.6028/jres.124.002

Journal of Research of the National Institute of Standards and Technology

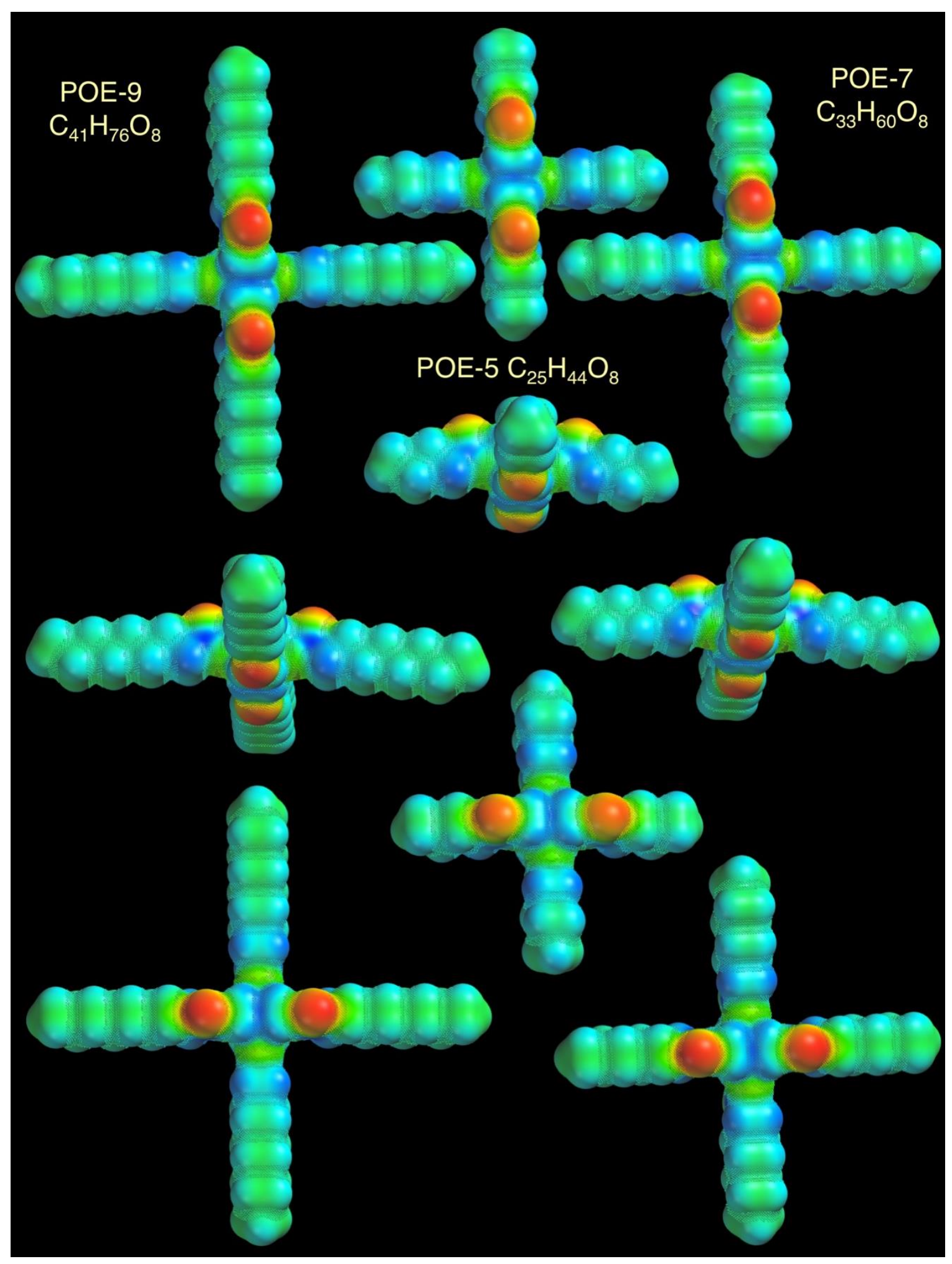

Fig. 1. Molecular size, shape, and charge distribution of the three base oils measured in this work. The color scale represents the electrostatic potential ranging from red (negative charge, $-184.4 \mathrm{~kJ} \cdot \mathrm{mol}^{-1}$ for POE-9) to blue (positive charge, $111.9 \mathrm{~kJ} \cdot \mathrm{mol}^{-1}$ for POE-9). See text in Sec. 2.1 for more details. Top row: front view., Center row: side view. Bottom row: back view. 


\subsection{Sample Preparation and Purity}

The samples measured in this work were the same samples used for the density measurements [12, 17]. The liquids were provided by the Naval Air Systems Command (NAVAIR). Compositional analyses of the sample liquids were performed at NIST Boulder with methods and results being presented in detail by Urness et al. [11]. The base oils had purities of $96.7 \%$ (POE-5), $97.3 \%$ (POE-7), and $93.0 \%$ (POE-9) by mole.

The sample liquids were transferred into $300 \mathrm{~mL}$ stainless steel cylinders and degassed. We used the "freeze-pump-thaw" cycling routine described by Outcalt [12] and in previous reports about viscosity measurements [18-20]. For the viscosity measurements in this work, the sample cylinders were mounted on the inlet of the thoroughly evacuated viscometer manifold and then samples were drawn into the viscometer and charged into the high-pressure cell with the syringe pump. More details will be given in the following sections.

We include in this report results of our earlier viscosity measurements on a POE-5 sample that was provided to NIST in 2006 from a lubricant producer. This sample was analyzed at that time in our Thermophysical Properties Division by gas chromatography and mass spectometry which detected one minor impurity. Based on uncalibrated areas, the purity of the sample was estimated at $99 \%$ by mole.

\section{Viscometer}

The measurements were carried out with a commercial oscillating piston viscometer, the ViscoPro 2000 SPL-440, which was purchased from Cambridge Viscosity, Inc., in 2010. ${ }^{2}$ The instrument was modified at NIST with regard to thermal insulation, calibration, sample charging, and pressurization, as well as automation and data acquisition. Initial experiences and measurements of rocket propellant with the viscometer were reported in a previous paper [21]. The current test stand is shown in Fig. 2. The instrument uses a variant of the falling cylinder technique [2,22], except that the motion of the sensing cylinder is not unidirectional and driven by gravity, but alternating and driven by electromagnetic induction from two magnetic coils. This electromagnetic drive of the oscillating sensing cylinder led some experimenters to use the term "electromagnetic viscometer" for the instrument [23]. However, in developing a standard test method for this viscometer, ASTM decided to use the more appropriate term "oscillating piston viscometer," because the viscosity is detected from the fluid dynamics around the alternating cylindrical sensor [24]. For the same reason, vibrating wire viscometers are not called "electromagnetic viscometers," even though the vibration of the wire is initiated by electromagnetic induction. ASTM Standard Test Method D7483 [24] covers only measurements at atmospheric pressure. No standard test method exists for measurements with this viscometer at elevated temperatures and pressures. The present paper provides guidance for such a standard test method because it reports about use of the viscometer in the widest range of temperature and pressure explored to date. In line with the reference character of the present paper, it is useful to quote other papers in which oscillating piston viscometers were used for measurements of a wide variety of liquids and gases [21, 23, 25-61].

\footnotetext{
${ }^{2}$ Certain commercial equipment, instruments, or materials are identified in this paper to describe materials and experimental procedures adequately. Such identification does not imply endorsement by the National Institute of Standards and Technology (NIST), nor does it imply that the particular product or equipment is necessarily the best available for the purpose.
} 


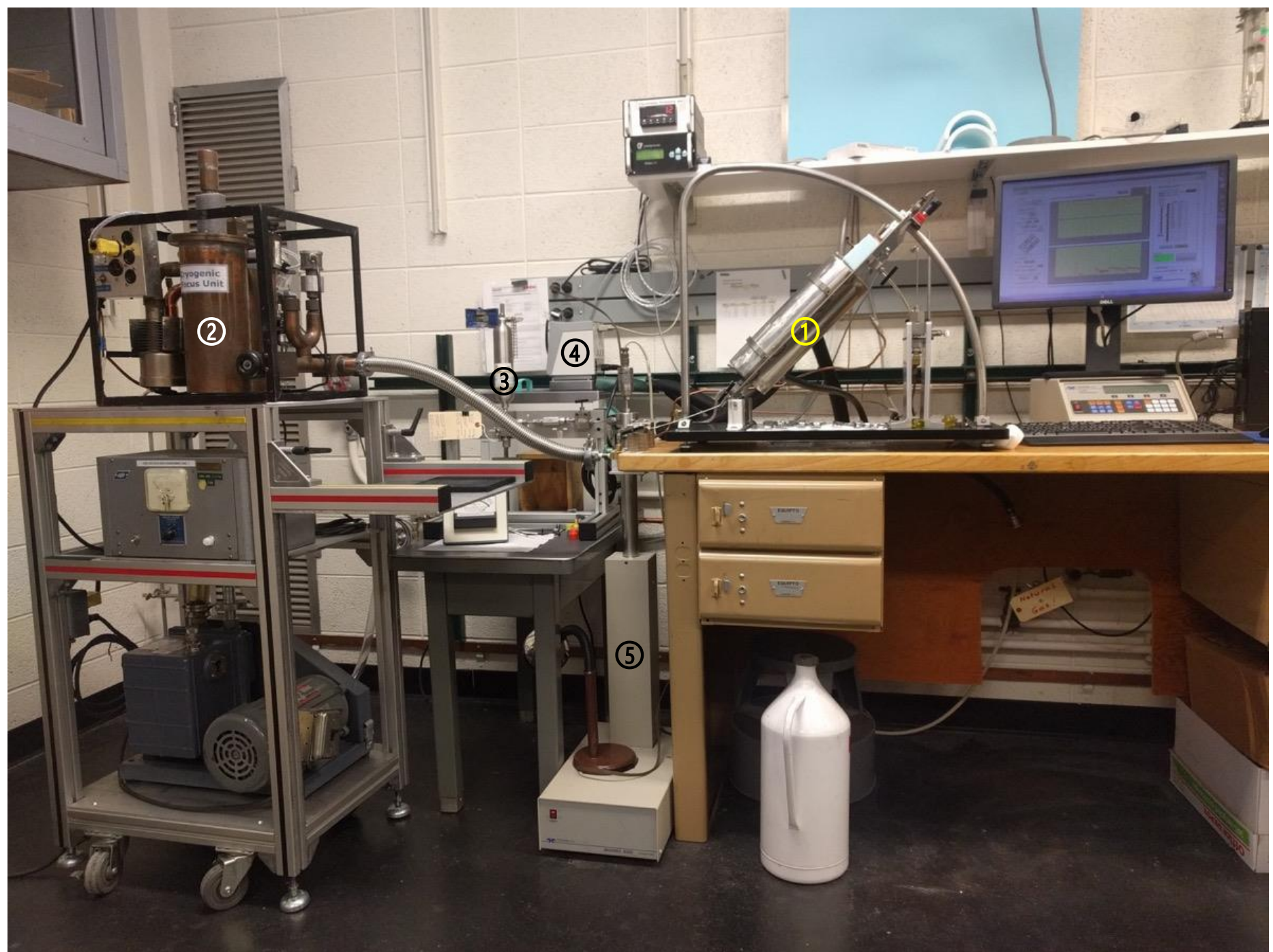

Fig. 2. View of the test stand with the oscillating piston viscometer (1) above the drawers of the work bench) and the vacuum system (2), sample cylinder (3), circulator (4), and syringe pump (5). 


\subsection{Calibration with Squalane}

For the lubricants measured in this project, three sensing cylinders were used in the viscosity ranges (1-20) $\mathrm{mPa} \cdot \mathrm{s},(2.5-50) \mathrm{mPa} \cdot \mathrm{s}$, and (5-100) $\mathrm{mPa} \cdot \mathrm{s}$. Since these sensors had not been used at NIST previously, they had to be calibrated. Squalane $\left(\mathrm{C}_{30} \mathrm{H}_{64}\right)$ was chosen as the reference liquid because its viscosity had been characterized recently in an international effort. The calibration required viscosity measurements of squalane with all three sensors in addition to the lubricant measurements. The results of the international efforts were summarized in two papers. Mylona et al. [62] published two reference correlations for the viscosity of squalane, one formulated in terms of temperature and density and one formulated in terms of temperature and pressure. Schmidt et al. [63] published a third reference correlation in terms of temperature and pressure and an additional viscosity data set that was measured at Imperial College (IC), London (UK) with a vibrating wire viscometer in the temperature range from $338.2 \mathrm{~K}$ to $473 \mathrm{~K}$ with pressures up to $200 \mathrm{MPa}$. This data set is the only one that overlaps with the temperature and pressure range of the viscometer used at NIST. It is therefore essential for the calibration of the three sensors. Unfortunately, it was found that none of the three reference correlations $[62,63]$ represents the IC data set within its estimated expanded uncertainty of $2 \%$ [63]. Rather, the combined range of deviations from the three correlations is from $-7.8 \%$ to $+7.4 \%$. If these correlations were used for viscometer calibrations with squalane, systematic errors of that magnitude would be propagated into other measurements. To avoid such compromising of the uncertainty of our measurements, a new correlation of the IC data set had to be developed in this project to represent these data within their quoted uncertainty of $2 \%$.

The correlation of the IC viscosity data set started with thermodynamic scaling, an approach that was not pursued in the formulation of the three previous correlations $[62,63]$ but that has been successfully implemented in many viscosity representations for compressed liquids over wide ranges of temperature, pressure, and viscosity $[64,65]$. Thermodynamic scaling is based on the insight that the relationships between any three thermophysical properties of monodisperse particles reduce from three-dimensional surfaces to two-dimensional lines if the particles interact only by repulsive forces. Ashurst and Hoover [66] were the first to point out this insight for viscosity and showed that the viscosity of the purely repulsive soft sphere potential can be expressed as a monovariate function of the parameter $\left(T / \rho^{\gamma}\right)$, defined with the absolute temperature $T$, density $\rho$, and the exponent $\gamma$, which is directly related to the strength of the repulsive potential. In 2012, Fomin et al. gave an empirical monovariate formulation for the viscosity of soft spheres in terms of this parameter [67].

The viscosity representation of the IC data set was formulated initially in terms of the parameter $\left(T / \rho^{\gamma}\right)$. In a manual process guided by experience and trial it turned out that the parameter required temperature shift terms in order to correlate the IC data set. The final formulation in terms of reduced temperature and reduced density is

$$
\varphi=\frac{\frac{T}{T_{0}}+a_{1}}{\left(\frac{\varrho}{\varrho_{0}}\right)^{a_{2}+a_{3} \frac{T}{T_{0}}}}
$$

with the reference temperature $T_{0}=273.15 \mathrm{~K}$, the reference density $\varrho_{0}=826.0088 \mathrm{~kg} \cdot \mathrm{m}^{-3}$ at $T_{0}$ and a pressure of $10 \mathrm{MPa}$, and the adjusted parameters $a_{1}=-0.6898, a_{2}=14.6818$, and $a_{3}=-3.3466$. The viscosity of the IC data set is obtained from

$$
\eta=\eta_{0} \exp \left\{b_{1}+\frac{b_{2}}{\left(b_{3}+\varphi\right)^{b_{4}}}\right\}
$$


with the dimensioning factor $\eta_{0}=1 \mathrm{mPa} \cdot \mathrm{s}$ and the parameters $b_{1}=-2.5214, b_{2}=4.2516, b_{3}=-0.1209$, and $b_{4}=0.3598$. The IC viscosity data set is represented by this formulation with an average and standard deviation of $(0.39 \pm 1.0) \%$, a maximum positive deviation of $2.5 \%$, and a maximum negative deviation of $-2.4 \%$. A more detailed view of the performance of the formulation on each of the seven isotherms is shown in the deviation plot in Fig. 3. Only two deviation points are outside the estimated expanded uncertainty band of $\pm 2 \%$ of the IC data set. Thus, the correlation represents the IC data set consistently and qualifies to provide reference data for calibrations of viscometers. It was used in this work to calibrate the measurements with the oscillating piston viscometer at temperatures of $340 \mathrm{~K}$ and above. Densities as input for Eq. (1) were calculated from the measured temperatures and pressures with the modified Tait-equation reported by Schmidt et al. [63]. At temperatures below $340 \mathrm{~K}$, the squalane viscosity correlation in terms of temperature and pressure by Mylona et al. [62] was used for the calibrations.

\section{$100\left(\left(\eta_{\text {exp }} / \eta_{\text {corr }}\right)-1\right)$}

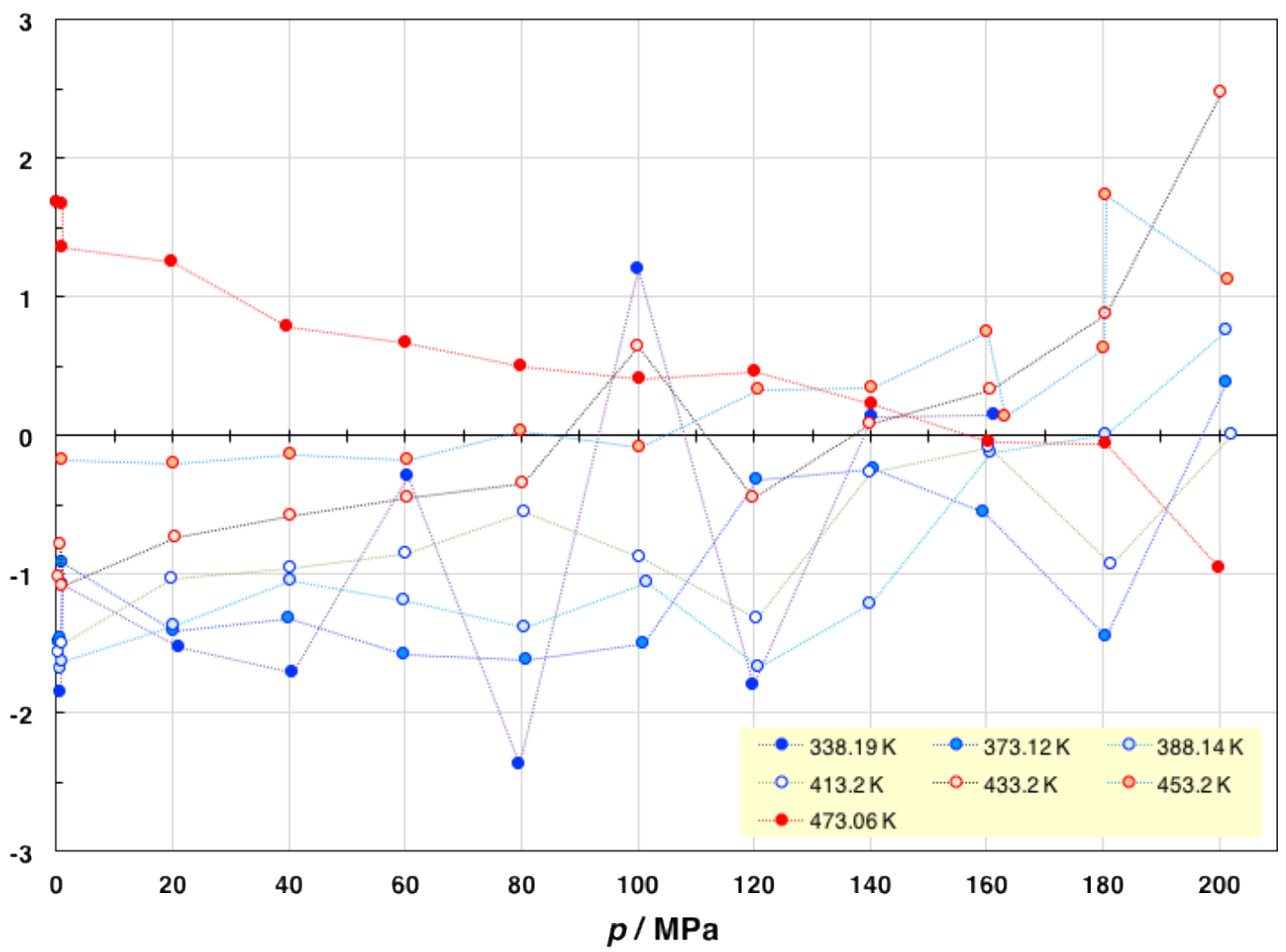

Fig. 3. Deviations of the experimental squalane viscosity data reported in Schmidt et al. [63] from values calculated with the formulation developed in this work, Eq. (1) and Eq. (2). Lines are drawn to aid the viewer to discern the isotherms.

The viscosity of squalane at atmospheric pressure has not only been measured frequently since 1957, but also over a very wide viscosity range. In their rheometric measurements of subcooled liquids to a lowest temperature of $169.5 \mathrm{~K}$, Deegan et al. [68] reached a viscosity of $3.740 \times 10^{11} \mathrm{mPa} \cdot \mathrm{s}$ for squalane. This data set was not mentioned in the analyses of Mylona et al. [62] nor those of Schmidt et al. [63]. It was obtained in this work from the authors and combined with the USC Stabinger data set of Comuñas et al. [69] and the IC data set reported by Schmidt et al. [63] after extrapolating each isotherm back to $0.1 \mathrm{MPa}$. The following temperature function was developed to represent these viscosity data within their estimated expanded experimental uncertainties 


$$
\eta_{0.1}=\eta_{0} \exp \left\{\frac{c_{1} T_{r}^{4}+c_{2} T_{r}^{3}+c_{3} T_{r}^{2}+c_{4} T_{r}+c_{5}}{T_{r}^{3}+c_{6} T_{r}^{2}+c_{7} T_{r}+c_{8}}\right\}
$$

Here, subscript " 0.1 " indicates the viscosity at $0.1 \mathrm{MPa}$. The reduced temperature is defined as in Eq. (1), $T_{\mathrm{r}}=T / T_{0}$, as is the dimensioning factor $\eta_{0}=1 \mathrm{mPa} \cdot \mathrm{s}$. The adjusted parameter values for $c_{i}$ are given in Table 2.

Table 2. Values of the parameters $c_{i}$ in Eq. (3).

\begin{tabular}{cccc}
\hline$i$ & $c_{i}$ & $i$ & $c_{i}$ \\
\hline 1 & -0.7816 & 5 & 1.8224 \\
2 & 0.8992 & 6 & -2.0234 \\
3 & 2.3825 & 7 & 1.4502 \\
4 & -3.9330 & 8 & -0.3448 \\
\hline
\end{tabular}

The data of Deegan et al. [68] are represented by Eq. (3) within $-6.2 \%$ and $9.1 \%$. The deviations of the USC Stabinger data set of Comuñas et al. [69] range from $-0.34 \%$ and $0.48 \%$, and those of the IC data set reported by Schmidt et al. [63] vary between $-2.7 \%$ and $0.26 \%$. With this performance over more than 11 orders of magnitude in viscosity, Eq. (3) provides viscosity information over an exceptionally wide range, which will be useful for future developments. For instance, it might be incorporated as the atmospheric pressure contribution into a wide-ranging formulation for the viscosity of squalane that represents all experimental data, including those to gigapascal pressures by Bair et al. [70]. Figure 4 shows also that Eq. (3) represents the data more accurately than the viscosity correlations at 0.1 MPa by Mylona et al. [62] and by Schmidt et al. [63].

The squalane sample was obtained from a commercial source and analyzed at NIST with gas chromatography (GC) and mass spectrometry (MS) detection. The purity was determined to be greater than $99.1 \%$ by mole from the uncalibrated raw area percent for an average of two repeat injections. The combined uncertainty was $0.5 \%$. The impurities were not identified by standards but were other branched and linear long-chain paraffins. For use in the viscometer, the squalane was transferred to a $300 \mathrm{~mL}$ stainless-steel cylinder and degassed by "freeze-pump-thaw" cycling as described above in Sec. 2.2.

In total, 715 viscosity data points were measured with all three sensing pistons for the calibration liquid squalane from $277 \mathrm{~K}$ to $450 \mathrm{~K}$ with pressures to $137 \mathrm{MPa}$. In an ad hoc approach, calibration functions in terms of pressure were obtained at each measured temperature. Reference viscosities were calculated from the Vogel-Fulcher-Tammann (VFT) correlation of Mylona et al. [62] at temperatures below $340 \mathrm{~K}$, and the correlation in Eq. (1) and in Eq. (2) of the IC data set that was developed in this work at temperatures above $340 \mathrm{~K}$. The VFT correlation of Mylona et al. [62] represents the experimental data of other laboratories within $\pm 3 \%$, and the correlation of the IC data set represents these data within their quoted uncertainty of $2 \%$. For each isotherm of the squalane measurements with a certain sensing piston, the deviations of the measured squalane viscosities from the reference squalane viscosities were correlated empirically as polynomials in terms of pressure, and these deviation polynomials were applied to correct the measured viscosities of the four sample liquids on the same isotherms. 
$100\left(\left(\eta_{\text {exp }} / \eta_{\text {corr }}\right)-1\right)$

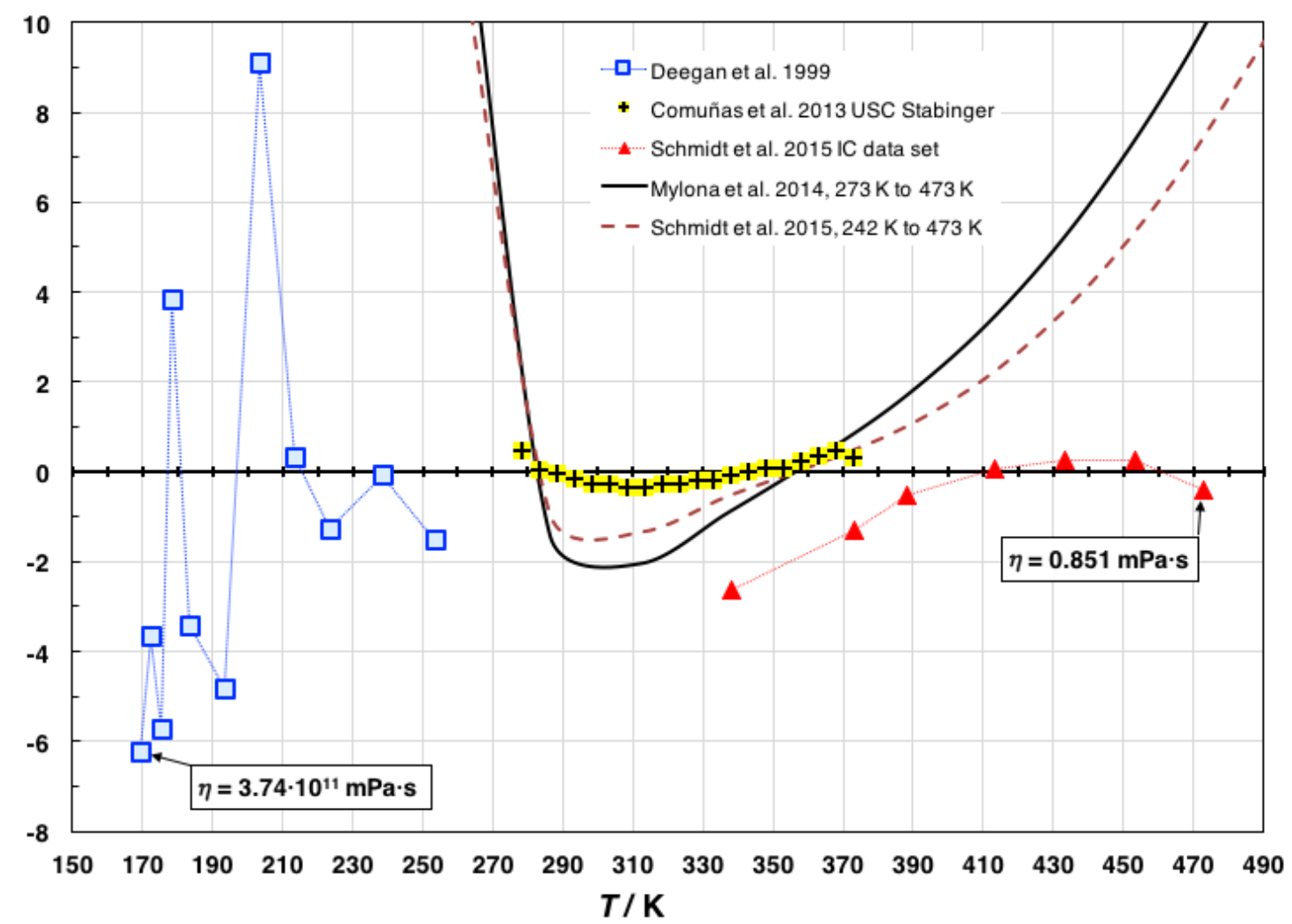

Fig. 4. Deviations of the experimental squalane viscosity data from values calculated with the wide-range viscosity-temperature correlation at $0.1 \mathrm{MPa}$ from Eq. (3). Lines are drawn to aid the viewer to discern trends. Also shown are the deviations of the previous correlations by Mylona et al. [62] and by Schmidt et al. [63] from the new correlation.

\subsection{Experimental Setup and Procedure}

Figure 2 shows the experimental setup with the vacuum system, the sample cylinder mount, the circulator, the syringe pump, and the viscometer. The tubular cell containing the sample and a viscosity sensing cylinder is rated to $20,000 \mathrm{psia}$ (pounds per square inch absolute) or $137 \mathrm{MPa}$. The temperature of the cell can be set and controlled between $270 \mathrm{~K}$ and $450 \mathrm{~K}$ with polydimethylsiloxane heat transfer liquid that is pumped from the small laboratory circulator through a thermal jacket around the high-pressure cell. The temperature of the tubular cell is measured with a commercial $100 \Omega$ platinum resistance temperature detector (RTD) that was calibrated and mounted on the outside of the pressure vessel by the manufacturer. The RTD is in a sealed space and cannot be removed from the pressure vessel to check its calibration. The manufacturer-quoted uncertainty of the temperature measurement is $0.1 \mathrm{~K}$. This uncertainty component contributes at most an uncertainty of $0.47 \%$ to the present measurements of the viscosity of POE- 9 at $290 \mathrm{~K}$ and $4.8 \mathrm{MPa}$ where the maximum gradient $(\partial \eta / \partial T)_{p}$ occurred.

The pressure in the viscometer is generated with a high-pressure syringe pump rated to $137 \mathrm{MPa}$ with a maximum sample volume of $65 \mathrm{~mL}$. Pressure was measured with a commercial transducer rated to $207 \mathrm{MPa}$ with a full-scale uncertainty of $0.05 \%$ or $0.1035 \mathrm{MPa}$. Prior to this project, the transducer calibration had been checked with a primary pressure balance at 55.2 MPa, 41.4 MPa, 27.6 MPa and 13.8 $\mathrm{MPa}$, and the highest deviation was $-0.17 \%$ at the lowest calibration pressure, as opposed to $0.8 \%$ 
based on the full-scale uncertainty. This uncertainty component contributes negligibly to the present measurements, because the gradients $(\partial \eta / \partial p)_{T}$ are rather flat for compressed liquids.

After degassing, sample cylinders were mounted on the inlet of the viscometer manifold, and the entire manifold was evacuated with the mechanical pump and with the diffusion pump. The piston of the syringe pump was cycled during the vacuum pumping to remove residues on the walls of the syringe pump cylinder. With the syringe pump piston at the top position, the vacuum system was valved off, and the sample cylinder valve was opened. Sample liquid was drawn into the syringe pump cylinder until its volume of $65 \mathrm{~mL}$ was filled. After closing the sample cylinder valve, the valve between the syringe pump and the high-pressure cell was opened and sample was pumped into the viscometer manifold until it began to drain from the outlet of the manifold. Then, pumping was stopped, the outlet valve was closed, and the measurement of an isotherm commenced. Customized LabVIEW software was used to program the circulator to the desired temperature, to set the appropriate equilibration time and the desired pressures, and to set the measurement duration at each pressure.

In the beginning of the project, viscosity data acquisition and scheduling were performed with software from the viscometer manufacturer. This was supplemented by a custom-developed LabVIEW utility that was adapted from the automated vibrating-tube densimeter [71] to control and schedule the pressures to be generated by the high-pressure syringe pump. The manufacturer software became increasingly unreliable during the measurement campaign, with more and more frequent crashes, and associated data losses and time losses requiring measurement series to be repeated. The software had also very limited capabilities to schedule the viscometer outside regular business hours. These problems were thoroughly eliminated by replacing the manufacturer software with a sophisticated custom-developed LabVIEW virtual instrument (VI) that included all the capabilities for an efficient, accurate, and automated operation of the viscometer based on our operational experiences. This LabVIEW VI accelerated the viscometer throughput by a factor of three so that three isotherms could be measured to $137 \mathrm{MPa}$ per day. Due to its agility, the LabVIEW VI provides much more transparency of the internal viscometer state to the user. For instance, the presence of sample liquid or solvent in the viscometer cell is indicated when the RTD registers a corresponding temperature change. Figure 5 shows the front panel of the LabVIEW VI for an entire isotherm. The custom-developed LabVIEW VI can be obtained from coauthor Damian Lauria upon reasonable request.

The viscosity measurements were carried out in the sequence POE-9, squalane, POE-7, squalane, POE-5, MIL-PRF-23699-qualified sample, squalane, with extensive rinsing of the viscometer in between each sample. The solvent was a mixture of hexane isomers. During the rinsing, the high-pressure cell was set to $35^{\circ} \mathrm{C}$. The volume of rinsing solvent was at least $300 \mathrm{~mL}$, which provided for 4.6 fillings of the cylinder of the high-pressure syringe pump. The internal volume of the high pressure cell is approximately $8 \mathrm{~mL}$, and the volume of the remaining parts of the viscometer manifold is approximately $5 \mathrm{~mL}$. Thus, the solvent volume was sufficient to rinse the viscometer volume several times over.

The MIL-PRF-23699-qualified sample was measured last because previous in-house density measurements found the sample was difficult to handle and remove from measurement equipment. [12]. During the viscosity measurements, it was observed that the MIL-PRF-23699-qualified sample diffused through the polytetrafluoroethylene tape seals on the top and the bottom of the sample cylinder as these showed the brown color of the sample liquid after a few days. In addition, after the measurements of the MIL-PRF-23699-qualified sample, it was observed that the solvent hexanes (a mixture of hexane isomers) was not miscible with that sample. Therefore, the viscometer was rinsed in addition with dodecane and then again with hexanes. Despite the more extensive rinsing with two solvents, the following repeat squalane calibration measurements at $360 \mathrm{~K}$ and $370 \mathrm{~K}$ with the sensing piston (5-100) $\mathrm{mPa} \cdot \mathrm{s}$ turned out to be invalid and could not be repeated again within the duration of the project. Therefore, it was not possible to report calibrated viscosity data from measurements with this piston at these two temperatures. When results are reported at these two temperatures they were obtained with one of the other two sensing pistons. 


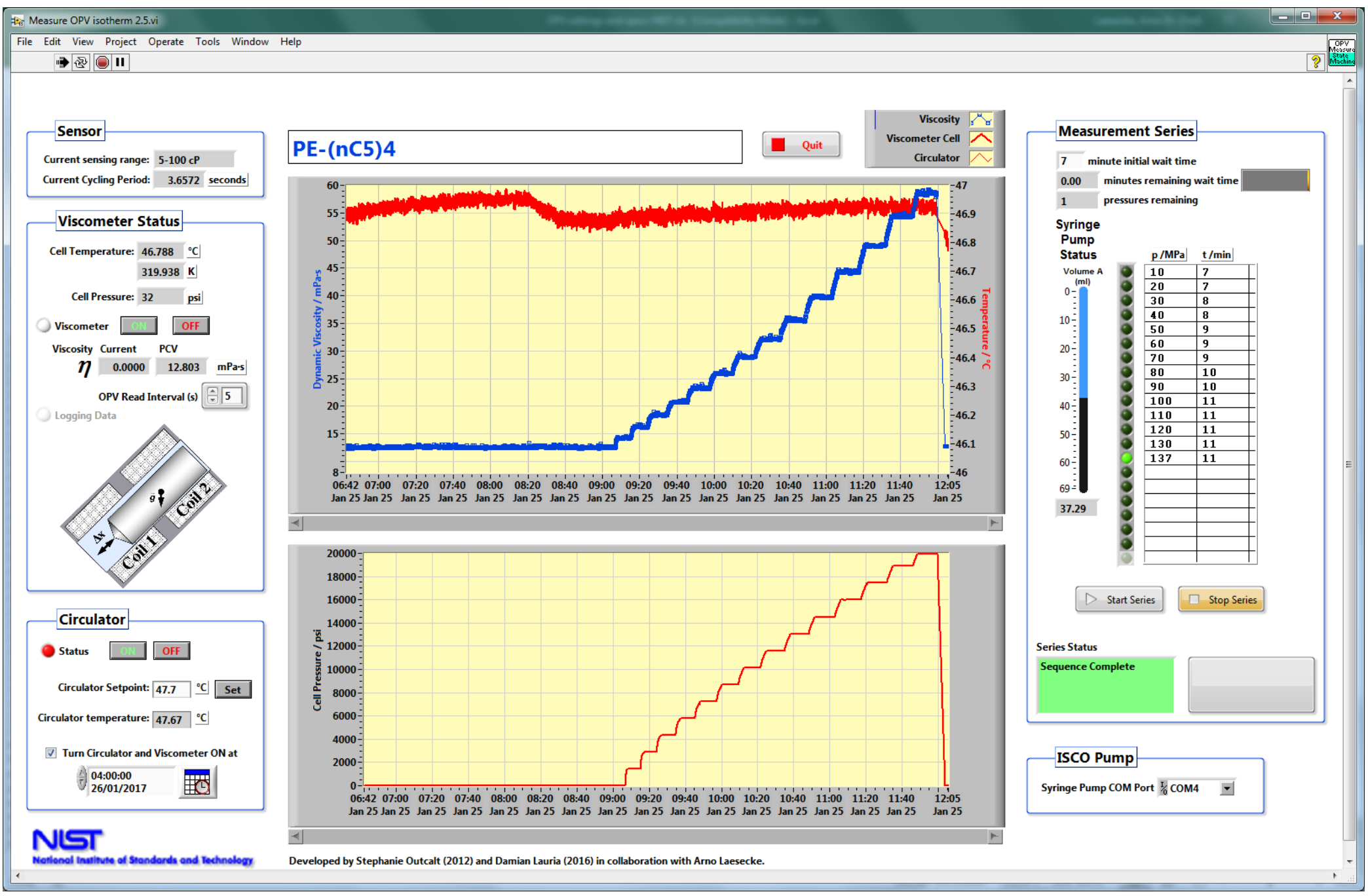

Fig. 5. Front panel of the custom LabVIEW virtual instrument (VI) developed in this project to automate the oscillating piston viscometer with the associated circulator and syringe pump for isothermal measurements over the entire pressure range. Features shown are traces of the cell temperature (red), the viscosity (blue), and the cell pressure (thin red) of the measurement of the POE-5 sample along the $320 \mathrm{~K}$ isotherm. 


\subsection{Data Analysis}

As an example for the 1942 measurements that were carried out in this work on the four lubricants and squalane and to illustrate the data analysis that was applied to each such record, Fig. 6 shows the graphical record of the measurement of the MIL-PRF-23699-qualified sample at $370 \mathrm{~K}$ with the sensing piston (5100) $\mathrm{mPa} \cdot \mathrm{s}$ from $0.083 \mathrm{MPa}$ to $137.31 \mathrm{MPa}$. Raw viscosity (green dots) was derived from the measured cycling period of the sensing piston. Pressure corrected viscosity (blue dots) was obtained from raw viscosity by applying proprietary correction functions from the manufacturer for thermal expansion and pressure effects on the geometry of the cell and the sensing pistons. The green and blue dots exhibit two phenomena. The first is a slow equilibration to the next pressure at low pressures which becomes sharper with increasing pressures. This is due to the decreasing compressibility of the liquid with increasing pressure. The variable equilibration time requires averaging the recorded viscosity over a variable time interval during the data analysis. The second phenomenon is the scattering of the viscosity recordings at constant pressures, which varied in strength and can be much greater than shown in Fig. 6 . The cause of this seemingly random scatter could not be determined unequivocally. It is suspected to result from interferences from magnetics research that is conducted in the same laboratory building. Nevertheless, the scatter could be filtered so that it did not deteriorate the reproducibility of the measurements. To assure the highest possible data quality, this manual inspection and data analysis was processed for all 1942 experimental records. The trace in Fig. 5 shows an experimental record with very little scattering, which is typical for about half of the measurements.

\section{Results}

The viscosity measurement results for the lubricants are reported in Tables 3 to 6 in the sequence in which they were measured both with respect to the sample liquids as well as with respect to the temperatures. The listed temperatures $T_{90}$, pressures $p$, and viscosities $\eta$ are averages over the durations of the measurements, as shown in the examples of Figs. 5 and 6 . The standard deviations $s_{T}, s_{p}$, and $s_{\eta} / \eta$ are given to indicate the repeatability of the measurements as a component towards their uncertainty which will be assessed below. In total, 368 data points were measured for POE-9, of which 196 are reported in Table 3. Due to solidification of the sample, the lowest temperature of these measurements was limited to $290 \mathrm{~K}$. In total, 407 data points were measured for POE-7, of which 281 are reported in Table 4. The lowest temperature of these data is $280 \mathrm{~K}$. In total, 407 data points were measured for POE-5, of which 268 are reported in Table 5. The lowest temperature of these data is $275 \mathrm{~K}$. In total, 300 data points were measured for the MIL-PRF-23699-qualified sample of which 202 are reported in Table 6. The lowest temperature of these data is $290 \mathrm{~K}$. The number of measured and reported data points varies from sample to sample due to the variation of their viscosities, while the experimental viscosity range of the instrument was fixed between $1 \mathrm{mPa} \cdot \mathrm{s}$ and $100 \mathrm{mPa} \cdot \mathrm{s}$. POE-9 has the highest viscosity because, as Fig. 1 shows, it is the largest and most complex molecule with strong interlocking possibilities of the nonanoate side chains. As the length of these side chains decreases from POE-9 to POE-7 and POE-5, so decreases the viscosity of the compounds. The viscosity data of the MIL-PRF-23699-qualified sample are of the most practical interest. They are shown in Fig. 7 as a function of pressure. Comparisons of these data showed that the viscosity of the MIL-PRF-23699-qualified sample is approximately $10 \%$ higher than that of POE-7 at pressures below $50 \mathrm{MPa}$, while it increases faster with increasing temperature and pressure, eventually exceeding the POE-7 viscosity by up to $55 \%$ at $450 \mathrm{~K}$ and $137 \mathrm{MPa}$. Compared to the viscosity of POE-9 it was approximately $20 \%$ lower across all temperatures and pressures of the present investigation. 


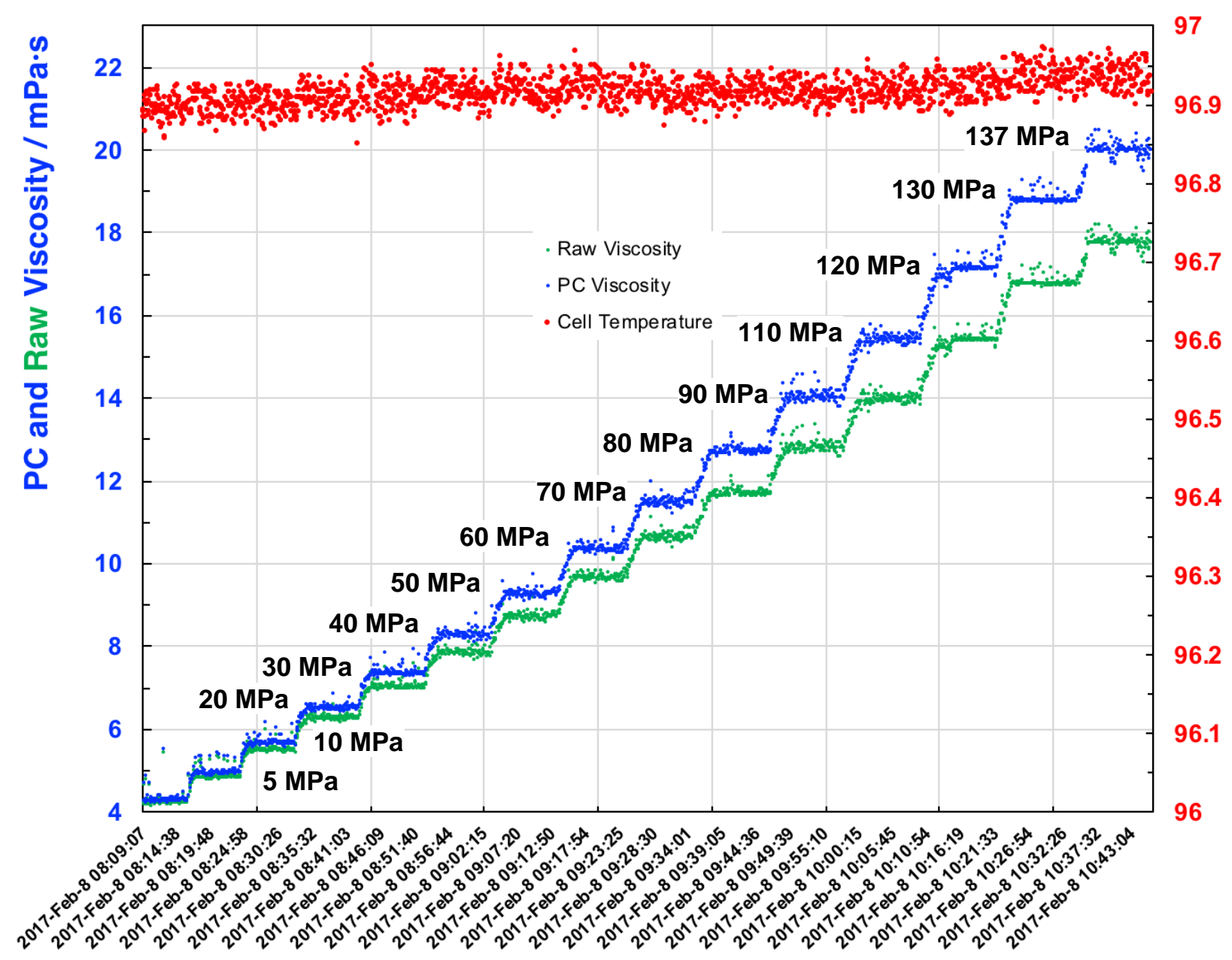

0
0
0
$\frac{1}{0}$
$\frac{\pi}{0}$
$\frac{0}{E}$
$\frac{10}{0}$
$\overline{0}$

\section{Measurement Date and Time}

Fig. 6. Graphical record of the measurement of the MIL-PRF-23699-qualified sample at $370 \mathrm{~K}\left(96.85^{\circ} \mathrm{C}\right.$ ) with the sensing piston (5-100) $\mathrm{mPa} \cdot \mathrm{s}$ from $0.083 \mathrm{MPa}$ to $137 \mathrm{MPa}$. Raw viscosity (green dots) was derived from the measured cycling period of the sensing piston. Pressure-corrected viscosity (blue dots) was obtained from raw viscosity by applying proprietary correction functions from the manufacturer for thermal expansion and pressure effects on the geometry of the cell and the sensing piston. 


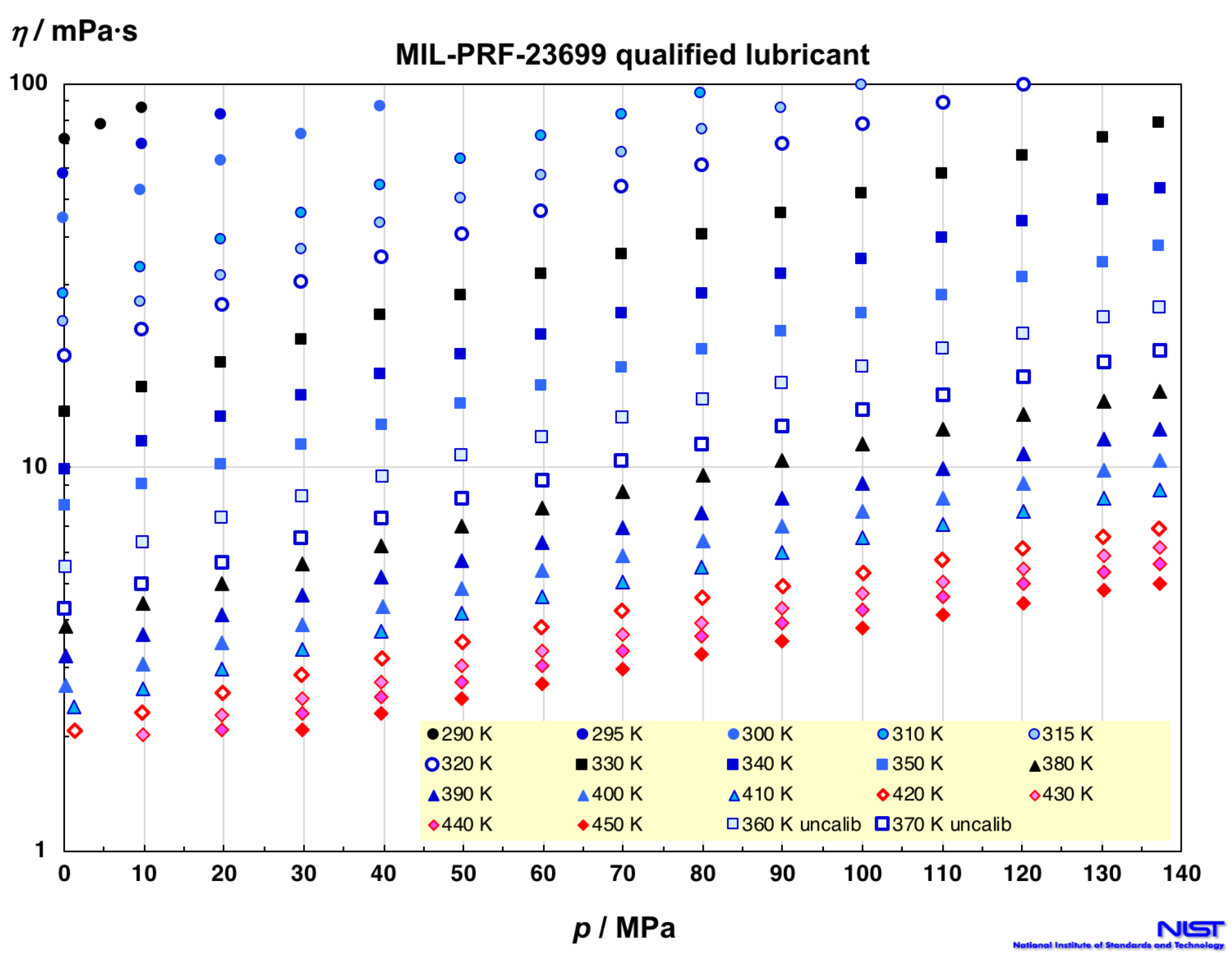

Fig. 7. Pressure dependence of the measured viscosity data for the MIL-PRF-23699-qualified lubricant along isotherms from $290 \mathrm{~K}$ to $450 \mathrm{~K}$ 
While the calibration with squalane ensures the mutual consistency of the measurements with the three sensing pistons within $\pm 3 \%$ below $340 \mathrm{~K}$ and within $\pm 2 \%$ above $340 \mathrm{~K}$, it is difficult to rigorously assess the total expanded estimated uncertainty of the viscosity measurements with this instrument. This would require an in-depth analysis of the fluid mechanics and secondary flows around the alternating sensing pistons as was done for falling body viscometers by Schaschke et al. [72]. Next, it would be necessary to derive the working equation that relates the period of the piston alternation to the viscosity of the sample, taking into account the effect of thermal expansion and of sample compression on the viscometer tube and the sensing pistons. Absent such analysis, and based on our experience with falling body viscometers [18, 19], the expanded uncertainty of the present measurements is estimated conservatively from $5 \%$ at atmospheric pressure to $10 \%$ at the maximum pressure of $137 \mathrm{MPa}$. More clues will be learned in the next section, where the present results are compared with experimental viscosity data from other investigations.

\section{Comparison with Other Measurements}

Literature data could only be found for the three pure polyolesters measured in this work. Bohner et al. [5] reported for each of them two viscosity points at $310.93 \mathrm{~K}$ and $372.04 \mathrm{~K}$ at atmospheric pressure without specifying the purity of the samples. The uncertainty of the viscosity data can be inferred from ASTM D445-53T Standard Test Method for Kinematic Viscosity of Transparent and Opaque Liquids (and Calculation of Dynamic Viscosity), which was followed by Bohner et al. Kishore and Shohba [73] reported for all three compounds Newtonian viscosities from $300 \mathrm{~K}$ to $410 \mathrm{~K}$ that were obtained at atmospheric pressure with a rotational rheometer by extrapolation to zero shear. They estimated an uncertainty of $2.5 \%$ for their results. The purity of their samples was not quantified. Wahlström and Vamling [7] reported three viscosity data for POE-5 that were determined, also at atmospheric pressure, with an Ubbelohde-type gravitational capillary viscometer. The uncertainty was quoted as smaller than $2 \%$ and the purity of the sample was quoted as higher than $95 \%$. Pensado et al. reported measurement results with a rolling-sphere viscometer at temperatures from $303.15 \mathrm{~K}$ to $353.15 \mathrm{~K}$ and pressures from $0.1 \mathrm{MPa}$ to $60 \mathrm{MPa}$. The uncertainty of the viscosities was quoted as $3 \%$. The first paper [8] contained the results for a selfsynthesized POE-9 sample the purity of which was estimated to be higher than $95 \%$. The second paper [9] contained the viscosity data for POE-5 and POE-7. The POE-5 and POE-7 samples were the same that Fandiño et al. [74] had prepared for density measurements with an estimated purity of higher than $95 \%$. Pensado et al. reported in both papers viscosity formulations in terms of temperature and pressure that represented their experimental results within their estimated experimental uncertainty. These formulations are used in the following comparisons of the various data sets as lines of reference.

Another set included in the comparison is a viscosity data set on a POE-5 sample that was mentioned in Sec. 2.2 and measured in our laboratory in 2006. The temperature range was from $253.15 \mathrm{~K}$ to $373.15 \mathrm{~K}$ at the atmospheric pressure of $0.08235 \mathrm{MPa}$ in Boulder, Colorado, USA. The instrument was a firstgeneration rotating concentric cylinder viscometer. The performance of a second generation device of this type, which could be calibrated to a viscosity as low as $0.6 \mathrm{mPa} \cdot \mathrm{s}$, was quantified in detail in our publication of 2012 [75]. Our extensive comparisons with certified viscosity reference standards revealed a deteriorating performance of the first-generation instrument below $4 \mathrm{mPa} \cdot \mathrm{s}$. Based on these performance verifications, we assigned to the POE-5 experimental viscosity data in Table 7 an expanded estimated uncertainty of $1 \%$ at viscosities above $4 \mathrm{mPa} \cdot \mathrm{s}$ and $2 \%$ below.

Percent deviations of the POE-viscosity data measured in this work and tabulated in Tables 3 to 5 from values calculated with the viscosity formulations by Pensado et al. $[8,9]$ are shown as a function of pressure in Figs. 8 to 10. The pattern of the deviations is similar for all three POEs. They are systematically lower than the correlations at low pressures and spread between $-5.7 \%$ at $320 \mathrm{~K}$ and $-23.5 \%$ at $430 \mathrm{~K}$ for POE-5, between $-0.4 \%$ at $280 \mathrm{~K}$ and $-16 \%$ at $340 \mathrm{~K}$ for POE-7, and between $-6.6 \%$ at $320 \mathrm{~K}$ and $15.7 \%$ at $290 \mathrm{~K}$ for POE-9. The deviations exhibit a strong fanning out with increasing pressure and range 
at $137 \mathrm{MPa}$ from $-21 \%$ at $330 \mathrm{~K}$ to $52 \%$ at $430 \mathrm{~K}$ for POE-5, from $-34 \%$ at $330 \mathrm{~K}$ to $80 \%$ at $450 \mathrm{~K}$ for POE-7, and from $-31 \%$ at $330 \mathrm{~K}$ to $45 \%$ at $450 \mathrm{~K}$ for POE-9. The magnitude of these deviations may be disconcerting but they can be rationalized straight forwardly for a number of reasons. The formulations of Pensado et al. [8,9] were based on their experimental data in the temperature range from $303.15 \mathrm{~K}$ to $353.15 \mathrm{~K}$ with pressures from $0.1 \mathrm{MPa}$ to $60 \mathrm{MPa}$. These are both considerably smaller than the combined range of the measurements carried out in the present study from $275 \mathrm{~K}$ to $450 \mathrm{~K}$ with pressures up to $137 \mathrm{MPa}$. Furthermore, Pensado et al. incorporated an exponential Vogel-Fulcher-Tammann (VFT) term to represent the viscosity-temperature dependence of their data. Thus, comparing the present measurement results with the formulations involves significant extrapolations beyond the range of their data basis. The convex VFT-temperature function is known to fail when extrapolated because of the strong viscositytemperature dependence of liquids. The comparisons for the three base oils show that it overpredicts their viscosities when extrapolated to lower temperatures and underpredicts them when extrapolated to higher temperatures.

This behavior is confirmed in Fig. 11, which shows a comparison of POE-5 viscosities at nearatmospheric pressure as a function of temperature. The data of Pensado et al. [9] deviate between $-1.7 \%$ and $2.3 \%$ from their formulation. The two data points of Bohner et al. [5] are both $-5 \%$ lower, while the three values of Wahlström and Vamling [7] are between $1.9 \%$ and $2.9 \%$ higher. The data series of Kishore and Shohba [73] exhibits strong scatter with mostly negative deviations. The measurements of Laesecke and Morrison of 2006 deviate systematically from $46 \%$ at $253.15 \mathrm{~K}$ to a minimum of $6.2 \%$ at $313.15 \mathrm{~K}$ and $323.15 \mathrm{~K}$, followed by a further increase to $12.4 \%$ at $373.15 \mathrm{~K}$. This trend of the deviations is typical for the viscosity overprediction by the formulation below $303.15 \mathrm{~K}$ and the underprediction above $353.15 \mathrm{~K}$. The systematic offset of $-6 \%$ is likely due to differences in sample compositions as will be discussed below. Figure 11 shows that the deviations of the low-pressure viscosities measured in the present study with the oscillating piston viscometer for POE-5 are consistent with those of the data measured by Laesecke and Morrison in 2006 with a different viscometer and a different sample. The values agree within their estimated experimental uncertainty from $275 \mathrm{~K}$ to $330 \mathrm{~K}$ but are systematically lower from $340 \mathrm{~K}$ to $430 \mathrm{~K}$ where a different sensing piston was employed. Thus, part of this offset may result from differences in the manufacturer calibrations of the two sensing pistons.

The two POE-5 measurements that were carried out in this laboratory years apart and on different samples agree in the systematic negative offset of our results for all three base oils from the formulations of Pensado et al. [8, 9]. In our view, these differences are due to differences in sample compositions. In our previous measurements of two lots of a perfluoropolyether oil at ambient pressure [76], we found differences in density between $0.08 \%$ and $0.14 \%$ while the measured viscosities of the two lots differed between $7.5 \%$ and $15 \%$. The density measurements that were conducted during this project in our laboratory on the same base oil samples as the viscosity measurements are between $0.4 \%$ and $0.7 \%$ systematically lower than the density measurements that were conducted on the samples that Pensado et al. used for their viscosity measurements [12]. These density deviations are by sign and magnitude consistent with the deviations of our viscosity measurements from those of Pensado et al. [8, 9]. As we have found for ionic liquids [77] and with perfluoropolyether oils [76], our experiences with the pentaerythritol esters in this work suggest that many deviations between viscosity data for liquids in the literature may be due to differences in sample compositions that were not analyzed and/or not reported because their relevance on viscosity was not recognized adequately. 


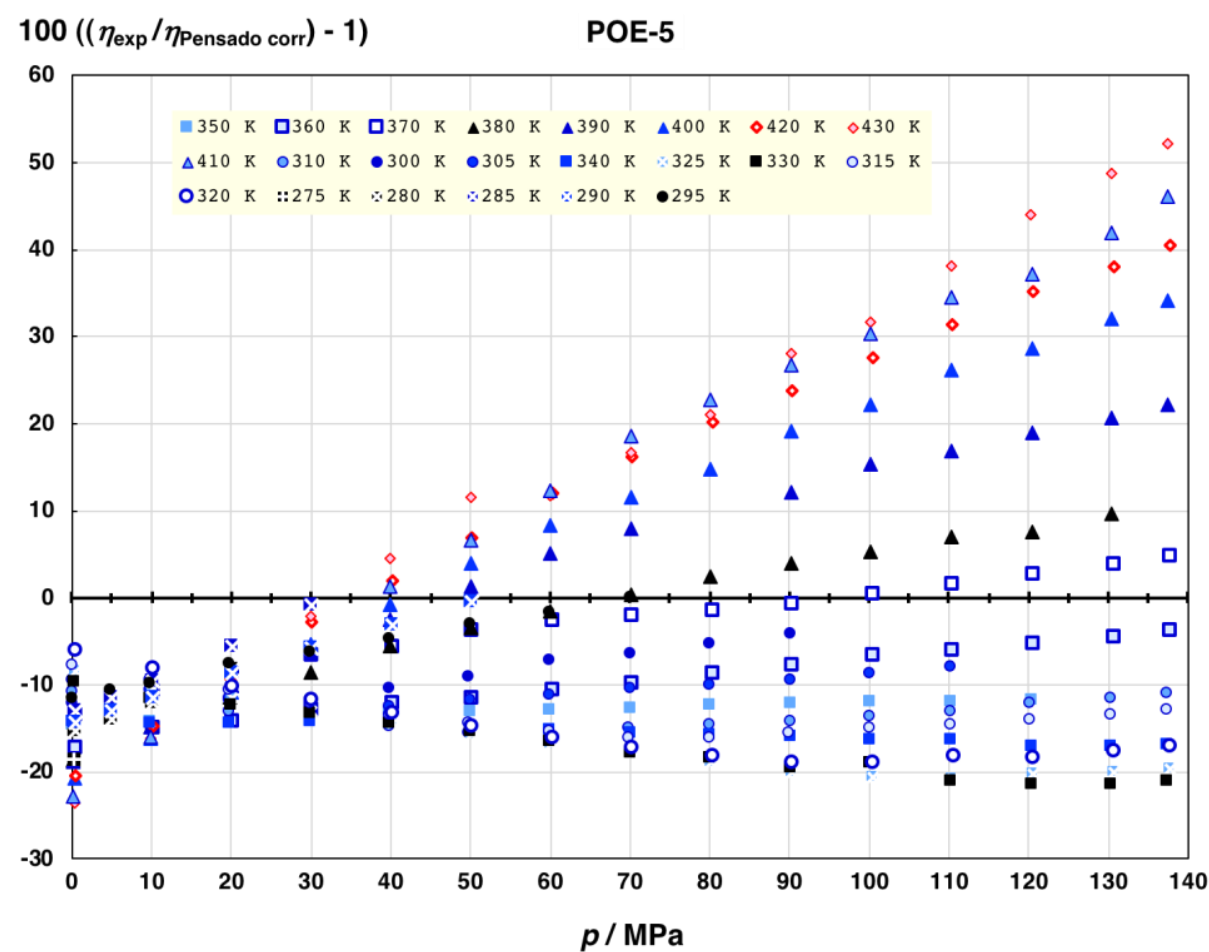

Fig. 8. Percent deviations of the POE-5 viscosity data measured in this work from the correlation by Pensado et al. [9], which was based on viscosity data at six temperatures from $303.15 \mathrm{~K}$ to $353.15 \mathrm{~K}$ and pressures to $60 \mathrm{MPa}$.

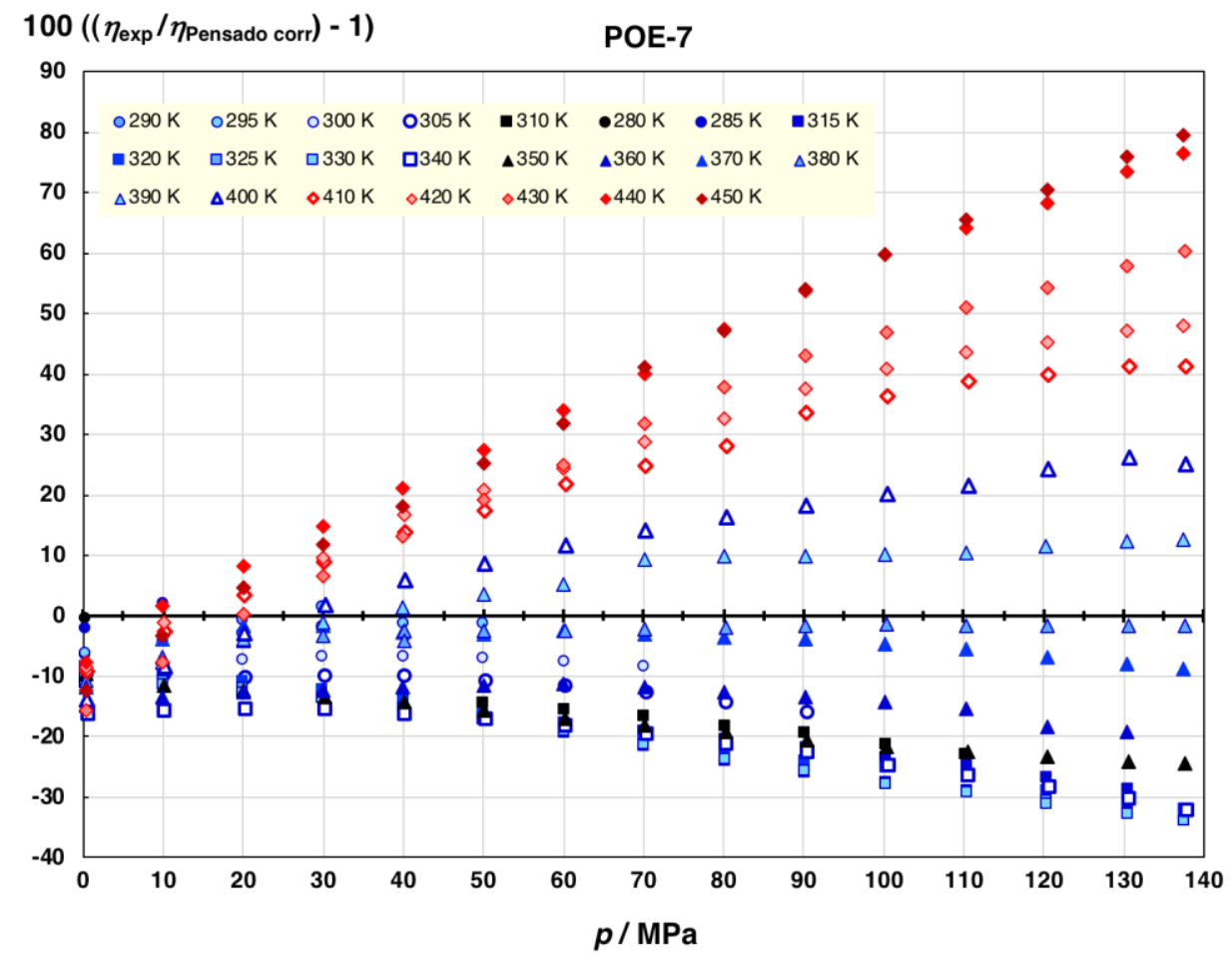

Fig. 9. Percent deviations of the POE-7 viscosity data measured in this work from the correlation by Pensado et al. [9], which was based on viscosity data at six temperatures from $303.15 \mathrm{~K}$ to $353.15 \mathrm{~K}$ and pressures to $60 \mathrm{MPa}$. 


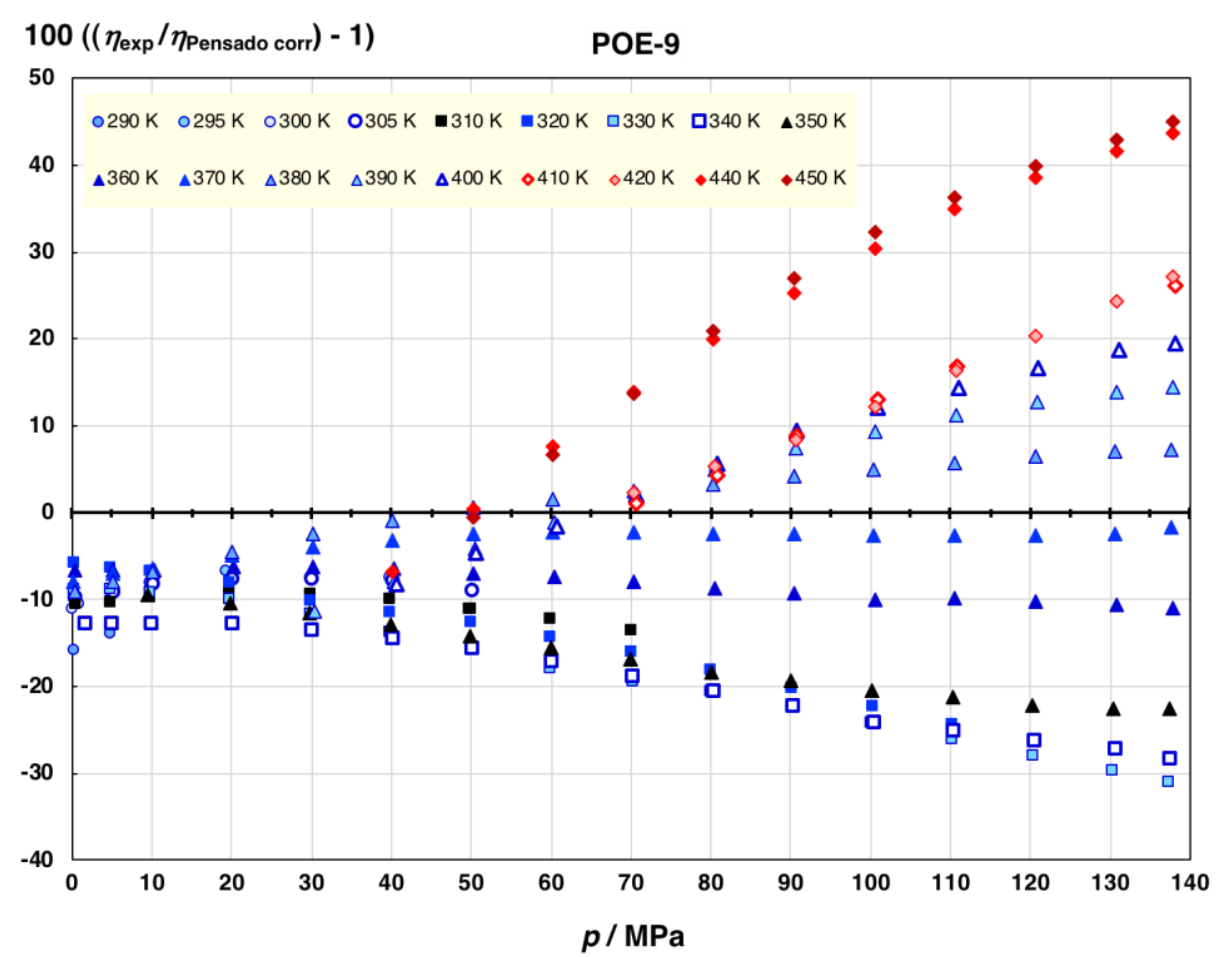

Fig. 10. Percent deviations of the POE-9 viscosity data measured in this work from the correlation by Pensado et al. [8], which was based on viscosity data at six temperatures from $303.15 \mathrm{~K}$ to $353.15 \mathrm{~K}$ and pressures to $60 \mathrm{MPa}$.

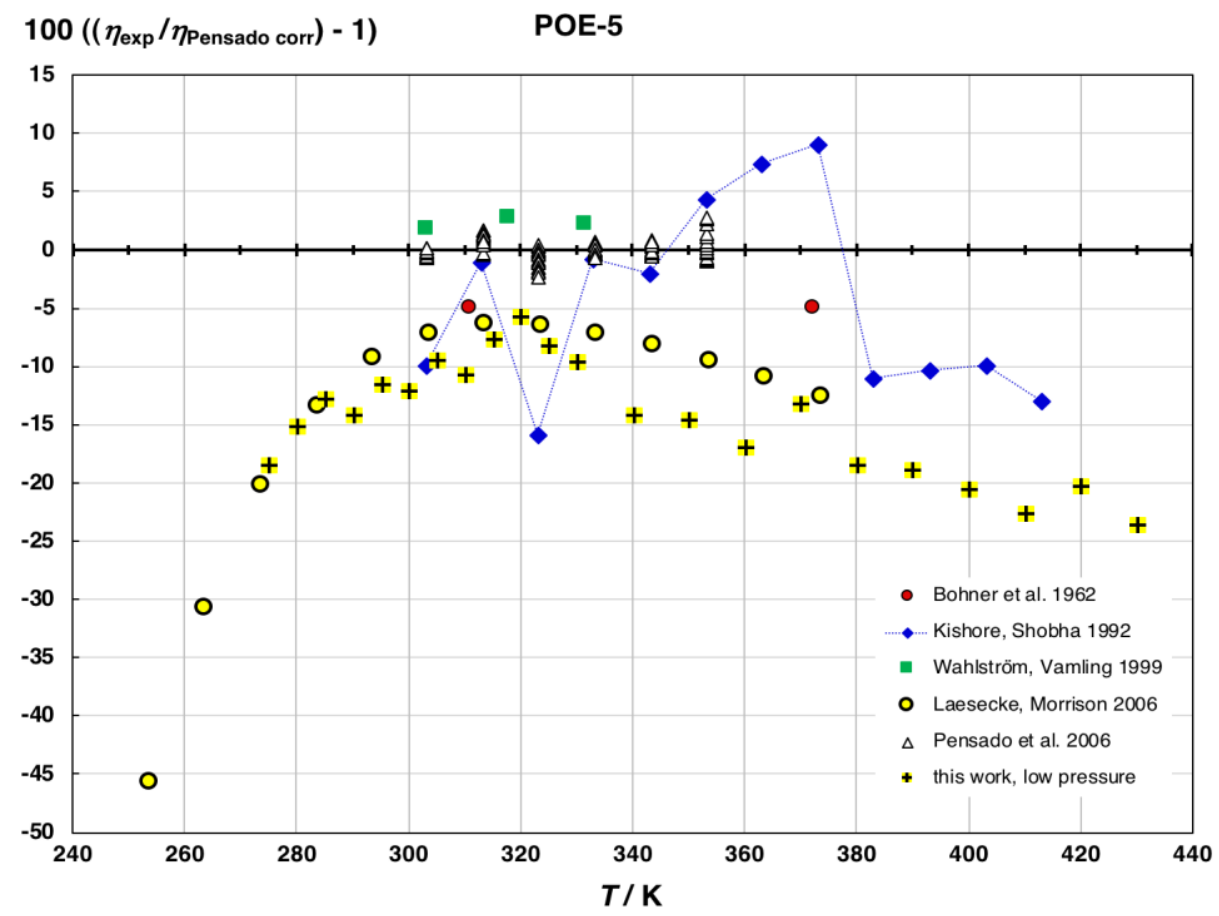

Fig. 11. Percent deviations of POE-5 viscosity data at atmospheric pressure from the literature and data reported in this work (Laesecke, Morrison 2006, Table 7 and Table 5) from the correlation by Pensado et al. [9], which was based on viscosity data at six temperatures from $303.15 \mathrm{~K}$ to $353.15 \mathrm{~K}$ and pressures to $60 \mathrm{MPa}$. 


\section{Concluding Remarks}

This work reports about comprehensive viscosity measurements of three pentaerythritol tetraalkanoate esters and one MIL-PRF-23699-qualified lubricant in the compressed liquid state at temperatures from $275 \mathrm{~K}$ to $450 \mathrm{~K}$ with pressures to $137 \mathrm{MPa}$ and in the viscosity range from $1 \mathrm{mPa} \cdot \mathrm{s}$ to $100 \mathrm{mPa} \cdot \mathrm{s}$. According to our knowledge, this is the widest temperature and pressure range in which an oscillating piston viscometer has been used so far. Therefore, our experiences and results provide orientation and guidance for other users of this metrology and for extending the current ASTM Standard Test method for this instrument to higher than atmospheric pressures.

As with most viscometers, the viscosity range of the oscillating piston method is tied to the geometry of the flow impedance, i.e., the size of the annular gap between the piston surface and the inner wall of the high-pressure cell. Sensing pistons with three outer diameters were needed in our measurements for the viscosity range from $1 \mathrm{mPa} \cdot \mathrm{s}$ to $100 \mathrm{mPa} \cdot \mathrm{s}$. Each sensor change required the removal of the sample from the high-pressure cell, removal of the high-pressure cell from the insulating enclosure, opening of the highpressure cell to exchange the sensing piston, re-assembly in the reverse sequence, completion of a hightemperature leak test of the thermal jacket, evacuation of the high-pressure cell and downstream manifold, and reloading of the sample liquid into the viscometer manifold for continued measurements. Besides being inconvenient and time-consuming, this procedure bears the risk of sample contamination. Obviously, a viscosity sensor with a wider viscosity range would be advantageous to avoid these problems. The torsionally vibrating quartz sensor (TVQ) offers two distinct advantages from which our measurements would have benefitted considerably [20]. First, the TVQ sensor can probe three orders of magnitude in viscosity, so that no sensor exchange would be needed. Second, the TVQ sensor is routinely used for absolute measurements which would have negated the need for extensive calibration measurements of squalane that were required for this project. Clearly, developing the TVQ sensor to further maturity will meet the numerous measurement needs in science and industry with higher accuracy and shorter measurement durations, i.e., higher productivity.

The existence of these measurement needs is beyond dispute. They are indicated here in the comparison of our experimental data with extrapolations of the viscosity formulations established by Pensado et al. [8,9] to represent their narrower range in viscosity measurements of the POE base oils. The formulations turned out to be unsuitable for extrapolation beyond the temperature range of their experimental data base, particularly to lower temperatures, and to the higher pressures of our experimental data. The formulations of Pensado et al. include a Tait-like term for the viscosity-pressure dependence, which is considered well behaved for that relationship. Despite that, the extrapolations were not successful. Had the formulations included free-volume terms, the extrapolations would have been much worse [18]. As long as the current viscosity models for liquids are not improved significantly, the need for measurements will remain unabated. Neither will it be reduced by advances of $a b$ initio quantum-chemical calculations of potential energy surfaces and the subsequent calculation of viscosities in the limit of zero density. Such calculations did indeed supersede the accuracy of measurements, but only for small molecules of spherical shape such as noble gases, (see Ref. [78] and references therein), or simple structures up to propane [79] or carbon dioxide [80] and in dilute gas states. Quantitative calculations of the properties of liquids with complex molecular structures, such as studied in this work, are not yet within reach of $a b$ initio methods. Measurements will remain the primary path to knowledge in the foreseeable future [81]. 
Journal of Research of the National Institute of Standards and Technology

\section{Appendix}

Tables 3 to 7 list the experimental viscosity data that were measured in this project.

Table 3. Experimental viscosity data for POE- 9 measured in this project at temperatures from $289.89 \mathrm{~K}$ to $450.13 \mathrm{~K}$ with pressures to 137.70 MPa.

\begin{tabular}{|c|c|c|c|c|c|}
\hline $\begin{array}{l}T_{90} \\
(\mathrm{~K}) \\
\end{array}$ & $\begin{array}{l}\boldsymbol{s}_{T} \\
(\mathrm{~K})\end{array}$ & $\begin{array}{l}p \\
(\mathrm{MPa})\end{array}$ & $\begin{array}{l}\boldsymbol{s}_{P} \\
(\mathrm{MPa})\end{array}$ & $\begin{array}{l}\eta \\
(\mathrm{mPa} \cdot \mathrm{s})\end{array}$ & $\begin{array}{l}\boldsymbol{s}_{\eta} / \eta \\
(\%)\end{array}$ \\
\hline 300.11 & 0.01 & 0.025 & 0.004 & 48.73 & 0.4 \\
\hline 300.11 & 0.01 & 0.839 & 0.007 & 49.65 & 0.3 \\
\hline 300.12 & 0.01 & 4.823 & 0.007 & 53.24 & 0.2 \\
\hline 300.12 & 0.01 & 9.810 & 0.006 & $\mathbf{5 8 . 3 7}$ & 0.3 \\
\hline 300.13 & 0.01 & 19.819 & 0.007 & 69.18 & 0.2 \\
\hline 300.12 & 0.01 & 29.860 & 0.007 & 81.03 & 0.3 \\
\hline 300.12 & 0.01 & 39.886 & 0.007 & 94.35 & 0.2 \\
\hline 289.89 & 0.01 & 0.181 & 0.012 & 80.78 & 0.3 \\
\hline 289.94 & 0.02 & 4.824 & 0.005 & 88.09 & 0.2 \\
\hline 295.07 & 0.01 & 0.317 & 0.007 & 64.31 & 0.4 \\
\hline 295.09 & 0.01 & 4.819 & 0.005 & 69.57 & 0.2 \\
\hline 295.10 & 0.01 & 9.819 & 0.007 & 75.97 & 0.2 \\
\hline 295.10 & 0.01 & 19.375 & 0.009 & 89.09 & 0.1 \\
\hline 305.03 & 0.01 & 0.150 & 0.006 & 39.43 & 0.5 \\
\hline 305.04 & 0.01 & 4.820 & 0.005 & 42.77 & 0.3 \\
\hline 305.06 & 0.01 & 9.813 & 0.006 & 46.85 & 0.6 \\
\hline 305.08 & 0.01 & 19.822 & 0.006 & 55.39 & 0.5 \\
\hline 305.10 & 0.02 & 29.825 & 0.006 & 64.80 & 0.3 \\
\hline 305.10 & 0.01 & 39.849 & 0.006 & 75.62 & 1.0 \\
\hline 305.09 & 0.01 & 49.881 & 0.009 & 87.16 & 0.3 \\
\hline 309.97 & 0.01 & 0.446 & 0.009 & 31.64 & 0.2 \\
\hline 310.00 & 0.01 & 4.788 & 0.005 & 34.03 & 0.5 \\
\hline 310.02 & 0.01 & 9.777 & 0.006 & 37.20 & 0.4 \\
\hline 310.03 & 0.01 & 19.788 & 0.007 & 44.05 & 0.3 \\
\hline 310.04 & 0.01 & 29.801 & 0.008 & 51.60 & 0.3 \\
\hline 310.05 & 0.01 & 39.811 & 0.007 & 60.01 & 0.4 \\
\hline 310.06 & 0.01 & 49.841 & 0.010 & 69.26 & 0.2 \\
\hline 310.06 & 0.01 & 49.888 & 0.006 & 69.29 & 0.4 \\
\hline 310.06 & 0.01 & 59.913 & 0.005 & 79.60 & 0.2 \\
\hline 310.06 & 0.01 & 69.950 & 0.005 & 91.10 & 0.4 \\
\hline 320.05 & 0.02 & 0.313 & 0.006 & 22.69 & 0.6 \\
\hline 320.07 & 0.01 & 4.806 & 0.005 & 24.29 & 0.2 \\
\hline 320.08 & 0.02 & 9.798 & 0.006 & 26.28 & 0.4 \\
\hline 320.08 & 0.01 & 19.810 & 0.007 & 30.44 & 0.3 \\
\hline 320.09 & 0.01 & 29.826 & 0.004 & 34.93 & 0.3 \\
\hline 320.09 & 0.01 & 39.856 & 0.007 & 40.28 & 0.3 \\
\hline 320.10 & 0.01 & 49.892 & 0.006 & 46.45 & 0.4 \\
\hline 320.10 & 0.01 & $\mathbf{5 9 . 9 3 5}$ & 0.007 & 53.08 & 0.2 \\
\hline 320.10 & 0.01 & 69.999 & 0.009 & 60.44 & 0.2 \\
\hline 320.10 & 0.01 & 80.053 & 0.007 & 68.41 & 0.2 \\
\hline 320.11 & 0.01 & 90.112 & 0.007 & 77.19 & 0.2 \\
\hline 320.10 & 0.01 & 100.180 & 0.007 & 86.85 & 0.2 \\
\hline 320.10 & 0.01 & 110.255 & 0.008 & 97.30 & 0.2 \\
\hline 330.11 & 0.01 & 0.344 & 0.005 & 15.87 & 0.2 \\
\hline 330.10 & 0.01 & 4.805 & 0.006 & 17.04 & 0.6 \\
\hline 330.10 & 0.01 & 9.814 & 0.006 & 18.40 & 0.6 \\
\hline 330.12 & 0.01 & 19.817 & 0.006 & 21.30 & 0.5 \\
\hline 330.14 & 0.02 & 29.836 & 0.006 & 24.34 & 0.2 \\
\hline 330.17 & 0.02 & 39.836 & 0.007 & 27.62 & 0.3 \\
\hline 330.19 & 0.01 & 49.849 & 0.005 & 31.33 & 0.2 \\
\hline 330.20 & 0.01 & $\mathbf{5 9 . 8 7 6}$ & 0.006 & 35.36 & 0.6 \\
\hline
\end{tabular}


Journal of Research of the National Institute of Standards and Technology

\begin{tabular}{|c|c|c|c|c|c|}
\hline $\begin{array}{l}T_{90} \\
(\mathrm{~K})\end{array}$ & $\begin{array}{l}\boldsymbol{s}_{T} \\
(\mathrm{~K})\end{array}$ & $\begin{array}{l}p \\
(\mathrm{MPa})\end{array}$ & $\begin{array}{l}\boldsymbol{s}_{P} \\
(\mathrm{MPa})\end{array}$ & $\begin{array}{l}\eta \\
(\mathrm{mPa} \cdot \mathrm{s})\end{array}$ & $\begin{array}{l}\boldsymbol{s}_{\eta} / \eta \\
(\%)\end{array}$ \\
\hline 330.20 & 0.02 & 70.179 & 0.007 & 40.23 & 0.5 \\
\hline 330.21 & 0.02 & 79.996 & 0.006 & 45.58 & 0.3 \\
\hline 330.22 & 0.02 & 90.052 & 0.006 & 51.35 & 0.3 \\
\hline 330.23 & 0.01 & 100.117 & 0.005 & 57.48 & 0.2 \\
\hline 330.23 & 0.02 & 110.184 & 0.009 & 64.23 & 0.2 \\
\hline 330.23 & 0.02 & 120.265 & 0.005 & 71.72 & 0.3 \\
\hline 330.24 & 0.01 & 130.340 & 0.007 & 79.87 & 0.1 \\
\hline 330.23 & 0.02 & 137.405 & 0.009 & 86.05 & 0.1 \\
\hline 340.06 & 0.01 & 1.367 & 0.005 & 11.72 & 1.0 \\
\hline 340.08 & 0.01 & 4.748 & 0.005 & 12.31 & 0.8 \\
\hline 340.10 & 0.01 & 9.759 & 0.005 & 13.25 & 0.8 \\
\hline 340.10 & 0.01 & 19.772 & 0.005 & 15.30 & 1.0 \\
\hline 340.11 & 0.02 & 29.782 & 0.005 & 17.50 & 0.6 \\
\hline 340.12 & 0.01 & 39.806 & 0.007 & 19.94 & 0.5 \\
\hline 340.13 & 0.01 & 49.829 & 0.006 & 22.61 & 0.4 \\
\hline 340.13 & 0.01 & 59.878 & 0.004 & 25.48 & 0.4 \\
\hline 340.14 & 0.02 & 69.918 & 0.006 & 28.55 & 0.4 \\
\hline 340.14 & 0.02 & 79.978 & 0.005 & 31.96 & 0.5 \\
\hline 340.14 & 0.02 & 90.031 & 0.007 & 35.65 & 0.5 \\
\hline 340.15 & 0.02 & 100.102 & 0.004 & 39.59 & 0.4 \\
\hline 340.15 & 0.02 & 110.176 & 0.005 & 44.38 & 0.3 \\
\hline 340.16 & 0.01 & 120.240 & 0.005 & 49.61 & 0.3 \\
\hline 340.16 & 0.02 & 130.311 & 0.008 & 55.47 & 0.3 \\
\hline 340.16 & 0.02 & 137.153 & 0.020 & $\mathbf{5 9 . 4 0}$ & 0.2 \\
\hline 350.16 & 0.01 & 9.421 & 0.006 & 10.56 & 1.3 \\
\hline 350.17 & 0.01 & 19.732 & 0.006 & 11.94 & 1.1 \\
\hline 350.18 & 0.01 & 29.736 & 0.007 & 13.43 & 0.9 \\
\hline 350.18 & 0.01 & 39.750 & 0.008 & 15.00 & 0.8 \\
\hline 350.19 & 0.01 & 49.781 & 0.007 & 16.77 & 0.7 \\
\hline 350.20 & 0.01 & 59.825 & 0.007 & 18.69 & 0.7 \\
\hline 350.20 & 0.01 & 69.874 & 0.006 & 20.82 & 0.6 \\
\hline 350.20 & 0.02 & 79.934 & 0.008 & 23.08 & 0.4 \\
\hline 350.20 & 0.02 & 89.999 & 0.008 & 25.68 & 0.5 \\
\hline 350.20 & 0.01 & 100.059 & 0.006 & 28.53 & 0.6 \\
\hline 350.20 & 0.01 & 110.139 & 0.007 & 31.73 & 0.5 \\
\hline 350.21 & 0.01 & 120.220 & 0.008 & 35.22 & 0.3 \\
\hline 350.20 & 0.01 & 130.234 & 0.008 & 39.32 & 0.3 \\
\hline 350.20 & 0.01 & 137.274 & 0.010 & 42.54 & 0.3 \\
\hline 390.05 & 0.02 & 30.245 & 0.007 & 5.588 & 0.3 \\
\hline 390.06 & 0.02 & 40.268 & 0.006 & 6.261 & 0.3 \\
\hline 390.07 & 0.01 & 60.339 & 0.006 & 7.817 & 0.2 \\
\hline 390.07 & 0.01 & 70.386 & 0.007 & 8.693 & 0.2 \\
\hline 390.07 & 0.02 & 80.446 & 0.005 & 9.621 & 0.2 \\
\hline 390.08 & 0.02 & 90.494 & 0.008 & 10.59 & 0.1 \\
\hline 390.09 & 0.01 & 100.567 & 0.009 & 11.59 & 0.1 \\
\hline 390.09 & 0.02 & 110.658 & 0.007 & 12.67 & 0.1 \\
\hline 390.10 & 0.02 & 120.724 & 0.008 & 13.79 & 0.1 \\
\hline 390.10 & 0.02 & 130.790 & 0.007 & 14.95 & 0.2 \\
\hline 390.10 & 0.02 & 137.825 & 0.024 & 15.80 & 0.2 \\
\hline 390.07 & 0.02 & 50.379 & 0.006 & 7.032 & 0.3 \\
\hline 400.09 & 0.02 & 40.256 & 0.006 & 5.245 & 0.6 \\
\hline 400.09 & 0.02 & 50.290 & 0.005 & 5.811 & 0.3 \\
\hline 400.09 & 0.01 & 60.335 & 0.006 & 6.405 & 0.4 \\
\hline 400.09 & 0.02 & 70.386 & 0.007 & 7.087 & 0.4 \\
\hline 400.09 & 0.02 & 80.435 & 0.008 & 7.826 & 0.3 \\
\hline 400.09 & 0.02 & 90.494 & 0.009 & 8.640 & 0.2 \\
\hline 400.10 & 0.01 & 100.550 & 0.007 & 9.434 & 0.2 \\
\hline 400.11 & 0.02 & 110.637 & 0.007 & 10.24 & 0.2 \\
\hline 400.10 & 0.02 & 120.707 & 0.008 & 11.14 & 0.3 \\
\hline
\end{tabular}


Journal of Research of the National Institute of Standards and Technology

\begin{tabular}{|c|c|c|c|c|c|}
\hline $\begin{array}{l}T_{90} \\
(\mathrm{~K})\end{array}$ & $\begin{array}{l}\boldsymbol{s}_{T} \\
(\mathrm{~K})\end{array}$ & $\begin{array}{l}p \\
(\mathrm{MPa})\end{array}$ & $\begin{array}{l}\boldsymbol{s}_{P} \\
(\mathrm{MPa})\end{array}$ & $\begin{array}{l}\eta \\
(\mathrm{mPa} \cdot \mathrm{s})\end{array}$ & $\begin{array}{l}\boldsymbol{s}_{\eta} / \eta \\
(\%)\end{array}$ \\
\hline 400.11 & 0.02 & 130.783 & 0.007 & 12.06 & 0.3 \\
\hline 400.11 & 0.02 & $\mathbf{1 3 7 . 8 3 5}$ & 0.012 & 12.68 & 0.2 \\
\hline 409.99 & 0.02 & 60.309 & 0.007 & 5.342 & 0.4 \\
\hline 409.99 & 0.02 & 70.361 & 0.008 & 5.853 & 0.3 \\
\hline 410.00 & 0.02 & 80.414 & 0.008 & 6.399 & 0.3 \\
\hline 410.01 & 0.02 & 90.468 & 0.010 & 7.064 & 0.2 \\
\hline 410.00 & 0.02 & 100.520 & 0.008 & 7.747 & 0.3 \\
\hline 410.00 & 0.02 & 110.605 & 0.008 & 8.464 & 0.1 \\
\hline 410.02 & 0.02 & 137.792 & 0.007 & 10.61 & 0.2 \\
\hline 420.15 & 0.02 & 70.340 & 0.006 & 5.017 & 0.5 \\
\hline 420.15 & 0.02 & 80.396 & 0.007 & 5.427 & 0.5 \\
\hline 420.16 & 0.01 & 90.444 & 0.007 & 5.867 & 0.3 \\
\hline 420.16 & 0.02 & 100.509 & 0.009 & 6.376 & 0.3 \\
\hline 420.18 & 0.01 & 110.578 & 0.011 & 6.942 & 0.3 \\
\hline 420.18 & 0.02 & 120.654 & 0.008 & 7.537 & 0.2 \\
\hline 420.18 & 0.02 & 130.724 & 0.008 & 8.179 & 0.1 \\
\hline 420.18 & 0.02 & 137.771 & 0.008 & 8.649 & 0.1 \\
\hline 359.99 & 0.01 & 0.220 & 0.005 & 7.794 & 0.3 \\
\hline 360.02 & 0.02 & 5.114 & 0.007 & 8.261 & 0.2 \\
\hline 360.03 & 0.01 & 10.114 & 0.006 & 8.765 & 0.2 \\
\hline 360.04 & 0.02 & 20.125 & 0.005 & 9.882 & 0.4 \\
\hline 360.05 & 0.01 & 30.135 & 0.006 & 11.07 & 0.2 \\
\hline 360.06 & 0.02 & 40.142 & 0.006 & 12.37 & 0.1 \\
\hline 360.06 & 0.02 & 50.170 & 0.007 & 13.78 & 0.2 \\
\hline 360.08 & 0.02 & 60.216 & 0.006 & 15.32 & 0.3 \\
\hline 360.08 & 0.02 & 70.268 & 0.009 & 16.99 & 0.2 \\
\hline 360.09 & 0.02 & 80.317 & 0.006 & 18.80 & 0.2 \\
\hline 360.10 & 0.02 & 90.374 & 0.006 & 20.77 & 0.2 \\
\hline 360.10 & 0.01 & 100.429 & 0.006 & 22.89 & 0.1 \\
\hline 360.10 & 0.01 & 110.503 & 0.008 & 25.48 & 0.2 \\
\hline 360.11 & 0.01 & 120.584 & 0.010 & 28.18 & 0.2 \\
\hline 360.12 & 0.01 & 130.664 & 0.008 & 31.08 & 0.1 \\
\hline 360.12 & 0.01 & 137.703 & 0.009 & 33.22 & 0.2 \\
\hline 369.83 & 0.02 & 0.123 & 0.008 & 6.371 & 0.4 \\
\hline 369.89 & 0.01 & 5.015 & 0.006 & 6.773 & 0.3 \\
\hline 369.93 & 0.01 & 10.012 & 0.005 & 7.165 & 0.2 \\
\hline 369.97 & 0.02 & 20.023 & 0.005 & 8.051 & 0.1 \\
\hline 370.00 & 0.02 & 30.029 & 0.007 & 8.998 & 0.1 \\
\hline 370.02 & 0.02 & 40.055 & 0.007 & 10.02 & 0.2 \\
\hline 370.04 & 0.02 & 50.084 & 0.006 & 11.13 & 0.1 \\
\hline 370.04 & 0.01 & 60.120 & 0.006 & 12.30 & 0.2 \\
\hline 370.06 & 0.01 & 70.168 & 0.007 & 13.55 & 0.3 \\
\hline 370.07 & 0.02 & 80.227 & 0.008 & 14.87 & 0.1 \\
\hline 370.08 & 0.02 & 90.283 & 0.007 & 16.34 & 0.2 \\
\hline 370.08 & 0.02 & 100.332 & 0.010 & 17.92 & 0.1 \\
\hline 370.08 & 0.01 & 110.402 & 0.010 & 19.68 & 0.1 \\
\hline 370.09 & 0.01 & 120.476 & 0.007 & 21.59 & 0.1 \\
\hline 370.10 & 0.01 & 130.555 & 0.006 & 23.70 & 0.1 \\
\hline 370.10 & 0.02 & 137.602 & 0.007 & 25.45 & 0.2 \\
\hline 379.98 & 0.02 & 0.151 & 0.005 & 5.306 & 0.2 \\
\hline 379.99 & 0.02 & 5.018 & 0.006 & 5.606 & 0.1 \\
\hline 379.99 & 0.02 & 10.024 & 0.007 & 5.942 & 0.1 \\
\hline 380.00 & 0.02 & 20.014 & 0.008 & 6.649 & 0.1 \\
\hline 380.02 & 0.02 & 30.030 & 0.007 & 7.405 & 0.1 \\
\hline 380.01 & 0.02 & 40.047 & 0.006 & 8.209 & 0.2 \\
\hline 380.02 & 0.02 & 50.061 & 0.007 & 9.089 & 0.3 \\
\hline 380.03 & 0.02 & 60.116 & 0.009 & 9.991 & 0.1 \\
\hline 380.03 & 0.02 & 70.169 & 0.010 & 10.99 & 0.1 \\
\hline 380.03 & 0.02 & 80.220 & 0.008 & 12.04 & 0.1 \\
\hline
\end{tabular}


Journal of Research of the National Institute of Standards and Technology

\begin{tabular}{llllll}
\hline$T_{90}$ & $\boldsymbol{s}_{T}$ & $p$ & $\boldsymbol{s}_{P}$ & $\begin{array}{l}\eta \\
(\mathrm{mPa} \cdot \mathrm{s})\end{array}$ \\
$(\mathrm{K})$ & $(\mathrm{K})$ & $(\mathrm{MPa})$ & $\begin{array}{l}\boldsymbol{s}_{\eta} / \eta \\
(\%)\end{array}$ \\
\hline $\mathbf{3 8 0 . 0 5}$ & 0.02 & $\mathbf{9 0 . 2 8 5}$ & 0.007 & $\mathbf{1 3 . 2 1}$ & 0.2 \\
$\mathbf{3 8 0 . 0 5}$ & 0.01 & $\mathbf{1 0 0 . 3 3 5}$ & 0.008 & $\mathbf{1 4 . 4 4}$ & 0.2 \\
$\mathbf{3 8 0 . 0 6}$ & 0.01 & $\mathbf{1 1 0 . 4 1 0}$ & 0.008 & $\mathbf{1 5 . 8 0}$ & 0.2 \\
$\mathbf{3 8 0 . 0 7}$ & 0.02 & $\mathbf{1 2 0 . 4 8 3}$ & 0.007 & $\mathbf{1 7 . 2 4}$ & 0.2 \\
$\mathbf{3 8 0 . 0 7}$ & 0.02 & $\mathbf{1 3 0 . 5 6 7}$ & 0.007 & $\mathbf{1 8 . 7 9}$ & 0.2 \\
$\mathbf{3 8 0 . 0 8}$ & 0.02 & $\mathbf{1 3 7 . 5 9 9}$ & 0.009 & $\mathbf{1 9 . 9 0}$ & 0.2 \\
\hline $\mathbf{4 4 0 . 0 3}$ & 0.02 & $\mathbf{4 0 . 1 0 7}$ & 0.008 & $\mathbf{3 . 0 8 1}$ & 0.2 \\
$\mathbf{4 4 0 . 0 3}$ & 0.02 & $\mathbf{5 0 . 1 2 9}$ & 0.008 & $\mathbf{3 . 4 5 4}$ & 0.2 \\
$\mathbf{4 4 0 . 0 3}$ & 0.01 & $\mathbf{6 0 . 1 7 2}$ & 0.008 & $\mathbf{3 . 8 4 9}$ & 0.2 \\
$\mathbf{4 4 0 . 0 2}$ & 0.02 & $\mathbf{7 0 . 2 2 7}$ & 0.008 & $\mathbf{4 . 2 3 9}$ & 0.2 \\
$\mathbf{4 4 0 . 0 2}$ & 0.02 & $\mathbf{8 0 . 2 7 4}$ & 0.007 & $\mathbf{4 . 6 4 1}$ & 0.2 \\
$\mathbf{4 4 0 . 0 1}$ & 0.02 & $\mathbf{9 0 . 3 3 5}$ & 0.009 & $\mathbf{5 . 0 3 8}$ & 0.2 \\
$\mathbf{4 4 0 . 0 2}$ & 0.01 & $\mathbf{1 0 0 . 3 8 4}$ & 0.011 & $\mathbf{5 . 4 4 8}$ & 0.2 \\
$\mathbf{4 4 0 . 0 2}$ & 0.02 & $\mathbf{1 1 0 . 4 6 8}$ & 0.005 & $\mathbf{5 . 8 6 0}$ & 0.2 \\
$\mathbf{4 4 0 . 0 2}$ & 0.01 & $\mathbf{1 2 0 . 5 4 8}$ & 0.009 & $\mathbf{6 . 2 5 0}$ & 0.2 \\
$\mathbf{4 4 0 . 0 2}$ & 0.02 & $\mathbf{1 3 0 . 6 2 5}$ & 0.011 & $\mathbf{6 . 6 4 4}$ & 0.2 \\
$\mathbf{4 4 0 . 0 3}$ & 0.02 & $\mathbf{1 3 7 . 6 7 5}$ & 0.008 & $\mathbf{6 . 9 1 5}$ & 0.2 \\
\hline $\mathbf{4 5 0 . 1 2}$ & 0.02 & $\mathbf{5 0 . 1 1 2}$ & 0.007 & $\mathbf{3 . 0 6 0}$ & 0.2 \\
$\mathbf{4 5 0 . 1 3}$ & 0.02 & $\mathbf{6 0 . 1 5 1}$ & 0.007 & $\mathbf{3 . 3 9 8}$ & 0.3 \\
$\mathbf{4 5 0 . 1 2}$ & 0.01 & $\mathbf{7 0 . 2 0 4}$ & 0.006 & $\mathbf{3 . 7 5 1}$ & 0.2 \\
$\mathbf{4 5 0 . 1 2}$ & 0.02 & $\mathbf{8 0 . 2 6 2}$ & 0.010 & $\mathbf{4 . 1 3 0}$ & 0.2 \\
$\mathbf{4 5 0 . 1 1}$ & 0.02 & $\mathbf{9 0 . 3 2 0}$ & 0.009 & $\mathbf{4 . 4 9 0}$ & 0.2 \\
$\mathbf{4 5 0 . 1 1}$ & 0.02 & $\mathbf{1 0 0 . 3 8 0}$ & 0.011 & $\mathbf{4 . 8 4 3}$ & 0.2 \\
$\mathbf{4 5 0 . 1 1}$ & 0.02 & $\mathbf{1 1 0 . 4 5 0}$ & 0.006 & $\mathbf{5 . 1 6 7}$ & 0.2 \\
$\mathbf{4 5 0 . 1 1}$ & 0.02 & $\mathbf{1 2 0 . 5 3 3}$ & 0.007 & $\mathbf{5 . 4 8 2}$ & 0.2 \\
$\mathbf{4 5 0 . 1 1}$ & 0.02 & $\mathbf{1 3 0 . 6 1 3}$ & 0.008 & $\mathbf{5 . 8 0 2}$ & 0.2 \\
$\mathbf{4 5 0 . 1 2}$ & 0.02 & $\mathbf{1 3 7 . 6 7 7}$ & 0.009 & $\mathbf{6 . 0 2 8}$ & 0.1 \\
\hline & & & & \\
\hline
\end{tabular}

Table 4. Experimental viscosity data for POE-7 measured in this project at temperatures from $280.04 \mathrm{~K}$ to $450.12 \mathrm{~K}$ with pressures to $137.55 \mathrm{MPa}$

\begin{tabular}{|c|c|c|c|c|c|}
\hline $\begin{array}{l}T_{90} \\
(\mathrm{~K})\end{array}$ & $\begin{array}{l}\boldsymbol{s}_{T} \\
(\mathrm{~K})\end{array}$ & $\begin{array}{l}p \\
(\mathrm{MPa})\end{array}$ & $\begin{array}{l}\boldsymbol{s}_{P} \\
(\mathrm{MPa})\end{array}$ & $\begin{array}{l}\eta \\
(\mathrm{mPa} \cdot \mathrm{s})\end{array}$ & $\begin{array}{l}\boldsymbol{s}_{\eta} / \eta \\
(\%)\end{array}$ \\
\hline 290.01 & 0.01 & 0.251 & 0.005 & 49.56 & 0.2 \\
\hline 290.02 & 0.01 & 9.931 & 0.007 & 59.34 & 0.2 \\
\hline 290.01 & 0.01 & 19.939 & 0.006 & 70.87 & 0.2 \\
\hline 290.01 & 0.01 & 29.938 & 0.007 & 83.96 & 0.3 \\
\hline 295.01 & 0.01 & 0.247 & 0.005 & 39.75 & 0.4 \\
\hline 295.03 & 0.01 & 9.927 & 0.006 & 47.19 & 0.3 \\
\hline 295.03 & 0.01 & 19.934 & 0.004 & 55.88 & 0.2 \\
\hline 295.02 & 0.02 & 29.944 & 0.007 & 65.78 & 0.2 \\
\hline 295.02 & 0.01 & 39.968 & 0.007 & 76.83 & 0.2 \\
\hline 295.03 & 0.02 & 49.996 & 0.007 & 89.27 & 0.1 \\
\hline 300.04 & 0.02 & 0.259 & 0.011 & 30.87 & 0.4 \\
\hline 300.04 & 0.01 & 9.918 & 0.008 & 36.47 & 0.4 \\
\hline 300.04 & 0.01 & 19.927 & 0.006 & 43.50 & 0.4 \\
\hline 300.02 & 0.01 & 29.934 & 0.007 & 51.17 & 0.3 \\
\hline 300.02 & 0.01 & 39.958 & 0.007 & 59.69 & 0.3 \\
\hline 300.02 & 0.01 & 49.996 & 0.006 & 69.11 & 0.3 \\
\hline 300.02 & 0.01 & 60.040 & 0.006 & 79.87 & 0.2 \\
\hline 300.01 & 0.01 & 70.097 & 0.009 & 91.65 & 0.2 \\
\hline 305.03 & 0.01 & 0.234 & 0.009 & 25.66 & 0.5 \\
\hline 305.03 & 0.01 & 9.929 & 0.006 & 29.94 & 0.4 \\
\hline 305.03 & 0.01 & 19.927 & 0.006 & 34.96 & 0.4 \\
\hline 305.03 & 0.01 & 29.935 & 0.008 & 40.98 & 0.4 \\
\hline 305.03 & 0.01 & 39.953 & 0.007 & 47.92 & 0.2 \\
\hline 305.03 & 0.01 & 49.983 & 0.008 & 55.31 & 0.2 \\
\hline 305.03 & 0.01 & 60.025 & 0.010 & 63.75 & 0.2 \\
\hline
\end{tabular}


Journal of Research of the National Institute of Standards and Technology

\begin{tabular}{|c|c|c|c|c|c|}
\hline $\begin{array}{l}T_{90} \\
(\mathrm{~K}) \\
\end{array}$ & $\begin{array}{l}\boldsymbol{s}_{T} \\
(\mathrm{~K}) \\
\end{array}$ & $\begin{array}{l}p \\
(\mathrm{MPa})\end{array}$ & $\begin{array}{l}\boldsymbol{s}_{P} \\
(\mathrm{MPa}) \\
\end{array}$ & $\begin{array}{l}\eta \\
(\mathrm{mPa} \cdot \mathrm{s})\end{array}$ & $\begin{array}{l}s_{\eta} / \eta \\
(\%)\end{array}$ \\
\hline 305.03 & 0.01 & 70.082 & 0.010 & 72.91 & 0.3 \\
\hline 305.03 & 0.01 & 80.144 & 0.008 & 82.91 & 0.2 \\
\hline 305.03 & 0.01 & 90.202 & 0.006 & 94.13 & 0.1 \\
\hline 309.98 & 0.01 & 0.246 & 0.007 & 21.03 & 0.5 \\
\hline 309.99 & 0.01 & 9.917 & 0.006 & 24.53 & 0.5 \\
\hline 309.99 & 0.01 & 29.931 & 0.007 & 32.84 & 0.3 \\
\hline 309.99 & 0.01 & 39.947 & 0.007 & 38.17 & 0.3 \\
\hline 310.00 & 0.01 & 49.980 & 0.007 & 44.15 & 0.3 \\
\hline 309.99 & 0.01 & 60.019 & 0.007 & 50.72 & 0.2 \\
\hline 310.00 & 0.01 & 70.071 & 0.007 & 58.09 & 0.3 \\
\hline 310.00 & 0.01 & 80.111 & 0.008 & 66.12 & 0.3 \\
\hline 310.00 & 0.01 & 90.179 & 0.011 & 75.26 & 0.2 \\
\hline 310.01 & 0.02 & 100.222 & 0.007 & 84.96 & 0.2 \\
\hline 310.01 & 0.01 & 110.281 & 0.008 & 95.79 & 0.1 \\
\hline 280.04 & 0.02 & 0.266 & 0.008 & 86.54 & 0.3 \\
\hline 284.96 & 0.01 & 0.251 & 0.008 & 66.09 & 0.3 \\
\hline 284.96 & 0.01 & 9.935 & 0.005 & 79.44 & 0.2 \\
\hline 315.03 & 0.01 & 0.282 & 0.006 & 17.84 & 0.6 \\
\hline 315.03 & 0.01 & 9.952 & 0.007 & 20.65 & 0.4 \\
\hline 315.04 & 0.01 & 19.954 & 0.008 & 23.91 & 0.5 \\
\hline 315.03 & 0.01 & 29.964 & 0.007 & 27.54 & 0.5 \\
\hline 315.04 & 0.01 & 39.988 & 0.008 & 31.46 & 0.2 \\
\hline 315.03 & 0.01 & 50.017 & 0.008 & 36.08 & 0.8 \\
\hline 315.03 & 0.01 & 60.061 & 0.008 & 41.40 & 0.2 \\
\hline 315.03 & 0.01 & 70.118 & 0.007 & 47.36 & 0.3 \\
\hline 315.03 & 0.01 & 80.168 & 0.008 & 53.78 & 0.2 \\
\hline 315.03 & 0.01 & 90.228 & 0.007 & 61.17 & 0.2 \\
\hline 315.03 & 0.01 & 100.283 & 0.008 & 69.02 & 0.1 \\
\hline 315.03 & 0.01 & 110.358 & 0.007 & 78.01 & 0.2 \\
\hline 315.04 & 0.01 & 120.424 & 0.007 & 87.38 & 0.2 \\
\hline 315.04 & 0.01 & $\mathbf{1 3 0 . 4 8 6}$ & 0.006 & 97.66 & 0.2 \\
\hline 320.03 & 0.02 & 0.262 & 0.012 & 15.41 & 0.4 \\
\hline 320.03 & 0.02 & 9.935 & 0.007 & 17.74 & 0.2 \\
\hline 320.03 & 0.02 & 19.928 & 0.006 & 20.52 & 0.2 \\
\hline 320.03 & 0.01 & 29.941 & 0.007 & 23.60 & 0.2 \\
\hline 320.03 & 0.02 & 39.959 & 0.008 & 26.88 & 0.1 \\
\hline 320.03 & 0.02 & 49.982 & 0.007 & 30.51 & 0.1 \\
\hline 320.04 & 0.02 & 60.030 & 0.007 & 34.36 & 0.2 \\
\hline 320.04 & 0.02 & 70.070 & 0.010 & 38.84 & 0.1 \\
\hline 320.04 & 0.01 & 80.122 & 0.006 & 44.00 & 0.1 \\
\hline 320.05 & 0.02 & 90.176 & 0.005 & 49.83 & 0.2 \\
\hline 325.04 & 0.01 & 0.263 & 0.007 & 12.93 & 0.3 \\
\hline 325.05 & 0.01 & 9.942 & 0.006 & 14.97 & 0.3 \\
\hline 325.05 & 0.01 & 19.944 & 0.006 & 17.26 & 0.3 \\
\hline 325.05 & 0.01 & 29.954 & 0.007 & 19.75 & 0.2 \\
\hline 325.06 & 0.01 & 39.979 & 0.007 & 22.55 & 0.2 \\
\hline 325.06 & 0.01 & 50.001 & 0.008 & 25.53 & 0.2 \\
\hline 325.06 & 0.01 & 60.043 & 0.007 & 28.76 & 0.2 \\
\hline 325.06 & 0.01 & 70.099 & 0.007 & 32.33 & 0.2 \\
\hline 325.05 & 0.01 & 80.154 & 0.011 & 36.17 & 0.2 \\
\hline 325.04 & 0.01 & 90.219 & 0.008 & 40.66 & 0.2 \\
\hline 325.04 & 0.01 & 100.281 & 0.009 & 45.77 & 0.2 \\
\hline 325.05 & 0.01 & 110.355 & 0.008 & 51.41 & 0.2 \\
\hline 325.04 & 0.01 & 120.430 & 0.009 & 57.51 & 0.2 \\
\hline 325.03 & 0.01 & 130.502 & 0.008 & 63.99 & 0.2 \\
\hline 325.03 & 0.01 & $\mathbf{1 3 7 . 5 4 3}$ & 0.006 & 68.89 & 0.2 \\
\hline 319.99 & 0.01 & 0.269 & 0.005 & 15.37 & 0.6 \\
\hline 320.01 & 0.01 & 80.160 & 0.007 & 44.45 & 0.3 \\
\hline 320.03 & 0.01 & 90.220 & 0.006 & 50.14 & 0.2 \\
\hline
\end{tabular}


Journal of Research of the National Institute of Standards and Technology

\begin{tabular}{|c|c|c|c|c|c|}
\hline $\begin{array}{l}T_{90} \\
(\mathrm{~K})\end{array}$ & $\begin{array}{l}\boldsymbol{s}_{T} \\
(\mathrm{~K})\end{array}$ & $\begin{array}{l}p \\
(\mathrm{MPa})\end{array}$ & $\begin{array}{l}\boldsymbol{s}_{P} \\
(\mathrm{MPa})\end{array}$ & $\begin{array}{l}\eta \\
(\mathrm{mPa} \cdot \mathrm{s})\end{array}$ & $\begin{array}{l}s_{\eta} / \eta \\
(\%)\end{array}$ \\
\hline 320.03 & 0.02 & 100.281 & 0.009 & 56.49 & 0.2 \\
\hline 320.04 & 0.02 & 110.347 & 0.010 & 63.52 & 0.2 \\
\hline 320.04 & 0.02 & 120.417 & 0.007 & 70.83 & 0.2 \\
\hline 320.05 & 0.02 & 130.479 & 0.009 & 79.14 & 0.2 \\
\hline 320.04 & 0.02 & $\mathbf{1 3 7 . 5 3 3}$ & 0.007 & 85.39 & 0.4 \\
\hline 329.99 & 0.01 & 0.275 & 0.005 & 11.09 & 0.3 \\
\hline 330.00 & 0.01 & 9.955 & 0.008 & 12.83 & 0.2 \\
\hline 330.00 & 0.01 & 19.958 & 0.008 & 14.71 & 0.2 \\
\hline 330.01 & 0.01 & 29.961 & 0.005 & 16.88 & 0.3 \\
\hline 330.01 & 0.01 & 39.977 & 0.007 & 19.15 & 0.1 \\
\hline 330.01 & 0.01 & 50.017 & 0.008 & 21.72 & 0.2 \\
\hline 330.01 & 0.01 & 60.064 & 0.008 & 24.48 & 0.2 \\
\hline 330.01 & 0.01 & 70.110 & 0.007 & 27.44 & 0.2 \\
\hline 330.02 & 0.01 & 80.158 & 0.007 & 30.61 & 0.1 \\
\hline 330.03 & 0.01 & 90.216 & 0.008 & 34.24 & 0.1 \\
\hline 330.03 & 0.01 & 100.280 & 0.007 & 37.99 & 0.1 \\
\hline 330.03 & 0.01 & 110.341 & 0.008 & 42.61 & 0.2 \\
\hline 330.03 & 0.01 & 120.413 & 0.007 & 47.42 & 0.1 \\
\hline 330.03 & 0.01 & 130.485 & 0.008 & 52.87 & 0.2 \\
\hline 330.03 & 0.01 & 137.529 & 0.009 & 56.91 & 0.1 \\
\hline 339.96 & 0.02 & 0.274 & 0.007 & 8.022 & 0.6 \\
\hline 339.98 & 0.01 & 9.961 & 0.007 & 9.284 & 0.2 \\
\hline 339.98 & 0.02 & 19.967 & 0.007 & 10.74 & 0.4 \\
\hline 339.99 & 0.01 & 29.978 & 0.008 & 12.33 & 0.4 \\
\hline 340.00 & 0.01 & 39.993 & 0.006 & 14.01 & 0.2 \\
\hline 340.01 & 0.02 & 50.023 & 0.009 & 15.88 & 0.2 \\
\hline 340.02 & 0.02 & 60.068 & 0.008 & 17.93 & 0.2 \\
\hline 340.02 & 0.02 & 70.113 & 0.008 & 20.15 & 0.2 \\
\hline 340.02 & 0.02 & 80.176 & 0.008 & 22.53 & 0.2 \\
\hline 340.02 & 0.01 & 90.233 & 0.007 & 25.14 & 0.2 \\
\hline 340.02 & 0.02 & 100.290 & 0.006 & 27.84 & 0.2 \\
\hline 340.03 & 0.02 & 110.362 & 0.009 & 30.85 & 0.2 \\
\hline 340.03 & 0.01 & 120.422 & 0.008 & 34.07 & 0.2 \\
\hline 340.04 & 0.01 & 130.497 & 0.009 & 37.57 & 0.1 \\
\hline 340.03 & 0.01 & $\mathbf{1 3 7 . 5 4 5}$ & 0.006 & 39.81 & 0.2 \\
\hline 349.97 & 0.02 & 0.266 & 0.005 & 6.777 & 0.5 \\
\hline 350.00 & 0.01 & 9.959 & 0.006 & 7.521 & 0.3 \\
\hline 350.01 & 0.01 & 19.962 & 0.006 & 8.498 & 0.4 \\
\hline 350.02 & 0.01 & 29.965 & 0.007 & 9.524 & 0.4 \\
\hline 350.03 & 0.01 & 39.985 & 0.007 & 10.70 & 0.4 \\
\hline 350.04 & 0.01 & $\mathbf{5 0 . 0 2 2}$ & 0.008 & 11.94 & 0.3 \\
\hline 350.05 & 0.01 & 60.053 & 0.007 & 13.28 & 0.3 \\
\hline 350.05 & 0.01 & 70.103 & 0.006 & 14.81 & 0.4 \\
\hline 350.06 & 0.01 & 80.169 & 0.007 & 16.49 & 0.3 \\
\hline 350.05 & 0.01 & 90.225 & 0.009 & 18.26 & 0.2 \\
\hline 350.06 & 0.01 & 100.284 & 0.008 & 20.24 & 0.2 \\
\hline 350.07 & 0.02 & 110.348 & 0.008 & 22.51 & 0.3 \\
\hline 350.07 & 0.02 & 120.415 & 0.010 & 25.00 & 0.2 \\
\hline 350.08 & 0.02 & 130.499 & 0.009 & 27.76 & 0.2 \\
\hline 350.07 & 0.01 & 137.549 & 0.009 & 29.92 & 0.2 \\
\hline 360.02 & 0.01 & 0.178 & 0.004 & 5.120 & 0.3 \\
\hline 360.03 & 0.02 & 9.854 & 0.006 & 5.822 & 0.3 \\
\hline 360.04 & 0.01 & 19.860 & 0.006 & 6.601 & 0.2 \\
\hline 360.03 & 0.01 & 29.863 & 0.008 & 7.451 & 0.2 \\
\hline 360.04 & 0.02 & 39.875 & 0.006 & 8.398 & 0.3 \\
\hline 360.04 & 0.01 & 49.903 & 0.008 & 9.425 & 0.2 \\
\hline 360.05 & 0.01 & 59.942 & 0.007 & 10.56 & 0.1 \\
\hline 360.05 & 0.01 & 69.986 & 0.006 & 11.72 & 0.2 \\
\hline 360.05 & 0.01 & 80.037 & 0.007 & 12.98 & 0.2 \\
\hline
\end{tabular}


Journal of Research of the National Institute of Standards and Technology

\begin{tabular}{|c|c|c|c|c|c|}
\hline $\begin{array}{l}T_{90} \\
(\mathrm{~K}) \\
\end{array}$ & $\begin{array}{l}\boldsymbol{s}_{T} \\
(\mathrm{~K}) \\
\end{array}$ & $\begin{array}{l}p \\
(\mathrm{MPa}) \\
\end{array}$ & $\begin{array}{l}\boldsymbol{s}_{P} \\
(\mathrm{MPa}) \\
\end{array}$ & $\begin{array}{l}\eta \\
(\mathrm{mPa} \cdot \mathrm{s}) \\
\end{array}$ & $\begin{array}{l}s_{\eta} / \eta \\
(\%)\end{array}$ \\
\hline 360.06 & 0.02 & 90.100 & 0.009 & 14.33 & 0.1 \\
\hline 360.07 & 0.01 & 100.150 & 0.008 & 15.78 & 0.1 \\
\hline 360.08 & 0.02 & 110.220 & 0.008 & 17.33 & 0.2 \\
\hline 369.99 & 0.01 & 9.843 & 0.006 & 5.241 & 0.3 \\
\hline 370.00 & 0.01 & 19.836 & 0.007 & 5.948 & 0.3 \\
\hline 370.00 & 0.02 & 29.844 & 0.006 & 6.589 & 0.4 \\
\hline 370.00 & 0.01 & 39.864 & 0.008 & 7.207 & 0.3 \\
\hline 369.99 & 0.02 & 49.900 & 0.007 & 7.952 & 0.2 \\
\hline 369.99 & 0.02 & 59.931 & 0.005 & 8.839 & 0.1 \\
\hline 369.98 & 0.02 & 69.974 & 0.029 & 9.717 & 0.2 \\
\hline 369.98 & 0.02 & 80.019 & 0.009 & 10.66 & 0.2 \\
\hline 369.98 & 0.02 & 90.082 & 0.008 & 11.71 & 0.3 \\
\hline 369.99 & 0.01 & 100.151 & 0.007 & 12.81 & 0.2 \\
\hline 369.99 & 0.02 & 110.216 & 0.011 & 13.97 & 0.2 \\
\hline 370.00 & 0.02 & 120.291 & 0.008 & 15.14 & 0.2 \\
\hline 370.00 & 0.01 & 130.361 & 0.007 & 16.42 & 0.1 \\
\hline 370.00 & 0.01 & 137.397 & 0.008 & 17.36 & 0.1 \\
\hline 380.00 & 0.02 & 0.195 & 0.005 & 3.660 & 0.3 \\
\hline 380.01 & 0.01 & 9.874 & 0.007 & 4.175 & 0.4 \\
\hline 380.01 & 0.02 & 19.886 & 0.008 & 4.720 & 0.3 \\
\hline 380.02 & 0.02 & 29.888 & 0.007 & 5.213 & 0.3 \\
\hline 380.02 & 0.02 & 49.946 & 0.007 & 6.295 & 0.2 \\
\hline 380.02 & 0.01 & 59.995 & 0.007 & 6.883 & 0.2 \\
\hline 380.03 & 0.02 & 70.033 & 0.007 & 7.539 & 0.3 \\
\hline 380.03 & 0.02 & 80.088 & 0.006 & 8.255 & 0.2 \\
\hline 380.04 & 0.02 & 90.142 & 0.008 & 9.025 & 0.2 \\
\hline 380.05 & 0.01 & 100.200 & 0.009 & 9.850 & 0.1 \\
\hline 380.05 & 0.01 & 110.268 & 0.006 & 10.72 & 0.1 \\
\hline 380.05 & 0.01 & 120.338 & 0.008 & 11.65 & 0.1 \\
\hline 380.06 & 0.02 & 130.406 & 0.012 & 12.67 & 0.1 \\
\hline 380.06 & 0.01 & 137.466 & 0.008 & 13.45 & 0.1 \\
\hline 380.02 & 0.02 & 40.035 & 0.012 & 5.667 & 0.3 \\
\hline 390.04 & 0.02 & 69.958 & 0.007 & 6.609 & 0.3 \\
\hline 390.04 & 0.02 & 80.008 & 0.007 & 7.186 & 0.3 \\
\hline 390.04 & 0.01 & 90.064 & 0.006 & 7.773 & 0.2 \\
\hline 390.05 & 0.01 & 100.115 & 0.009 & 8.408 & 0.2 \\
\hline 390.05 & 0.01 & 110.189 & 0.007 & 9.109 & 0.2 \\
\hline 390.06 & 0.01 & 120.249 & 0.007 & 9.915 & 0.2 \\
\hline 390.06 & 0.02 & 130.331 & 0.010 & 10.75 & 0.2 \\
\hline 390.06 & 0.02 & 137.377 & 0.007 & 11.37 & 0.1 \\
\hline 390.01 & 0.01 & 0.176 & 0.005 & 3.057 & 0.1 \\
\hline 390.00 & 0.01 & 9.845 & 0.009 & 3.459 & 0.3 \\
\hline 390.01 & 0.01 & 19.861 & 0.006 & 3.907 & 0.2 \\
\hline 390.01 & 0.01 & 29.872 & 0.006 & 4.365 & 0.2 \\
\hline 390.02 & 0.01 & 39.885 & 0.008 & 4.843 & 0.3 \\
\hline 390.03 & 0.01 & 49.909 & 0.007 & 5.363 & 0.1 \\
\hline 390.03 & 0.01 & $\mathbf{5 9 . 9 5 0}$ & 0.007 & 5.894 & 0.1 \\
\hline 400.01 & 0.02 & 0.216 & 0.008 & 2.562 & 0.1 \\
\hline 399.98 & 0.02 & 9.885 & 0.005 & 2.930 & 0.2 \\
\hline 399.96 & 0.01 & 19.876 & 0.006 & 3.337 & 0.2 \\
\hline 399.97 & 0.02 & 29.879 & 0.007 & 3.749 & 0.2 \\
\hline 399.97 & 0.01 & 39.898 & 0.006 & 4.186 & 0.2 \\
\hline 399.99 & 0.01 & 49.921 & 0.020 & 4.607 & 0.2 \\
\hline 399.99 & 0.01 & 59.963 & 0.010 & 5.088 & 0.1 \\
\hline 400.00 & 0.02 & 70.002 & 0.006 & 5.575 & 0.1 \\
\hline 400.00 & 0.02 & 80.054 & 0.009 & 6.085 & 0.1 \\
\hline 400.01 & 0.02 & 90.106 & 0.006 & 6.624 & 0.1 \\
\hline 400.01 & 0.02 & 100.153 & 0.006 & 7.205 & 0.1 \\
\hline 400.02 & 0.02 & 110.215 & 0.006 & 7.800 & 0.1 \\
\hline
\end{tabular}


Journal of Research of the National Institute of Standards and Technology

\begin{tabular}{|c|c|c|c|c|c|}
\hline $\begin{array}{l}T_{90} \\
(\mathrm{~K}) \\
\end{array}$ & $\begin{array}{l}\boldsymbol{s}_{T} \\
(\mathrm{~K}) \\
\end{array}$ & $\begin{array}{l}p \\
(\mathrm{MPa})\end{array}$ & $\begin{array}{l}\boldsymbol{s}_{P} \\
(\mathrm{MPa}) \\
\end{array}$ & $\begin{array}{l}\eta \\
(\mathrm{mPa} \cdot \mathrm{s})\end{array}$ & $\begin{array}{l}s_{\eta} / \eta \\
(\%)\end{array}$ \\
\hline 400.00 & 0.02 & 120.294 & 0.010 & 8.531 & 0.8 \\
\hline 399.99 & 0.01 & 130.353 & 0.008 & 9.280 & 0.1 \\
\hline 399.98 & 0.02 & $\mathbf{1 3 7 . 4 0 8}$ & 0.008 & 9.635 & 0.1 \\
\hline 410.02 & 0.01 & 0.151 & 0.004 & 2.342 & 0.2 \\
\hline 410.02 & 0.01 & 9.821 & 0.007 & 2.669 & 0.2 \\
\hline 410.01 & 0.01 & 19.837 & 0.007 & 3.026 & 0.2 \\
\hline 410.02 & 0.02 & 29.846 & 0.007 & 3.388 & 0.2 \\
\hline 410.03 & 0.01 & 39.861 & 0.009 & 3.776 & 0.1 \\
\hline 410.03 & 0.02 & 49.885 & 0.007 & 4.138 & 0.1 \\
\hline 410.03 & 0.01 & 59.921 & 0.005 & 4.568 & 0.2 \\
\hline 410.04 & 0.02 & 69.971 & 0.008 & 4.980 & 0.1 \\
\hline 410.03 & 0.01 & 80.029 & 0.005 & 5.441 & 0.1 \\
\hline 410.04 & 0.02 & 90.091 & 0.007 & 6.030 & 0.2 \\
\hline 410.04 & 0.02 & 100.152 & 0.008 & 6.545 & 0.1 \\
\hline 410.03 & 0.02 & 110.208 & 0.007 & 7.079 & 0.1 \\
\hline 410.04 & 0.02 & 120.277 & 0.008 & 7.572 & 0.2 \\
\hline 410.05 & 0.02 & 130.341 & 0.008 & 8.120 & 0.1 \\
\hline 410.05 & 0.02 & $\mathbf{1 3 7 . 3 9 3}$ & 0.008 & 8.461 & 0.1 \\
\hline 420.01 & 0.02 & 0.201 & 0.010 & 2.064 & 0.3 \\
\hline 420.02 & 0.01 & 9.893 & 0.007 & 2.351 & 0.2 \\
\hline 420.03 & 0.02 & 19.891 & 0.005 & 2.635 & 0.2 \\
\hline 420.02 & 0.01 & 29.907 & 0.006 & 2.917 & 0.2 \\
\hline 420.02 & 0.02 & 39.921 & 0.007 & 3.284 & 0.2 \\
\hline 420.03 & 0.02 & 49.936 & 0.008 & 3.596 & 0.2 \\
\hline 420.03 & 0.02 & 59.971 & 0.005 & 3.912 & 0.2 \\
\hline 420.02 & 0.02 & 70.021 & 0.007 & 4.279 & 0.2 \\
\hline 419.98 & 0.01 & 80.068 & 0.007 & 4.666 & 0.2 \\
\hline 419.97 & 0.02 & 90.122 & 0.006 & 5.105 & 0.3 \\
\hline 420.03 & 0.02 & 100.177 & 0.006 & 5.512 & 0.2 \\
\hline 420.07 & 0.02 & 110.236 & 0.006 & 5.931 & 0.2 \\
\hline 420.06 & 0.02 & 120.315 & 0.009 & 6.331 & 0.1 \\
\hline 420.07 & 0.02 & 130.382 & 0.007 & 6.764 & 0.2 \\
\hline 420.08 & 0.01 & $\mathbf{1 3 7 . 4 3 1}$ & 0.007 & 7.064 & 0.2 \\
\hline 430.04 & 0.02 & 0.190 & 0.006 & 1.680 & 0.3 \\
\hline 430.03 & 0.01 & 9.858 & 0.008 & 1.929 & 0.4 \\
\hline 430.03 & 0.02 & 19.869 & 0.007 & 2.202 & 0.4 \\
\hline 430.02 & 0.02 & 29.875 & 0.005 & 2.464 & 0.2 \\
\hline 430.02 & 0.02 & 39.894 & 0.006 & 2.747 & 0.2 \\
\hline 430.02 & 0.02 & 49.929 & 0.008 & 3.045 & 0.2 \\
\hline 430.03 & 0.02 & 59.967 & 0.007 & 3.352 & 0.2 \\
\hline 430.03 & 0.01 & 70.016 & 0.006 & 3.710 & 0.4 \\
\hline 430.03 & 0.02 & 80.067 & 0.009 & 4.079 & 0.1 \\
\hline 430.04 & 0.02 & 90.123 & 0.005 & 4.441 & 0.2 \\
\hline 430.04 & 0.02 & 100.181 & 0.009 & 4.789 & 0.1 \\
\hline 430.03 & 0.02 & 110.240 & 0.007 & 5.163 & 0.2 \\
\hline 430.04 & 0.02 & 120.318 & 0.010 & 5.541 & 0.1 \\
\hline 430.04 & 0.02 & 130.396 & 0.010 & 5.942 & 0.1 \\
\hline 430.05 & 0.01 & $\mathbf{1 3 7 . 4 5 1}$ & 0.010 & 6.240 & 0.1 \\
\hline 440.08 & 0.02 & 0.175 & 0.006 & 1.638 & 0.3 \\
\hline 440.06 & 0.02 & 9.850 & 0.006 & 1.885 & 0.3 \\
\hline 440.07 & 0.02 & 19.855 & 0.007 & 2.097 & 0.2 \\
\hline 440.07 & 0.02 & 29.869 & 0.007 & 2.325 & 0.4 \\
\hline 440.06 & 0.02 & 39.882 & 0.006 & 2.564 & 0.2 \\
\hline 440.08 & 0.02 & 49.908 & 0.007 & 2.818 & 0.2 \\
\hline 440.09 & 0.02 & 59.945 & 0.008 & 3.099 & 0.2 \\
\hline 440.11 & 0.01 & 69.997 & 0.006 & 3.387 & 0.2 \\
\hline 440.11 & 0.02 & 80.034 & 0.005 & 3.722 & 0.5 \\
\hline 440.10 & 0.02 & 90.083 & 0.009 & 4.054 & 0.1 \\
\hline 440.09 & 0.02 & 100.143 & 0.006 & 4.402 & 0.2 \\
\hline
\end{tabular}


Journal of Research of the National Institute of Standards and Technology

\begin{tabular}{llllll}
\hline$T_{90}$ & $\boldsymbol{s}_{T}$ & $p$ & $\boldsymbol{s}_{P}$ & $\eta$ & $\eta$ \\
$(\mathrm{K})$ & $(\mathrm{K})$ & $(\mathrm{MPa})$ & $(\mathrm{MPa})$ & $\begin{array}{l}\boldsymbol{s}_{\eta} / \eta \\
(\%)\end{array}$ \\
\hline $\mathbf{4 4 0 . 1 0}$ & 0.01 & $\mathbf{1 1 0 . 2 0 8}$ & 0.006 & $\mathbf{4 . 7 2 8}$ & 0.2 \\
$\mathbf{4 4 0 . 0 9}$ & 0.01 & $\mathbf{1 2 0 . 2 7 2}$ & 0.006 & $\mathbf{5 . 0 5 6}$ & 0.2 \\
$\mathbf{4 4 0 . 0 9}$ & 0.01 & $\mathbf{1 3 0 . 3 5 2}$ & 0.008 & $\mathbf{5 . 4 4 0}$ & 0.1 \\
$\mathbf{4 4 0 . 0 9}$ & 0.01 & $\mathbf{1 3 7 . 4 1 5}$ & 0.008 & $\mathbf{5 . 7 1 0}$ & 0.1 \\
\hline $\mathbf{4 5 0 . 0 9}$ & 0.02 & $\mathbf{0 . 1 7 7}$ & 0.006 & $\mathbf{1 . 3 9 8}$ & 0.2 \\
$\mathbf{4 5 0 . 0 9}$ & 0.02 & $\mathbf{9 . 8 4 4}$ & 0.007 & $\mathbf{1 . 6 0 0}$ & 0.3 \\
$\mathbf{4 5 0 . 1 0}$ & 0.01 & $\mathbf{1 9 . 8 4 6}$ & 0.006 & $\mathbf{1 . 8 0 3}$ & 0.3 \\
$\mathbf{4 5 0 . 1 0}$ & 0.01 & $\mathbf{2 9 . 8 5 1}$ & 0.007 & $\mathbf{2 . 0 0 4}$ & 0.5 \\
$\mathbf{4 5 0 . 1 0}$ & 0.02 & $\mathbf{3 9 . 8 7 5}$ & 0.007 & $\mathbf{2 . 2 0 5}$ & 0.2 \\
$\mathbf{4 5 0 . 1 0}$ & 0.02 & $\mathbf{4 9 . 9 0 9}$ & 0.006 & $\mathbf{2 . 4 3 3}$ & 0.2 \\
$\mathbf{4 5 0 . 1 1}$ & 0.02 & $\mathbf{5 9 . 9 4 6}$ & 0.008 & $\mathbf{2 . 6 6 3}$ & 0.2 \\
$\mathbf{4 5 0 . 1 0}$ & 0.02 & $\mathbf{6 9 . 9 9 4}$ & 0.007 & $\mathbf{2 . 9 6 8}$ & 0.2 \\
$\mathbf{4 5 0 . 1 1}$ & 0.02 & $\mathbf{8 0 . 0 4 2}$ & 0.007 & $\mathbf{3 . 2 1 8}$ & 0.2 \\
$\mathbf{4 5 0 . 1 0}$ & 0.02 & $\mathbf{9 0 . 1 0 0}$ & 0.008 & $\mathbf{3 . 5 0 3}$ & 0.1 \\
$\mathbf{4 5 0 . 1 1}$ & 0.02 & $\mathbf{1 0 0 . 1 4 6}$ & 0.007 & $\mathbf{3 . 7 7 8}$ & 0.2 \\
$\mathbf{4 5 0 . 1 1}$ & 0.02 & $\mathbf{1 1 0 . 2 1 2}$ & 0.006 & $\mathbf{4 . 0 7 3}$ & 0.1 \\
$\mathbf{4 5 0 . 1 1}$ & 0.02 & $\mathbf{1 2 0 . 2 8 1}$ & 0.007 & $\mathbf{4 . 3 6 1}$ & 0.2 \\
$\mathbf{4 5 0 . 1 1}$ & 0.01 & $\mathbf{1 3 0 . 3 5 0}$ & 0.006 & $\mathbf{4 . 6 7 7}$ & 0.1 \\
$\mathbf{4 5 0 . 1 2}$ & 0.02 & $\mathbf{1 3 7 . 4 0 0}$ & 0.007 & $\mathbf{4 . 9 0 4}$ & 0.1 \\
\hline
\end{tabular}

Table 5. Experimental viscosity data for POE-5 measured in this project at temperatures from $275.06 \mathrm{~K}$ to $430.07 \mathrm{~K}$ with pressures to 137.41 MPa.

\begin{tabular}{|c|c|c|c|c|c|}
\hline $\begin{array}{l}T_{90} \\
(\mathrm{~K})\end{array}$ & $\begin{array}{l}\boldsymbol{s}_{T} \\
(\mathrm{~K})\end{array}$ & $\begin{array}{l}p \\
(\mathrm{MPa})\end{array}$ & $\begin{array}{l}\boldsymbol{s}_{P} \\
(\mathrm{MPa})\end{array}$ & $\begin{array}{l}\eta \\
(\mathrm{mPa} \cdot \mathrm{s})\end{array}$ & $\begin{array}{l}\boldsymbol{s}_{\eta} / \eta \\
(\%)\end{array}$ \\
\hline 350.03 & 0.01 & 0.137 & 0.006 & 5.225 & 0.3 \\
\hline 350.03 & 0.01 & 9.827 & 0.009 & 5.950 & 0.2 \\
\hline 350.03 & 0.01 & 19.828 & 0.006 & 6.740 & 0.1 \\
\hline 350.03 & 0.01 & 29.842 & 0.006 & 7.603 & 0.3 \\
\hline 350.04 & 0.01 & 39.859 & 0.009 & 8.632 & 0.5 \\
\hline 350.04 & 0.01 & 49.893 & 0.009 & 9.649 & 0.1 \\
\hline 350.04 & 0.01 & 59.928 & 0.009 & 10.78 & 0.2 \\
\hline 350.05 & 0.01 & 69.986 & 0.010 & 12.00 & 0.1 \\
\hline 350.05 & 0.01 & 80.043 & 0.008 & 13.32 & 0.1 \\
\hline 350.05 & 0.01 & 90.090 & 0.007 & 14.74 & 0.1 \\
\hline 350.06 & 0.01 & 100.160 & 0.006 & 16.24 & 0.1 \\
\hline 350.06 & 0.01 & 110.223 & 0.009 & 17.85 & 0.1 \\
\hline 350.06 & 0.01 & 120.297 & 0.010 & 19.55 & 0.1 \\
\hline 360.04 & 0.01 & 0.154 & 0.006 & 4.156 & 0.3 \\
\hline 360.05 & 0.01 & 9.822 & 0.006 & 4.756 & 0.3 \\
\hline 360.05 & 0.01 & 19.817 & 0.007 & 5.347 & 0.1 \\
\hline 360.06 & 0.02 & 29.820 & 0.006 & 6.020 & 0.3 \\
\hline 360.07 & 0.01 & 39.838 & 0.007 & 6.727 & 0.2 \\
\hline 360.07 & 0.01 & 49.865 & 0.006 & 7.475 & 0.2 \\
\hline 360.07 & 0.02 & 59.911 & 0.006 & 8.306 & 0.3 \\
\hline 360.07 & 0.01 & 69.946 & 0.007 & 9.205 & 0.1 \\
\hline 360.07 & 0.02 & 79.989 & 0.008 & 10.19 & 0.1 \\
\hline 360.07 & 0.02 & 90.042 & 0.007 & 11.26 & 0.1 \\
\hline 360.08 & 0.01 & 100.115 & 0.007 & 12.40 & 0.2 \\
\hline 360.08 & 0.01 & 110.191 & 0.010 & 13.59 & 0.2 \\
\hline 360.09 & 0.01 & 120.245 & 0.007 & 14.86 & 0.2 \\
\hline 360.08 & 0.01 & 130.316 & 0.009 & 16.23 & 0.1 \\
\hline 360.08 & 0.01 & 137.352 & 0.006 & 17.27 & 0.1 \\
\hline 369.98 & 0.02 & 0.131 & 0.007 & 3.629 & 0.4 \\
\hline 369.98 & 0.02 & 9.798 & 0.007 & 4.102 & 0.2 \\
\hline 369.99 & 0.02 & 19.800 & 0.008 & 4.623 & 0.2 \\
\hline 370.00 & 0.01 & 29.803 & 0.007 & 5.165 & 0.2 \\
\hline 370.00 & 0.01 & 39.827 & 0.007 & 5.702 & 0.1 \\
\hline
\end{tabular}


Journal of Research of the National Institute of Standards and Technology

\begin{tabular}{|c|c|c|c|c|c|}
\hline $\begin{array}{l}T_{90} \\
(\mathrm{~K})\end{array}$ & $\begin{array}{l}\boldsymbol{s}_{T} \\
(\mathrm{~K})\end{array}$ & $\begin{array}{l}p \\
(\mathrm{MPa})\end{array}$ & $\begin{array}{l}\boldsymbol{s}_{P} \\
(\mathrm{MPa})\end{array}$ & $\begin{array}{l}\eta \\
(\mathrm{mPa} \cdot \mathrm{s})\end{array}$ & $\begin{array}{l}s_{\eta} / \eta \\
(\%)\end{array}$ \\
\hline 370.00 & 0.01 & 49.861 & 0.009 & 6.342 & 0.1 \\
\hline 370.01 & 0.01 & 59.906 & 0.009 & 6.967 & 0.2 \\
\hline 370.01 & 0.02 & 69.949 & 0.007 & 7.612 & 0.1 \\
\hline 370.02 & 0.01 & 79.999 & 0.008 & 8.290 & 0.2 \\
\hline 370.02 & 0.01 & 90.058 & 0.008 & 9.037 & 0.2 \\
\hline 370.03 & 0.01 & 100.140 & 0.005 & 9.862 & 0.1 \\
\hline 370.04 & 0.01 & 110.197 & 0.008 & 10.76 & 0.1 \\
\hline 370.04 & 0.01 & 120.266 & 0.008 & 11.70 & 0.1 \\
\hline 370.04 & 0.02 & 130.336 & 0.006 & 12.70 & 0.1 \\
\hline 370.04 & 0.01 & 137.395 & 0.009 & 13.46 & 0.1 \\
\hline 380.01 & 0.02 & 0.139 & 0.006 & 2.896 & 0.2 \\
\hline 380.02 & 0.02 & 9.816 & 0.006 & 3.278 & 0.1 \\
\hline 380.02 & 0.01 & 19.814 & 0.007 & 3.691 & 0.2 \\
\hline 380.02 & 0.02 & 29.814 & 0.007 & 4.124 & 0.2 \\
\hline 380.03 & 0.01 & 39.838 & 0.009 & 4.594 & 0.2 \\
\hline 380.03 & 0.02 & 49.874 & 0.006 & 5.067 & 0.2 \\
\hline 380.04 & 0.02 & 59.913 & 0.009 & 5.558 & 0.1 \\
\hline 380.03 & 0.02 & 69.958 & 0.007 & 6.088 & 0.1 \\
\hline 380.04 & 0.02 & 79.990 & 0.006 & 6.657 & 0.2 \\
\hline 380.04 & 0.02 & 90.044 & 0.008 & 7.242 & 0.2 \\
\hline 380.05 & 0.01 & 100.123 & 0.009 & 7.846 & 0.1 \\
\hline 380.05 & 0.01 & 110.186 & 0.007 & 8.507 & 0.2 \\
\hline 380.00 & 0.02 & 120.265 & 0.008 & 9.148 & 0.1 \\
\hline 379.97 & 0.02 & 130.367 & 0.010 & 9.950 & 0.1 \\
\hline 389.95 & 0.02 & 0.142 & 0.005 & 2.494 & 0.3 \\
\hline 389.98 & 0.01 & 29.821 & 0.007 & 3.532 & 0.1 \\
\hline 389.99 & 0.01 & 39.842 & 0.005 & 3.926 & 0.2 \\
\hline 390.00 & 0.01 & 49.876 & 0.006 & 4.353 & 0.2 \\
\hline 390.01 & 0.02 & 59.915 & 0.007 & 4.812 & 0.7 \\
\hline 390.02 & 0.01 & 90.075 & 0.006 & 6.168 & 0.3 \\
\hline 390.02 & 0.01 & 100.138 & 0.009 & 6.726 & 0.7 \\
\hline 390.03 & 0.01 & 110.205 & 0.010 & 7.228 & 0.2 \\
\hline 390.03 & 0.01 & 120.273 & 0.006 & 7.786 & 0.2 \\
\hline 390.03 & 0.01 & 130.341 & 0.007 & 8.350 & 0.1 \\
\hline 390.04 & 0.01 & 137.389 & 0.007 & 8.797 & 0.2 \\
\hline 390.01 & 0.01 & 70.073 & 0.008 & 5.257 & 0.3 \\
\hline 390.00 & 0.01 & 19.872 & 0.009 & 3.171 & 0.4 \\
\hline 390.01 & 0.01 & 9.864 & 0.006 & 2.799 & 1.4 \\
\hline 399.93 & 0.02 & 0.151 & 0.013 & 2.136 & 0.3 \\
\hline 399.93 & 0.02 & 9.831 & 0.006 & 2.390 & 0.2 \\
\hline 399.92 & 0.02 & 19.832 & 0.008 & 2.699 & 0.2 \\
\hline 399.93 & 0.01 & 29.832 & 0.006 & 3.034 & 0.3 \\
\hline 399.93 & 0.02 & 39.851 & 0.005 & 3.370 & 0.2 \\
\hline 399.94 & 0.02 & 49.882 & 0.008 & 3.732 & 0.1 \\
\hline 399.95 & 0.01 & 59.932 & 0.007 & 4.113 & 0.1 \\
\hline 399.94 & 0.01 & 69.965 & 0.010 & 4.471 & 0.2 \\
\hline 399.94 & 0.02 & 80.016 & 0.005 & 4.857 & 0.2 \\
\hline 399.94 & 0.02 & 90.074 & 0.006 & 5.315 & 0.1 \\
\hline 399.95 & 0.01 & 100.134 & 0.007 & 5.738 & 0.1 \\
\hline 399.96 & 0.01 & 110.208 & 0.007 & 6.235 & 0.1 \\
\hline 399.96 & 0.01 & 120.267 & 0.009 & 6.687 & 0.1 \\
\hline 399.97 & 0.01 & 130.345 & 0.009 & 7.212 & 0.1 \\
\hline 399.97 & 0.01 & 137.390 & 0.006 & 7.585 & 0.1 \\
\hline 419.97 & 0.01 & 0.131 & 0.006 & 1.698 & 0.5 \\
\hline 419.96 & 0.01 & 9.807 & 0.007 & 1.903 & 0.4 \\
\hline 419.96 & 0.01 & 19.810 & 0.007 & 2.116 & 0.6 \\
\hline 419.96 & 0.01 & 29.807 & 0.005 & 2.367 & 0.3 \\
\hline 419.97 & 0.01 & 39.831 & 0.005 & 2.594 & 0.3 \\
\hline 419.96 & 0.01 & 49.859 & 0.008 & 2.838 & 0.2 \\
\hline
\end{tabular}


Journal of Research of the National Institute of Standards and Technology

\begin{tabular}{|c|c|c|c|c|c|}
\hline $\begin{array}{l}T_{90} \\
(\mathrm{~K})\end{array}$ & $\begin{array}{l}\boldsymbol{s}_{T} \\
(\mathrm{~K})\end{array}$ & $\begin{array}{l}p \\
(\mathrm{MPa})\end{array}$ & $\begin{array}{l}\boldsymbol{s}_{P} \\
(\mathrm{MPa})\end{array}$ & $\begin{array}{l}\eta \\
(\mathrm{mPa} \cdot \mathrm{s})\end{array}$ & $\begin{array}{l}s_{\eta} / \eta \\
(\%)\end{array}$ \\
\hline 419.95 & 0.02 & 59.908 & 0.009 & 3.102 & 0.2 \\
\hline 419.95 & 0.02 & 69.950 & 0.011 & 3.354 & 0.2 \\
\hline 419.96 & 0.02 & 79.988 & 0.007 & 3.616 & 0.3 \\
\hline 419.96 & 0.01 & 90.057 & 0.005 & 3.881 & 0.1 \\
\hline 419.96 & 0.01 & 100.121 & 0.009 & 4.164 & 0.2 \\
\hline 419.98 & 0.01 & 110.197 & 0.009 & 4.459 & 0.2 \\
\hline 419.98 & 0.01 & 120.262 & 0.008 & 4.773 & 0.1 \\
\hline 419.98 & 0.01 & 130.326 & 0.006 & 5.062 & 0.2 \\
\hline 419.98 & 0.01 & 137.362 & 0.009 & 5.296 & 0.1 \\
\hline 430.04 & 0.01 & 0.172 & 0.008 & 1.467 & 0.2 \\
\hline 430.02 & 0.01 & 9.821 & 0.006 & 1.674 & 0.2 \\
\hline 430.03 & 0.01 & 19.810 & 0.007 & 1.880 & 0.2 \\
\hline 430.03 & 0.01 & 29.819 & 0.006 & 2.111 & 0.3 \\
\hline 430.04 & 0.02 & 39.839 & 0.006 & 2.341 & 0.2 \\
\hline 430.03 & 0.02 & 49.850 & 0.007 & 2.595 & 0.1 \\
\hline 430.04 & 0.02 & 59.890 & 0.007 & 2.694 & 0.2 \\
\hline 430.03 & 0.02 & 69.936 & 0.006 & 2.920 & 0.2 \\
\hline 430.02 & 0.02 & 79.987 & 0.009 & 3.143 & 0.2 \\
\hline 430.03 & 0.02 & 90.042 & 0.008 & 3.448 & 0.2 \\
\hline 430.04 & 0.02 & 100.109 & 0.008 & 3.674 & 0.2 \\
\hline 430.04 & 0.01 & 110.163 & 0.010 & 3.987 & 0.2 \\
\hline 430.05 & 0.02 & 120.225 & 0.012 & 4.304 & 0.1 \\
\hline 430.06 & 0.02 & 130.297 & 0.008 & 4.605 & 0.1 \\
\hline 430.07 & 0.02 & 137.350 & 0.008 & 4.823 & 0.1 \\
\hline 410.03 & 0.02 & 0.144 & 0.005 & 1.839 & 0.3 \\
\hline 410.03 & 0.02 & 9.822 & 0.008 & 2.101 & 0.4 \\
\hline 410.00 & 0.01 & 19.822 & 0.007 & 2.369 & 0.2 \\
\hline 410.00 & 0.02 & 39.849 & 0.007 & 2.950 & 0.1 \\
\hline 410.00 & 0.02 & 49.872 & 0.007 & 3.259 & 0.4 \\
\hline 410.00 & 0.02 & 59.914 & 0.008 & 3.601 & 0.2 \\
\hline 410.01 & 0.01 & 69.960 & 0.007 & 3.987 & 0.3 \\
\hline 410.01 & 0.02 & 80.008 & 0.008 & 4.326 & 0.2 \\
\hline 410.02 & 0.02 & 90.064 & 0.007 & 4.681 & 0.3 \\
\hline 410.02 & 0.02 & 100.132 & 0.010 & 5.036 & 0.2 \\
\hline 410.02 & 0.01 & 110.200 & 0.008 & 5.444 & 0.2 \\
\hline 410.01 & 0.02 & 120.267 & 0.009 & 5.802 & 0.2 \\
\hline 410.01 & 0.02 & 130.324 & 0.006 & 6.275 & 0.2 \\
\hline 410.03 & 0.02 & 137.369 & 0.009 & 6.653 & 0.1 \\
\hline 310.02 & 0.01 & 0.111 & 0.005 & 16.65 & 0.3 \\
\hline 310.02 & 0.02 & 9.781 & 0.005 & 19.43 & 0.2 \\
\hline 310.02 & 0.02 & 19.790 & 0.010 & 22.36 & 0.1 \\
\hline 310.00 & 0.01 & 29.803 & 0.009 & 25.75 & 0.2 \\
\hline 309.99 & 0.01 & 39.826 & 0.007 & 29.57 & 0.2 \\
\hline 310.02 & 0.01 & 49.838 & 0.006 & 33.69 & 0.3 \\
\hline 310.02 & 0.01 & 59.889 & 0.007 & 38.56 & 0.1 \\
\hline 310.03 & 0.01 & 69.928 & 0.008 & 44.05 & 0.1 \\
\hline 310.03 & 0.01 & 79.984 & 0.010 & 50.18 & 0.2 \\
\hline 310.04 & 0.01 & 90.024 & 0.012 & 56.75 & 0.2 \\
\hline 310.04 & 0.01 & 100.092 & 0.009 & 64.09 & 0.1 \\
\hline 310.04 & 0.01 & 110.149 & 0.007 & 72.22 & 0.2 \\
\hline 310.01 & 0.01 & 120.246 & 0.010 & 81.36 & 0.1 \\
\hline 309.97 & 0.01 & 130.335 & 0.012 & 91.00 & 0.1 \\
\hline 309.96 & 0.01 & 137.408 & 0.009 & 98.51 & 0.2 \\
\hline 300.03 & 0.01 & 0.120 & 0.006 & 24.33 & 0.3 \\
\hline 300.04 & 0.01 & 9.797 & 0.006 & 28.53 & 0.4 \\
\hline 300.04 & 0.01 & 19.791 & 0.007 & 33.22 & 0.2 \\
\hline 300.05 & 0.01 & 29.795 & 0.007 & 38.41 & 0.2 \\
\hline 300.04 & 0.01 & 39.803 & 0.007 & 44.84 & 0.1 \\
\hline 300.04 & 0.01 & 49.837 & 0.008 & 52.04 & 0.1 \\
\hline
\end{tabular}


Journal of Research of the National Institute of Standards and Technology

\begin{tabular}{|c|c|c|c|c|c|}
\hline $\begin{array}{l}T_{90} \\
(\mathrm{~K})\end{array}$ & $\begin{array}{l}\boldsymbol{s}_{T} \\
(\mathrm{~K})\end{array}$ & $\begin{array}{l}p \\
(\mathrm{MPa})\end{array}$ & $\begin{array}{l}\boldsymbol{s}_{P} \\
(\mathrm{MPa})\end{array}$ & $\begin{array}{l}\eta \\
(\mathrm{mPa} \cdot \mathrm{s})\end{array}$ & $\begin{array}{l}s_{\eta} / \eta \\
(\%)\end{array}$ \\
\hline \begin{tabular}{|l|}
300.03 \\
\end{tabular} & 0.02 & \begin{tabular}{|c|}
59.890 \\
\end{tabular} & 0.006 & 60.44 & 0.2 \\
\hline 300.03 & 0.01 & 69.933 & 0.005 & 69.05 & 0.1 \\
\hline 300.03 & 0.01 & 79.980 & 0.008 & 78.80 & 0.2 \\
\hline 300.02 & 0.01 & 90.042 & 0.006 & 89.67 & 0.1 \\
\hline 305.03 & 0.01 & 0.117 & 0.005 & 20.39 & 1.1 \\
\hline 305.03 & 0.01 & 9.797 & 0.006 & 23.63 & 0.4 \\
\hline 305.02 & 0.01 & 19.798 & 0.006 & 27.36 & 0.3 \\
\hline 305.03 & 0.01 & 29.802 & 0.008 & 31.49 & 0.2 \\
\hline 305.03 & 0.01 & 39.827 & 0.007 & 36.28 & 0.2 \\
\hline 305.03 & 0.01 & 49.849 & 0.006 & 42.01 & 0.2 \\
\hline 305.03 & 0.01 & 59.901 & 0.011 & 48.29 & 0.2 \\
\hline 305.03 & 0.01 & 69.942 & 0.007 & 55.22 & 0.2 \\
\hline 305.03 & 0.01 & 79.982 & 0.007 & 62.73 & 0.2 \\
\hline 305.02 & 0.01 & 90.041 & 0.008 & 71.10 & 0.1 \\
\hline 305.02 & 0.01 & 100.117 & 0.006 & 80.39 & 0.1 \\
\hline 305.03 & 0.01 & 110.175 & 0.007 & 90.42 & 0.1 \\
\hline 340.05 & 0.01 & 0.129 & 0.005 & 6.58 & 0.7 \\
\hline 340.03 & 0.01 & 9.808 & 0.009 & 7.56 & 0.6 \\
\hline 340.02 & 0.01 & 19.809 & 0.005 & 8.70 & 0.4 \\
\hline 340.01 & 0.01 & 29.813 & 0.006 & 9.97 & 0.2 \\
\hline 340.01 & 0.01 & 39.830 & 0.007 & 11.31 & 0.2 \\
\hline 340.01 & 0.01 & 49.873 & 0.006 & 12.76 & 0.2 \\
\hline 340.01 & 0.01 & 59.921 & 0.008 & 14.32 & 0.2 \\
\hline 340.01 & 0.02 & 69.965 & 0.007 & 16.00 & 0.2 \\
\hline 340.02 & 0.01 & 80.018 & 0.010 & 17.83 & 0.2 \\
\hline 340.02 & 0.02 & 90.083 & 0.013 & 19.81 & 0.2 \\
\hline 340.02 & 0.01 & 100.138 & 0.011 & 21.92 & 0.1 \\
\hline 340.01 & 0.01 & 110.210 & 0.006 & 24.23 & 0.1 \\
\hline 340.01 & 0.01 & 120.288 & 0.009 & 26.55 & 0.2 \\
\hline 340.02 & 0.01 & 130.348 & 0.009 & 29.16 & 0.2 \\
\hline 340.01 & 0.02 & 137.399 & 0.008 & 31.21 & 0.1 \\
\hline 325.01 & 0.02 & 0.125 & 0.008 & 10.49 & 0.8 \\
\hline 324.97 & 0.02 & 9.798 & 0.006 & 12.05 & 0.3 \\
\hline 324.97 & 0.01 & 19.792 & 0.007 & 13.90 & 0.2 \\
\hline 324.96 & 0.01 & 29.794 & 0.009 & 15.90 & 0.3 \\
\hline 324.96 & 0.01 & 39.817 & 0.006 & 18.05 & 0.1 \\
\hline 324.96 & 0.01 & 49.841 & 0.008 & 20.39 & 0.2 \\
\hline 324.97 & 0.01 & 59.886 & 0.007 & 22.98 & 0.2 \\
\hline 324.95 & 0.01 & 69.930 & 0.007 & 25.74 & 0.2 \\
\hline 324.96 & 0.01 & 79.968 & 0.008 & 28.70 & 0.2 \\
\hline 324.96 & 0.01 & 90.030 & 0.006 & 31.91 & 0.2 \\
\hline 324.96 & 0.01 & 100.096 & 0.010 & 35.51 & 0.2 \\
\hline 324.96 & 0.02 & 110.176 & 0.009 & 39.52 & 0.2 \\
\hline 324.96 & 0.01 & 120.235 & 0.011 & 44.25 & 0.2 \\
\hline 324.96 & 0.01 & 130.297 & 0.008 & 49.25 & 0.4 \\
\hline 324.97 & 0.01 & 137.355 & 0.003 & 53.00 & 0.2 \\
\hline 330.00 & 0.01 & 0.158 & 0.004 & 8.965 & 1.0 \\
\hline 330.01 & 0.01 & 9.831 & 0.008 & 10.25 & 0.3 \\
\hline 330.01 & 0.01 & 19.834 & 0.006 & 11.81 & 0.2 \\
\hline 330.01 & 0.01 & 29.845 & 0.007 & 13.52 & 0.2 \\
\hline 330.02 & 0.01 & 39.868 & 0.005 & 15.35 & 0.2 \\
\hline 330.02 & 0.01 & 49.896 & 0.008 & 17.35 & 0.3 \\
\hline 330.02 & 0.01 & 59.935 & 0.010 & 19.45 & 0.2 \\
\hline 330.02 & 0.01 & 69.987 & 0.006 & 21.70 & 0.1 \\
\hline 330.03 & 0.01 & 80.034 & 0.008 & 24.24 & 0.3 \\
\hline 330.02 & 0.01 & 90.083 & 0.008 & 26.87 & 0.2 \\
\hline 330.03 & 0.01 & 100.146 & 0.007 & 30.25 & 0.3 \\
\hline 330.03 & 0.01 & 110.224 & 0.006 & 32.82 & 0.2 \\
\hline 330.04 & 0.01 & 120.301 & 0.007 & 36.30 & 0.2 \\
\hline
\end{tabular}


Journal of Research of the National Institute of Standards and Technology

\begin{tabular}{|c|c|c|c|c|c|}
\hline $\begin{array}{l}T_{90} \\
(\mathrm{~K})\end{array}$ & $\begin{array}{l}\boldsymbol{s}_{T} \\
(\mathrm{~K})\end{array}$ & $\begin{array}{l}p \\
(\mathrm{MPa})\end{array}$ & $\begin{array}{l}\boldsymbol{s}_{P} \\
(\mathrm{MPa})\end{array}$ & $\begin{array}{l}\eta \\
(\mathrm{mPa} \cdot \mathrm{s})\end{array}$ & $\begin{array}{l}s_{\eta} / \eta \\
(\%)\end{array}$ \\
\hline 330.04 & 0.01 & 130.355 & 0.008 & 40.10 & 0.2 \\
\hline 330.05 & 0.01 & 137.405 & 0.009 & 43.16 & 0.2 \\
\hline 315.06 & 0.01 & 0.101 & 0.007 & 14.41 & 0.5 \\
\hline 315.07 & 0.01 & 9.768 & 0.007 & 16.64 & 0.3 \\
\hline 315.07 & 0.02 & 19.766 & 0.006 & 19.28 & 0.3 \\
\hline 315.08 & 0.01 & 29.762 & 0.008 & 22.10 & 0.2 \\
\hline 315.08 & 0.01 & 39.783 & 0.007 & 25.17 & 0.2 \\
\hline 315.07 & 0.01 & 49.805 & 0.008 & 28.64 & 0.1 \\
\hline 315.08 & 0.01 & 59.848 & 0.007 & 32.46 & 0.2 \\
\hline 315.08 & 0.01 & 69.898 & 0.008 & 36.60 & 0.2 \\
\hline 315.09 & 0.01 & 79.942 & 0.007 & 41.40 & 0.2 \\
\hline 315.09 & 0.01 & 89.995 & 0.004 & 47.08 & 0.2 \\
\hline 315.08 & 0.01 & 100.072 & 0.006 & 53.23 & 0.1 \\
\hline 315.09 & 0.01 & 110.138 & 0.008 & 59.82 & 0.1 \\
\hline 315.09 & 0.01 & 120.185 & 0.007 & 67.07 & 0.2 \\
\hline 315.08 & 0.01 & 130.257 & 0.006 & 75.04 & 0.1 \\
\hline 315.09 & 0.01 & 137.303 & 0.009 & 81.09 & 0.1 \\
\hline 320.02 & 0.01 & 0.135 & 0.005 & 12.53 & 0.4 \\
\hline 320.03 & 0.01 & 9.815 & 0.007 & 14.40 & 0.3 \\
\hline 320.03 & 0.01 & 19.819 & 0.008 & 16.52 & 0.3 \\
\hline 320.04 & 0.02 & 29.820 & 0.007 & 18.88 & 0.2 \\
\hline 320.05 & 0.01 & 39.838 & 0.008 & 21.45 & 0.3 \\
\hline 320.05 & 0.01 & 49.874 & 0.008 & 24.28 & 0.2 \\
\hline 320.05 & 0.01 & 59.913 & 0.005 & 27.31 & 0.2 \\
\hline 320.06 & 0.02 & 69.966 & 0.007 & 30.62 & 0.2 \\
\hline 320.06 & 0.01 & 80.017 & 0.008 & 34.29 & 0.2 \\
\hline 320.07 & 0.01 & 90.073 & 0.006 & 38.28 & 0.2 \\
\hline 320.07 & 0.01 & 100.143 & 0.012 & 42.97 & 0.2 \\
\hline 320.07 & 0.01 & 110.217 & 0.021 & 48.43 & 0.4 \\
\hline 320.07 & 0.01 & 120.293 & 0.009 & 53.94 & 0.1 \\
\hline 320.07 & 0.01 & 130.358 & 0.007 & 60.32 & 0.2 \\
\hline 320.07 & 0.01 & 137.402 & 0.006 & 65.25 & 0.2 \\
\hline 275.06 & 0.01 & 0.107 & 0.008 & 86.85 & 0.2 \\
\hline 279.97 & 0.01 & 0.116 & 0.006 & 65.78 & 0.3 \\
\hline 279.98 & 0.01 & 4.793 & 0.007 & 71.02 & 0.2 \\
\hline 279.98 & 0.01 & 9.781 & 0.006 & 77.48 & 0.3 \\
\hline 279.97 & 0.01 & 19.788 & 0.010 & 91.56 & 0.3 \\
\hline 285.06 & 0.01 & 0.094 & 0.006 & 50.09 & 0.3 \\
\hline 285.08 & 0.02 & 4.776 & 0.008 & 54.38 & 0.2 \\
\hline 285.07 & 0.01 & 9.777 & 0.006 & 59.49 & 0.1 \\
\hline 285.07 & 0.01 & 19.776 & 0.007 & 70.94 & 0.2 \\
\hline 285.07 & 0.01 & 29.795 & 0.008 & 84.65 & 0.2 \\
\hline 290.02 & 0.01 & 0.106 & 0.007 & 37.87 & 0.3 \\
\hline 290.02 & 0.01 & 4.794 & 0.006 & 41.20 & 0.4 \\
\hline 290.02 & 0.01 & 9.790 & 0.005 & 45.07 & 0.2 \\
\hline 290.01 & 0.01 & 19.794 & 0.006 & 53.59 & 0.2 \\
\hline 290.01 & 0.01 & 29.797 & 0.007 & 63.18 & 0.2 \\
\hline 290.01 & 0.01 & 39.813 & 0.007 & 74.00 & 0.3 \\
\hline 290.02 & 0.01 & 49.841 & 0.005 & 86.08 & 0.1 \\
\hline 295.07 & 0.01 & 0.120 & 0.005 & 30.55 & 0.3 \\
\hline 295.08 & 0.01 & 4.802 & 0.006 & 33.17 & 0.3 \\
\hline 295.08 & 0.01 & 9.798 & 0.006 & 36.10 & 0.2 \\
\hline 295.07 & 0.01 & 19.794 & 0.007 & 42.88 & 0.3 \\
\hline 295.07 & 0.01 & 29.795 & 0.010 & 50.09 & 0.2 \\
\hline 295.07 & 0.01 & 39.808 & 0.007 & 58.26 & 0.1 \\
\hline 295.07 & 0.01 & 49.848 & 0.009 & 67.51 & 0.1 \\
\hline 295.07 & 0.01 & 59.886 & 0.007 & 77.67 & 0.1 \\
\hline 295.07 & 0.01 & 69.939 & 0.006 & 89.12 & 0.1 \\
\hline
\end{tabular}


Journal of Research of the National Institute of Standards and Technology

Table 6. Experimental viscosity data of the MIL-PRF-23699-qualified lubricant measured in this project at temperatures from $290.04 \mathrm{~K}$ to $450.13 \mathrm{~K}$ with pressures to $137.40 \mathrm{MPa}$.

\begin{tabular}{|c|c|c|c|c|c|}
\hline $\begin{array}{l}T_{90} \\
(\mathrm{~K})\end{array}$ & $\begin{array}{l}\boldsymbol{s}_{T} \\
(\mathrm{~K})\end{array}$ & $\begin{array}{l}p \\
(\mathrm{MPa})\end{array}$ & $\begin{array}{l}\boldsymbol{s}_{P} \\
(\mathrm{MPa})\end{array}$ & $\begin{array}{l}\eta \\
(\mathrm{mPa} \cdot \mathrm{s})\end{array}$ & $\begin{array}{l}\boldsymbol{s}_{\eta} / \eta \\
(\%)\end{array}$ \\
\hline 315.04 & 0.01 & 0.029 & 0.005 & 23.92 & 0.6 \\
\hline 315.02 & 0.01 & 100.050 & 0.011 & 99.02 & 0.3 \\
\hline 315.02 & 0.01 & 89.995 & 0.010 & 86.10 & 0.3 \\
\hline 315.02 & 0.01 & 79.941 & 0.007 & 75.61 & 0.2 \\
\hline 315.02 & 0.01 & 69.898 & 0.009 & 66.05 & 0.1 \\
\hline 315.01 & 0.01 & 59.865 & 0.011 & 57.49 & 0.3 \\
\hline 315.00 & 0.01 & 49.827 & 0.009 & 49.78 & 0.3 \\
\hline 315.01 & 0.01 & 39.787 & 0.007 & 42.94 & 0.2 \\
\hline 315.01 & 0.01 & 29.759 & 0.009 & 36.72 & 0.3 \\
\hline 315.02 & 0.01 & 19.733 & 0.015 & 31.49 & 0.5 \\
\hline 315.02 & 0.01 & 9.709 & 0.006 & 26.93 & 0.4 \\
\hline 300.01 & 0.01 & 0.051 & 0.006 & 44.20 & 0.2 \\
\hline 300.02 & 0.01 & 9.732 & 0.006 & 52.58 & 0.3 \\
\hline 300.03 & 0.01 & 19.737 & 0.008 & 62.48 & 0.4 \\
\hline 300.04 & 0.01 & 29.740 & 0.007 & 73.69 & 0.3 \\
\hline 300.04 & 0.02 & 39.759 & 0.009 & 86.81 & 0.4 \\
\hline 310.09 & 0.01 & 0.030 & 0.005 & 28.13 & 0.3 \\
\hline 310.08 & 0.01 & 9.717 & 0.007 & 33.00 & 0.5 \\
\hline 310.08 & 0.01 & 19.721 & 0.007 & 38.97 & 0.5 \\
\hline 310.07 & 0.01 & 29.725 & 0.008 & 45.85 & 0.2 \\
\hline 310.07 & 0.01 & 39.748 & 0.008 & 53.83 & 0.4 \\
\hline 310.08 & 0.01 & 49.776 & 0.005 & 63.00 & 0.3 \\
\hline 310.07 & 0.01 & 59.807 & 0.008 & 72.39 & 0.2 \\
\hline 310.08 & 0.01 & 69.868 & 0.008 & 82.28 & 0.2 \\
\hline 310.08 & 0.01 & 79.917 & 0.008 & 94.34 & 0.3 \\
\hline 290.04 & 0.01 & 0.064 & 0.005 & 71.13 & 0.4 \\
\hline 290.05 & 0.01 & 4.748 & 0.006 & 77.76 & 0.3 \\
\hline 290.04 & 0.01 & 9.747 & 0.009 & 85.65 & 0.5 \\
\hline 295.06 & 0.01 & 0.056 & 0.006 & 57.81 & 0.3 \\
\hline 295.07 & 0.01 & 9.736 & 0.007 & 68.88 & 0.4 \\
\hline 295.06 & 0.01 & 19.747 & 0.007 & 82.45 & 0.3 \\
\hline 320.09 & 0.01 & 0.075 & 0.007 & 19.48 & 0.6 \\
\hline 320.07 & 0.01 & 9.753 & 0.006 & 22.74 & 0.4 \\
\hline 320.07 & 0.01 & 19.742 & 0.007 & 26.48 & 0.6 \\
\hline 320.07 & 0.01 & 29.753 & 0.008 & 30.47 & 0.3 \\
\hline 320.07 & 0.01 & 39.776 & 0.006 & 35.22 & 0.2 \\
\hline 320.08 & 0.01 & 49.798 & 0.010 & 40.60 & 0.4 \\
\hline 320.09 & 0.01 & 59.836 & 0.007 & 46.59 & 0.3 \\
\hline 320.09 & 0.01 & 69.885 & 0.008 & 53.59 & 0.3 \\
\hline 320.09 & 0.01 & 79.958 & 0.007 & 61.08 & 0.2 \\
\hline 320.09 & 0.01 & 90.010 & 0.007 & 69.36 & 0.3 \\
\hline 320.09 & 0.01 & 100.067 & 0.008 & 78.43 & 0.2 \\
\hline 320.08 & 0.01 & 110.145 & 0.009 & 88.50 & 0.2 \\
\hline 320.09 & 0.01 & 120.214 & 0.008 & 99.51 & 0.1 \\
\hline 330.06 & 0.01 & 0.088 & 0.006 & 13.92 & 0.5 \\
\hline 330.07 & 0.01 & 9.767 & 0.007 & 16.15 & 0.6 \\
\hline 330.07 & 0.02 & 19.758 & 0.008 & 18.57 & 0.6 \\
\hline 330.08 & 0.01 & 29.760 & 0.008 & 21.36 & 0.4 \\
\hline 330.09 & 0.01 & 39.782 & 0.007 & 24.71 & 0.4 \\
\hline 330.08 & 0.01 & 49.811 & 0.009 & 28.05 & 0.5 \\
\hline 330.09 & 0.01 & 59.853 & 0.006 & 31.75 & 0.6 \\
\hline 330.09 & 0.01 & 69.897 & 0.007 & 35.62 & 0.5 \\
\hline 330.10 & 0.01 & 79.942 & 0.008 & 40.06 & 0.7 \\
\hline 330.10 & 0.02 & 89.996 & 0.006 & 45.79 & 0.5 \\
\hline 330.10 & 0.01 & 100.062 & 0.007 & 51.31 & 0.6 \\
\hline 330.11 & 0.01 & 110.129 & 0.006 & 58.02 & 0.2 \\
\hline
\end{tabular}


Journal of Research of the National Institute of Standards and Technology

\begin{tabular}{|c|c|c|c|c|c|}
\hline $\begin{array}{l}T_{90} \\
(\mathrm{~K})\end{array}$ & $\begin{array}{l}\boldsymbol{s}_{T} \\
(\mathrm{~K})\end{array}$ & $\begin{array}{l}p \\
(\mathrm{MPa})\end{array}$ & $\begin{array}{l}s_{P} \\
(\mathrm{MPa})\end{array}$ & $\begin{array}{l}\eta \\
(\mathrm{mPa} \cdot \mathrm{s})\end{array}$ & $\begin{array}{l}\boldsymbol{s}_{\eta} / \eta \\
(\%)\end{array}$ \\
\hline 330.10 & 0.01 & 120.210 & 0.009 & 64.82 & 0.3 \\
\hline 330.11 & 0.01 & 130.265 & 0.010 & 72.13 & 0.2 \\
\hline 330.11 & 0.01 & 137.310 & 0.010 & 78.39 & 0.2 \\
\hline 339.96 & 0.01 & 0.087 & 0.005 & 9.846 & 0.6 \\
\hline 339.97 & 0.01 & 9.758 & 0.007 & 11.58 & 0.8 \\
\hline 339.98 & 0.01 & 19.763 & 0.007 & 13.41 & 0.9 \\
\hline 339.98 & 0.01 & 29.763 & 0.007 & 15.34 & 0.2 \\
\hline 339.98 & 0.02 & 39.775 & 0.008 & 17.38 & 0.6 \\
\hline 339.96 & 0.01 & 49.808 & 0.007 & 19.68 & 0.5 \\
\hline 339.96 & 0.02 & 59.843 & 0.006 & 21.94 & 0.5 \\
\hline 339.95 & 0.01 & 69.896 & 0.007 & 25.03 & 0.7 \\
\hline 339.96 & 0.02 & 79.938 & 0.008 & 28.20 & 0.5 \\
\hline 339.96 & 0.01 & 89.993 & 0.008 & 31.72 & 0.3 \\
\hline 339.95 & 0.01 & 100.061 & 0.007 & 34.76 & 0.6 \\
\hline 339.89 & 0.01 & 110.161 & 0.007 & 39.28 & 0.4 \\
\hline 339.86 & 0.02 & 120.259 & 0.011 & 43.41 & 0.6 \\
\hline 339.83 & 0.01 & 130.343 & 0.008 & 49.68 & 0.2 \\
\hline 339.83 & 0.01 & 137.402 & 0.011 & 52.93 & 0.6 \\
\hline 349.99 & 0.01 & 0.076 & 0.007 & 7.893 & 1.1 \\
\hline 350.01 & 0.01 & 9.755 & 0.008 & 8.969 & 1.0 \\
\hline 350.02 & 0.01 & 19.762 & 0.008 & 10.11 & 0.8 \\
\hline 350.03 & 0.01 & 29.770 & 0.006 & 11.43 & 1.1 \\
\hline 350.03 & 0.01 & 39.799 & 0.008 & 12.86 & 0.5 \\
\hline 350.04 & 0.01 & 49.816 & 0.007 & 14.51 & 1.1 \\
\hline 350.05 & 0.02 & $\mathbf{5 9 . 8 5 7}$ & 0.008 & 16.19 & 0.2 \\
\hline 350.05 & 0.01 & 69.913 & 0.009 & 18.05 & 0.6 \\
\hline 350.05 & 0.01 & 79.959 & 0.010 & 20.12 & 0.3 \\
\hline 350.06 & 0.01 & 90.003 & 0.006 & 22.46 & 0.1 \\
\hline 350.06 & 0.01 & 100.071 & 0.010 & 25.01 & 0.2 \\
\hline 350.07 & 0.02 & 110.144 & 0.009 & 27.91 & 0.2 \\
\hline 350.07 & 0.01 & 120.213 & 0.007 & 31.09 & 0.5 \\
\hline 350.06 & 0.01 & 130.275 & 0.010 & 34.13 & 0.4 \\
\hline 350.06 & 0.01 & 137.337 & 0.011 & 37.55 & 0.1 \\
\hline 380.10 & 0.01 & 0.072 & 0.005 & 3.849 & 0.1 \\
\hline 380.10 & 0.01 & 9.752 & 0.006 & 4.404 & 0.4 \\
\hline 380.10 & 0.01 & 19.745 & 0.009 & 4.970 & 0.3 \\
\hline 380.11 & 0.02 & 29.752 & 0.006 & 5.585 & 0.4 \\
\hline 380.11 & 0.01 & 39.770 & 0.007 & 6.233 & 0.2 \\
\hline 380.11 & 0.02 & 49.804 & 0.007 & 7.043 & 0.2 \\
\hline 380.12 & 0.01 & 59.853 & 0.008 & 7.822 & 0.3 \\
\hline 380.13 & 0.01 & 69.902 & 0.006 & 8.673 & 0.3 \\
\hline 380.13 & 0.01 & 79.954 & 0.009 & 9.549 & 0.2 \\
\hline 380.14 & 0.02 & 90.003 & 0.007 & 10.45 & 0.2 \\
\hline 380.14 & 0.01 & 100.064 & 0.007 & 11.49 & 0.3 \\
\hline 380.15 & 0.02 & 110.128 & 0.008 & 12.59 & 0.2 \\
\hline 380.16 & 0.02 & 120.187 & 0.008 & 13.68 & 0.2 \\
\hline 380.17 & 0.02 & 130.255 & 0.011 & 14.84 & 0.1 \\
\hline 380.18 & 0.01 & 137.317 & 0.007 & 15.72 & 0.1 \\
\hline 390.03 & 0.01 & 0.204 & 0.004 & 3.223 & 0.2 \\
\hline 390.04 & 0.01 & 9.747 & 0.008 & 3.662 & 0.3 \\
\hline 390.05 & 0.02 & 19.752 & 0.009 & 4.145 & 0.3 \\
\hline 390.05 & 0.01 & 29.751 & 0.007 & 4.663 & 0.2 \\
\hline 390.07 & 0.01 & 39.760 & 0.007 & 5.171 & 0.3 \\
\hline 390.08 & 0.02 & 49.796 & 0.010 & 5.739 & 0.3 \\
\hline 390.09 & 0.02 & $\mathbf{5 9 . 8 3 7}$ & 0.010 & 6.374 & 0.4 \\
\hline 390.09 & 0.02 & 69.870 & 0.008 & 6.954 & 0.2 \\
\hline 390.10 & 0.02 & 79.923 & 0.007 & 7.635 & 0.3 \\
\hline 390.11 & 0.01 & 89.978 & 0.008 & 8.325 & 0.2 \\
\hline 390.11 & 0.01 & 100.046 & 0.007 & 9.092 & 0.3 \\
\hline
\end{tabular}


Journal of Research of the National Institute of Standards and Technology

\begin{tabular}{|c|c|c|c|c|c|}
\hline $\begin{array}{l}T_{90} \\
(\mathrm{~K})\end{array}$ & $\begin{array}{l}\boldsymbol{s}_{T} \\
(\mathrm{~K})\end{array}$ & $\begin{array}{l}p \\
(\mathrm{MPa})\end{array}$ & $\begin{array}{l}\boldsymbol{s}_{P} \\
(\mathrm{MPa})\end{array}$ & $\begin{array}{l}\eta \\
(\mathrm{mPa} \cdot \mathrm{s})\end{array}$ & $\begin{array}{l}s_{\eta} / \eta \\
(\%)\end{array}$ \\
\hline 390.12 & 0.01 & 110.109 & 0.018 & 9.966 & 0.4 \\
\hline 390.13 & 0.01 & 120.174 & 0.009 & 10.89 & 0.3 \\
\hline 390.13 & 0.01 & 130.250 & 0.008 & 11.81 & 0.2 \\
\hline 390.14 & 0.02 & 137.313 & 0.010 & 12.51 & 0.1 \\
\hline 400.00 & 0.02 & 0.088 & 0.005 & 2.709 & 0.6 \\
\hline 400.01 & 0.02 & 9.758 & 0.006 & 3.079 & 0.6 \\
\hline 400.02 & 0.01 & 19.756 & 0.006 & 3.479 & 0.5 \\
\hline 400.02 & 0.02 & 29.765 & 0.009 & 3.904 & 0.4 \\
\hline 400.03 & 0.02 & 39.789 & 0.008 & 4.355 & 0.3 \\
\hline 400.04 & 0.02 & 49.804 & 0.007 & 4.836 & 0.3 \\
\hline 400.05 & 0.02 & 59.833 & 0.008 & 5.360 & 0.4 \\
\hline 400.05 & 0.02 & 69.890 & 0.010 & 5.875 & 0.2 \\
\hline 400.06 & 0.02 & 79.936 & 0.009 & 6.448 & 0.3 \\
\hline 400.07 & 0.01 & 89.981 & 0.009 & 7.034 & 0.3 \\
\hline 400.08 & 0.02 & 100.051 & 0.008 & 7.667 & 0.2 \\
\hline 400.08 & 0.01 & 110.114 & 0.008 & 8.331 & 0.1 \\
\hline 400.10 & 0.01 & 120.183 & 0.011 & 9.043 & 0.2 \\
\hline 400.10 & 0.01 & 130.249 & 0.009 & 9.846 & 0.2 \\
\hline 400.11 & 0.01 & 137.281 & 0.007 & 10.40 & 0.2 \\
\hline 409.88 & 0.01 & 1.271 & 0.033 & 2.367 & 0.3 \\
\hline 409.90 & 0.02 & 9.753 & 0.007 & 2.643 & 0.1 \\
\hline 409.92 & 0.02 & 19.744 & 0.012 & 2.990 & 0.1 \\
\hline 409.93 & 0.01 & 29.748 & 0.006 & 3.354 & 0.1 \\
\hline 409.94 & 0.01 & 39.769 & 0.010 & 3.743 & 0.1 \\
\hline 409.95 & 0.01 & 49.785 & 0.006 & 4.154 & 0.1 \\
\hline 409.96 & 0.02 & 59.826 & 0.007 & 4.591 & 0.1 \\
\hline 409.97 & 0.01 & 69.861 & 0.005 & 5.042 & 0.1 \\
\hline 409.98 & 0.02 & 79.900 & 0.009 & 5.518 & 0.1 \\
\hline 409.98 & 0.01 & 89.947 & 0.008 & 6.025 & 0.1 \\
\hline 409.99 & 0.01 & 100.016 & 0.009 & 6.548 & 0.2 \\
\hline 409.99 & 0.01 & 110.068 & 0.008 & 7.106 & 0.1 \\
\hline 409.99 & 0.02 & 120.141 & 0.007 & 7.686 & 0.1 \\
\hline 410.00 & 0.02 & 130.205 & 0.008 & 8.296 & 0.1 \\
\hline 410.01 & 0.01 & 137.266 & 0.009 & 8.746 & 0.1 \\
\hline 420.01 & 0.01 & 1.215 & 0.004 & 2.067 & 0.3 \\
\hline 420.02 & 0.01 & 9.730 & 0.005 & 2.302 & 0.1 \\
\hline 420.01 & 0.01 & 19.732 & 0.007 & 2.588 & 0.2 \\
\hline 420.02 & 0.02 & 29.736 & 0.007 & 2.887 & 0.1 \\
\hline 420.03 & 0.02 & 39.749 & 0.008 & 3.192 & 0.2 \\
\hline 420.03 & 0.01 & 49.775 & 0.008 & 3.512 & 0.2 \\
\hline 420.04 & 0.02 & 59.817 & 0.007 & 3.847 & 0.1 \\
\hline 420.05 & 0.02 & 69.864 & 0.011 & 4.216 & 0.2 \\
\hline 420.05 & 0.02 & 79.904 & 0.006 & 4.564 & 0.1 \\
\hline 420.07 & 0.01 & 89.945 & 0.007 & 4.926 & 0.1 \\
\hline 420.07 & 0.02 & 100.016 & 0.006 & 5.321 & 0.1 \\
\hline 420.08 & 0.02 & 110.074 & 0.008 & 5.719 & 0.2 \\
\hline 420.08 & 0.02 & 120.137 & 0.009 & 6.136 & 0.1 \\
\hline 420.09 & 0.02 & 130.199 & 0.006 & 6.583 & 0.2 \\
\hline 420.09 & 0.02 & 137.243 & 0.008 & 6.897 & 0.2 \\
\hline 429.94 & 0.01 & 9.742 & 0.006 & 2.008 & 0.4 \\
\hline 429.93 & 0.02 & 19.738 & 0.005 & 2.253 & 0.3 \\
\hline 429.93 & 0.02 & 29.749 & 0.008 & 2.502 & 0.1 \\
\hline 429.93 & 0.02 & 39.765 & 0.008 & 2.763 & 0.3 \\
\hline 429.94 & 0.01 & 49.798 & 0.010 & 3.027 & 0.2 \\
\hline 429.95 & 0.02 & 59.824 & 0.008 & 3.309 & 0.2 \\
\hline 429.96 & 0.01 & 69.862 & 0.007 & 3.665 & 0.3 \\
\hline 429.96 & 0.02 & 79.913 & 0.009 & 3.917 & 1.4 \\
\hline 429.96 & 0.01 & 89.956 & 0.006 & 4.313 & 1.0 \\
\hline 429.97 & 0.02 & 100.021 & 0.008 & 4.691 & 0.6 \\
\hline
\end{tabular}


Journal of Research of the National Institute of Standards and Technology

\begin{tabular}{|c|c|c|c|c|c|}
\hline $\begin{array}{l}T_{90} \\
(\mathrm{~K})\end{array}$ & $\begin{array}{l}\boldsymbol{s}_{T} \\
(\mathrm{~K})\end{array}$ & $\begin{array}{l}p \\
(\mathrm{MPa})\end{array}$ & $\begin{array}{l}\boldsymbol{s}_{P} \\
(\mathrm{MPa})\end{array}$ & $\begin{array}{l}\eta \\
(\mathrm{mPa} \cdot \mathrm{s})\end{array}$ & $\begin{array}{l}\boldsymbol{s}_{\eta} / \eta \\
(\%)\end{array}$ \\
\hline 429.98 & 0.02 & 110.086 & 0.008 & 5.041 & 0.1 \\
\hline 429.99 & 0.02 & 120.141 & 0.010 & 5.446 & 0.2 \\
\hline 429.99 & 0.02 & 130.208 & 0.008 & 5.868 & 0.3 \\
\hline 429.99 & 0.02 & 137.260 & 0.011 & 6.173 & 0.3 \\
\hline 439.97 & 0.02 & 19.717 & 0.006 & 2.071 & 0.4 \\
\hline 439.97 & 0.02 & 29.716 & 0.006 & 2.293 & 0.3 \\
\hline 439.96 & 0.01 & 39.731 & 0.008 & 2.523 & 0.6 \\
\hline 439.96 & 0.01 & 49.763 & 0.007 & 2.749 & 0.4 \\
\hline 439.97 & 0.01 & 59.814 & 0.007 & 3.027 & 0.5 \\
\hline 439.97 & 0.02 & 69.867 & 0.009 & 3.312 & 0.1 \\
\hline 439.97 & 0.01 & 79.917 & 0.007 & 3.619 & 0.3 \\
\hline 439.98 & 0.02 & 89.958 & 0.006 & 3.932 & 0.2 \\
\hline 439.98 & 0.02 & 100.025 & 0.008 & 4.262 & 0.2 \\
\hline 439.99 & 0.01 & 110.087 & 0.007 & 4.601 & 0.2 \\
\hline 440.00 & 0.01 & 120.142 & 0.010 & 4.959 & 0.1 \\
\hline 440.00 & 0.01 & 130.198 & 0.007 & 5.336 & 0.2 \\
\hline 440.00 & 0.01 & 137.254 & 0.011 & 5.610 & 0.1 \\
\hline 450.11 & 0.02 & 29.738 & 0.009 & 2.070 & 0.8 \\
\hline 450.11 & 0.02 & 39.747 & 0.007 & 2.283 & 0.4 \\
\hline 450.11 & 0.02 & 49.776 & 0.005 & 2.501 & 0.2 \\
\hline 450.11 & 0.01 & 59.820 & 0.007 & 2.736 & 0.3 \\
\hline 450.10 & 0.02 & 69.855 & 0.011 & 2.993 & 0.2 \\
\hline 450.11 & 0.02 & 79.907 & 0.005 & 3.257 & 0.2 \\
\hline 450.11 & 0.02 & 89.955 & 0.009 & 3.536 & 0.2 \\
\hline 450.11 & 0.01 & 100.022 & 0.010 & 3.822 & 0.1 \\
\hline 450.11 & 0.01 & 110.091 & 0.007 & 4.128 & 0.1 \\
\hline 450.11 & 0.02 & 120.147 & 0.007 & 4.435 & 0.2 \\
\hline 450.13 & 0.02 & 130.209 & 0.010 & 4.763 & 0.1 \\
\hline 450.13 & 0.01 & 137.252 & 0.010 & 5.001 & 0.2 \\
\hline
\end{tabular}

Table 7. Experimental viscosity data for POE-5 measured in this laboratory by Laesecke and Morrison in 2006 at temperatures from $253.15 \mathrm{~K}$ to $373.15 \mathrm{~K}$ and at an ambient pressure of $0.08235 \mathrm{MPa}$ in Boulder, Colorado, USA. The estimated uncertainty of the temperature measurement is $0.02 \mathrm{~K}$, that of the pressure measurement is $0.25 \mathrm{hPa}$, and that of the viscosity measurement is $1 \%$ at viscosities above $4 \mathrm{mPa} \cdot \mathrm{s}$ and $2 \%$ below (see text).

\begin{tabular}{lll}
\hline $\begin{array}{l}T_{90} \\
\mathrm{~K}\end{array}$ & $\begin{array}{l}p \\
\mathrm{MPa}\end{array}$ & $\begin{array}{l}\eta \\
\mathrm{mPa} \cdot \mathrm{s}\end{array}$ \\
\hline 373.15 & 0.08235 & $\mathbf{3 . 4 7 1 1}$ \\
363.15 & 0.08235 & $\mathbf{4 . 2 0 7 1}$ \\
353.15 & 0.08235 & $\mathbf{5 . 1 9 4 2}$ \\
343.15 & 0.08235 & $\mathbf{6 . 5 5 1 9}$ \\
333.15 & 0.08235 & $\mathbf{8 . 4 7 8 5}$ \\
323.15 & 0.08235 & $\mathbf{1 1 . 3 0 7}$ \\
313.15 & 0.08235 & $\mathbf{1 5 . 6 3 2}$ \\
303.15 & 0.08235 & $\mathbf{2 2 . 5 6 6}$ \\
293.15 & 0.08235 & $\mathbf{3 4 . 3 2 3}$ \\
283.15 & 0.08235 & $\mathbf{5 5 . 6 1 6}$ \\
273.15 & 0.08235 & $\mathbf{9 7 . 3 6 4}$ \\
263.15 & 0.08235 & $\mathbf{1 8 7 . 6 1}$ \\
253.15 & 0.08235 & $\mathbf{4 0 5 . 3 0}$ \\
\hline
\end{tabular}




\section{Acknowledgments}

The authors thank James McDonnell and Dawn Schmidt at the Naval Air Systems Command (NAVAIR) for funding this work and supplying the MIL-PRF-23699-qualified lubricant and the base oils. Thanks are due to Dr. Tara Lovestead the National Institute of Standards and Technology (NIST) for the squalane analysis and to Dr. Ala Bazyleva of the NIST Thermodynamics Research Center for valuable comments about squalane's stereoisomerism and for assuring the correctness of the data reported in Tables 3 to 6. Professor Sid Nagel (University of Chicago) kindly provided the viscosity data of the paper by Deegan et al. [68]. Clemens Junker acknowledges the Wolfram-Funk-Award 2015 and appreciates the opportunity to join the Applied Chemicals and Materials Division at the National Institute of Standards and Technology (NIST) in Boulder, Colorado, USA, as a Guest Researcher during July 2017. Eric Morrison, then a graduate student at the Colorado School of Mines, collaborated in the measurements of POE-5 in 2006 with support from the NIST Professional Research Experience Program (PREP). Dr. Thomas J. Bruno of NIST analyzed the POE-5 sample in 2007.

\section{References}

[1] Stehr W, Dobler K (2011) Tribologie ist überall-Von der Bratwurst bis zum Lagerschaden (Dr. Tillwich GmbH), 4th Ed.

[2] Bair B (2007) High-pressure rheology for quantitative elastohydrodynamics (Elsevier, Amsterdam), 1st Ed.

[3] Rudnick LR (2006) Synthetics, mineral oils, and bio-based lubricants: Chemistry and technology. Chemical Industries, ed Heinemann H (CRC Press, Boca Raton, FL).

[4] Davison CSC (1957) Wear prevention in early history. Wear 1(2):155-159. https://doi.org/10.1016/0043-1648(57)90007-8

[5] Bohner GE, Krimmel JA, Schmidt-Collérus JJ, Stacey RD (1962) Properties of polyester fluids with desirable synthetic lubricant characteristics. Journal of Chemical and Engineering Data 7(4):547-553. https://doi.org/10.1021/je60015a035

[6] Geller VZ, Paulaitis ME, Bivens DB, Yokozeki A (1996) Viscosity of HFC-32 and HFC-32/lubricant mixtures. International Journal of Thermophysics 17(1):75-83. https://doi.org/10.1007/BF01448211

[7] Wahlström A, Vamling L (1999) Viscosity for mixtures of HFCs and pentaerythritol esters. 20th International Congress of Refrigeration, (Sydney, Australia), Vol. II, paper no. 348.

[8] Pensado AS, Comuñas MJP, Lugo L, Fernàndez J (2006) High-pressure characterization of dynamic viscosity and derived properties for squalane and two pentaerythritol ester lubricants: Pentaerythritol tetra-2-ethylhexanoate and pentaerythritol tetranonanoate. Industrial and Engineering Chemistry Research 45(7):2394-2404. https://doi.org/10.1021/ie051275w

[9] Pensado AS, Comuñas MJP, Fernández J (2006) Relationship between viscosity coefficients and volumetric properties: measurements and modeling for pentaerythritol esters. Industrial and Engineering Chemistry Research 45(26):9171-9183. https://doi.org/10.1021/ie0606035

[10] Paredes X, Pensado AS, Comuñas MJP, Fernández J (2010) Experimental dynamic viscosities of dipentaerythritol ester lubricants at high pressure. Journal of Chemical and Engineering Data 55(9):3216-3223. https://doi.org/10.1021/je100057b

[11] Urness KN, Gough RV, Widegren JA, Bruno TJ (2016) Thermal decomposition kinetics of polyol ester lubricants. Energy Fuels 30(12):10161-10170. https://doi.org/10.1021/acs.energyfuels.6b01863

[12] Outcalt SL (2018) Compressed-liquid density measurements of four polyolester-based lubricants. Energy Fuels 32 (3):37753782. https://doi.org/10.1021/acs.energyfuels.8b00050

[13] Hehre WJ (2003) A guide to molecular mechanics and quantum chemical calculations (Wavefunction, Inc., Irvine, CA).

[14] Connolly ML (1996) Molecular Surfaces: A Review. Available at https://web.archive.org/web/20130315235132/http://www.netsci.org/Science/Compchem/feature14.html

[15] Lemmon EW, Huber ML, McLinden MO (2018) NIST Standard Reference Database 23: Reference Fluid Thermodynamic and Transport Properties (REFPROP), Version 10.0. (National Institute of Standards and Technology, Standard Reference Data Program, Gaithersburg, MD). Available at https://www.nist.gov/publications/nist-standard-reference-database-23-referencefluid-thermodynamic-and-transport

[16] Bair S, Yamaguchi T (2017) The equation of state and the temperature, pressure, and shear dependence of viscosity for a highly viscous reference liquid, dipentaerythritol hexaisononanoate. Journal of Tribology 139(1):011801. https://doi.org/10.1115/1.4033050

[17] Outcalt SL (2018) Calibration fluids and calibration equations: How choices may affect the results of density measurements made with U-tube densimeters. Journal of Research of the National Institute of Standards and Technology 123:123017. https://doi.org/10.6028/jres.123.017

[18] Laesecke A, Bair S (2011) High pressure viscosity measurements of 1,1,1,2-tetrafluoroethane. International Journal of Thermophysics 32(5):925-941. https://doi.org/10.1021/je9501954

[19] Bair S, Laesecke A (2017) Viscosity measurements of R32 and R410A to $350 \mathrm{MPa}$. International Journal of Refrigeration 83:157-167. https://doi.org/10.1016/j.ijrefrig.2017.07.016

[20] Laesecke A, Meier K, Hafer RF (2018) Wide-ranging absolute viscosity measurements of sub- and supercritical 1,1,1trifluoroethane (R143a). Journal of Molecular Liquids 251:128-141. https://doi.org/10.1016/j.molliq.2017.12.010 
[21] Laesecke A, Cousins DS (2013) Wide-ranging viscosity measurements of rocket propellant RP-2. AIAA Journal of Propulsion and Power 29(6):1323-1327. https://doi.org/10.2514/1.B34941

[22] Isdale JD (1991) Falling-cylinder viscometers. Measurement of the Transport Properties of Fluids, eds Wakeham WA, Nagashima A, Sengers JV (Blackwell Scientific Publications, Oxford, UK), Vol. 3, 1st Ed., pp 105-110.

[23] Zhao H, Memon A, Gao J, Taylor SD, Sieben D, Ratulowski J, Alboudwarej H, Pappas J, Creek J (2016) Heavy oil viscosity measurements: Best practices and guidelines. Energy Fuels 30(7):5277-5290. https://doi.org/10.1021/acs.energyfuels.6b00300

[24] ASTM International (2017) ASTM D7483-13a Standard Test Method for Determination of Dynamic Viscosity and Derived Kinematic Viscosity of Liquids by Oscillating Piston Viscometer (ASTM International, West Conshohocken, PA). https://doi.org/10.1520/D7483-13AR17

[25] Takigawa K, Sandler SI, Yokozeki A (2002) Solubility and viscosity of refrigerant/lubricant mixtures: Hydrofluorocarbon/alkylbenzene systems. International Journal of Refrigeration 25(8):1014-1024. https://doi.org/10.1016/S0140-7007(02)00025-7

[26] Jakeways CV, Goodwin ARH (2005) The viscosity and density of 1-propene,1,1,2,3,3,3-hexafluoro-oxidized,polymd and polydimethylsiloxane at temperatures from ( 313 to 373$) \mathrm{K}$ and a pressure of $0.1 \mathrm{MPa}$. Journal of Chemical Thermodynamics 37(10):1093-1097. https://doi.org/10.1016/j.jct.2005.01.012

[27] Lundstrum R, Goodwin ARH, Hsu K, Frels M, Caudwell DR, Trusler JPM, Marsh KN (2005) Measurement of the viscosity and density of two reference fluids, with nominal viscosities at $\mathrm{T}=298 \mathrm{~K}$ and $\mathrm{P}=0.1 \mathrm{MPa}$ of (16 and 29) $\mathrm{mPa} \cdot \mathrm{s}$, at temperatures between (298 and 393) K and pressures below 55 MPa. Journal of Chemical and Engineering Data 50(4):1377-1388. https://doi.org/10.1021/je0500779

[28] Ahosseini A, Scurto AM (2008) Viscosity of imidazolium-based ionic liquids at elevated pressures: Cation and anion effects. International Journal of Thermophysics 29(4):1222-1243. https://doi.org/10.1007/s10765-008-0497-7

[29] Libotean S, Martín A, Salavera D, Valles M, Esteve X, Coronas A (2008) Densities, viscosities, and heat capacities of ammonia + lithium nitrate and ammonia + lithium nitrate + water solutions between (293.15 and 353.15) K. Journal of Chemical and Engineering Data 53(10):2383-2388. https://doi.org/10.1021/je8003035

[30] Marcelino Neto MA,. Barbosa Jr JR (2008) Solubility, density and viscosity of a mixture of R-600a and polyol ester oil. International Journal of Refrigeration 31(1):34-44. https://doi.org/10.1016/j.ijrefrig.2007.08.004

[31] Ahosseini A, Ortega E, Sensenich B, Scurto AM (2009) Viscosity of n-alkyl-3-methyl-imidazolium bis(trifluoromethylsulfonyl) amide ionic liquids saturated with compressed $\mathrm{CO}_{2}$. Fluid Phase Equilibria 286(1):62-68. https://doi.org/10.1016/j.fluid.2009.07.013

[32] Aparicio S, Alcalde R (2009) Insights into the ethyl lactate + water mixed solvent. Journal of Physical Chemistry B 113(43):14257-14269. https://doi.org/10.1021/jp904668e

[33] Aparicio S, Alcalde R (2009) The green solvent ethyl lactate: An experimental and theoretical characterization. Green Chemistry 11(1):65-78. https://doi.org/10.1039/B811909K

[34] Aparicio S, Alcalde R, Garciá B, Leal JM (2009) High-pressure study of the methylsulfate and tosylate imidazolium ionic liquids. Journal of Physical Chemistry B 113(16):5593-5606. https://doi.org/10.1021/jp9003467

[35] Rajagopal K, Andrade LLPR, Paredes MLL (2009) High-pressure viscosity measurements for the binary system cyclohexane + $n$-hexadecane in the temperature range of (318.15 to 413.15) K. Journal of Chemical and Engineering Data 54(10):2967-2970. https://doi.org/10.1021/je9000262

[36] Seeton CJ (2009) Carbon Dioxide-Lubricant Two-Phase Flow Patterns in Small Horizontal Wetted Wall Channels: The Effects of Refrigerant/Lubricant Thermophysical Properties. Ph. D. Thesis.(University of Illinois at Urbana-Champaign, Champaign, IL). Available at http://hdl.handle.net/2142/83940

[37] Atilhan M, Aparicio S, Alcalde R, Iglesias-Silva GA, El-Halwagi M, Hall KR (2010) Viscosity measurements and data correlation for two synthetic natural gas mixtures. Journal of Chemical and Engineering Data 55(7):2498-2504. https://doi.org/10.1021/je900872m

[38] Atilhan M, Aparicio S, Iglesias-Silva GA, El-Halwagi M, Hall KR (2010) On the viscosity of natural gases from Qatari North Field Reservoir. Journal of Chemical and Engineering Data 55(11):5117-5123. https://doi.org/10.1021/je100673w

[39] Duncan AM, Ahosseini A, McHenry R, Depcik CD, Stagg-Williams SM, Scurto AM (2010) High-pressure viscosity of biodiesel from soybean, canola, and coconut oils. Energy Fuels 24(10):5708-5716. https://doi.org/10.1021/ef100382f

[40] Marcelino Neto MA, Barbosa Jr JR (2010) Solubility, density and viscosity of mixtures of isobutane (R-600a) and a linear alkylbenzene lubricant oil. Fluid Phase Equilibria 292(1-2):7-12. https://doi.org/10.1016/j.fluid.2009.12.029

[41] Bandrés I, Alcalde R, Lafuente C, Atilhan M, Aparicio S (2011) On the viscosity of pyridinium based ionic liquids: An experimental and computational study. Journal of Physical Chemistry B 115(43):12499-12513. https://doi.org/10.1021/jp203433u

[42] Cain N, Roberts G, Kiserow D, Carbonell R (2011) Modeling the thermodynamic and transport properties of decahydronaphthalene/propane mixtures: Phase equilibria, density, and viscosity. Fluid Phase Equilibria 305(1):25-33. https://doi.org/10.1016/j.fluid.2011.02.009

[43] Chaudhari SK, Salavera D, Coronas A (2011) Densities, viscosities, heat capacities, and vapor-liquid equilibria of ammonia + sodium thiocyanate solutions at several temperatures. Journal of Chemical and Engineering Data 56(6):2861-2869. https://doi.org/10.1021/je200038n

[44] Giri BR, Blais P, Marriott RA (2011) Viscosity and density measurements for sour gas fluids at high temperatures and pressures. Carbon Dioxide Sequestration and Related Technologies, eds Wu Y, Carroll JJ, Du Z (John Wiley \& Sons, Salem, MA), pp 2340.

[45] Kariznovi M, Nourozieh H, Abedi J (2011) Measurement and modeling of liquid saturated properties (solubility, density, and viscosity) of (ethane + n-tetradecane) binary systems. Journal of Chemical and Engineering Data 56(9):3669-3672. https://doi.org/10.1021/je200575c

[46] Duncan AM, Pavlicek N, Depcik CD, Scurto AM, Stagg-Williams SM (2012) High-pressure viscosity of soybean-oil-based biodiesel blends with ultra-low-sulfur diesel fuel. Energy Fuels 26(11):7023-7036. https://doi.org/10.1021/ef3012068 


\section{Journal of Research of the National Institute of Standards and Technology}

[47] Kariznovi M, Nourozieh H, Abedi J (2012) Measurement and equation of state prediction of vapor-liquid equilibrium and physical properties for the system methane + n-octadecane. Fluid Phase Equilibria 314:102-106. https://doi.org/10.1016/j.fluid.2011.10.018

[48] Kariznovi M, Nourozieh H, Abedi J (2012) Vapor-liquid phase equilibria and physical properties measurements for ternary systems (methane + decane + hexadecane). Journal of Chemical and Engineering Data 57(9):2535-2542. https://doi.org/10.1021/je300482b

[49] Guan JG, Kariznovi M, Nourozieh H, Abedi J (2013) Density and viscosity for mixtures of Athabasca bitumen and aromatic solvents. Journal of Chemical and Engineering Data 58(3):611-624. https://doi.org/10.1021/je3010722

[50] Kariznovi M, Nourozieh H, Abedi J (2013) Experimental measurements and predictions of density, viscosity, and carbon dioxide solubility in methanol, ethanol, and 1-propanol. Journal of Chemical Thermodynamics 57:408-415. https://doi.org/10.1016/j.jct.2012.10.002

[51] Kariznovi M, Nourozieh H, Guan JG, Abedi J (2013) Measurement and modeling of density and viscosity for mixtures of Athabasca bitumen and heavy n-alkane. Fuel 112:83-95. https://doi.org/10.1016/j.fuel.2013.04.071

[52] Nourozieh H, Bayestehparvin B, Kariznovi M, Abedi J (2013) Equilibrium properties of (carbon dioxide $+n$-decane $+n$ octadecane) systems: Experiments and thermodynamic modeling. Journal of Chemical and Engineering Data 58(5):1236-1243. https://doi.org/10.1021/je4000394

[53] Nourozieh H, Kariznovi M, Abedi J(2013) Measurement and correlation of saturated liquid properties and gas solubility for decane, tetradecane and their binary mixtures saturated with carbon dioxide. Fluid Phase Equilibria 337:246-254. https://doi.org/10.1016/j.fluid.2012.09.037

[54] Nourozieh H, Kariznovi M, Guan JG, Abedi J (2013) Measurement of thermophysical properties and modeling for pseudobinary mixtures of $n$-decane and Athabasca bitumen. Fluid Phase Equilibria 347:62-75. https://doi.org/10.1016/j.fluid.2013.03.010

[55] Petrowsky M, Fleshman AM, Frech R (2013) Application of the compensated Arrhenius formalism to fluidity data of polar organic liquids. Journal of Physical Chemistry B 117(10):2971-2978. https://doi.org/10.1021/jp312034e

[56] Ghanavati M, Hassanzadeh H, Abedi J (2014) Application of Taylor dispersion technique to measure mutual diffusion coefficient in hexane + bitumen system. AIChE Journal 60(7):2670-2682. https://doi.org/10.1002/aic.14438

[57] Abdelmassih G, Esteve X (2015) Densities and viscosities of aqueous alkaline nitrate and nitrite solutions used in absorption heat pumps. Journal of Chemical and Engineering Data 60(8):2454-2460. https://doi.org/10.1021/acs.jced.5b00103

[58] Dang Y, Kamiaka T, Dang C, Hihara E (2015) Liquid viscosity of low-GWP refrigerant mixtures (R32 + R1234yf) and (R125 + R1234yf). Journal of Chemical Thermodynamics 89:183-188. https://doi.org/10.1016/j.jct.2015.05.009

[59] Feja S, Hanzelmann C (2015) Experimental studies of thermodynamic properties of R744-oil-mixtures up to $140{ }^{\circ} \mathrm{C}$ and $150 \mathrm{bar}$. International Journal of Refrigeration 60:135-141. https://doi.org/10.1016/j.ijrefrig.2015.07.018

[60] Nourozieh H, Kariznovi M, Abedi J (2015) Modeling and measurement of thermo-physical properties for Athabasca bitumen and n-heptane mixtures. Fuel 157:73-81. https://doi.org/10.1016/j.fuel.2015.04.032

[61] Ahosseini A, Ren W, Weatherley LR, Scurto AM (2017) Viscosity and self-diffusivity of ionic liquids with compressed hydrofluorocarbons: 1-Hexyl-3-methyl-imidazolium bis(trifluoromethylsulfonyl)amide and 1,1,1,2-tetrafluoroethane. Fluid Phase Equilibria 437:34-42. https://doi.org/10.1016/j.fluid.2016.11.022

[62] Mylona SK, Assael MJ, Comuñas MJP, Paredes X, Gaciño FM, Fernández J, Bazile JP, Boned C, Daridon JL, Galliero G, Pauly J, Harris KR (2014) Reference correlations for the density and viscosity of squalane from 273 to $473 \mathrm{~K}$ at pressures to $200 \mathrm{MPa}$. Journal of Physical and Chemical Reference Data 43(1):013104. https://doi.org/10.1063/1.4863984

[63] Schmidt KAG, Pagnutti D, Curran MD, Singh A, Trusler JPM, Maitland GC, McBride-Wright (2015) New experimental data and reference models for the viscosity and density of squalane. Journal of Chemical and Engineering Data 60(1):137-150. https://doi.org/10.1021/je5008789

[64] Bair S, Casalini R (2008) A scaling parameter and function for the accurate correlation of viscosity with temperature and pressure across eight orders of magnitude of viscosity. ASME Journal of Tribology 130(October):041802. https://doi.org/10.1115/1.2959116

[65] Fernández J, López ER (2014) Density scaling approach. Experimental Thermodynamics Volume IX : Advances in Transport Properties of Fluids, eds Assael MJ, Goodwin ARH, Vesovic V, Wakeham WA (Royal Society of Chemistry, Cambridge, UK), pp 307-336. http://dx.doi.org/10.1039/9781782625254

[66] Ashurst WT, Hoover WG (1975) Dense fluid shear viscosity and thermal conductivity—The excess. AIChE Journal 21(2):410411. https://doi.org/10.1002/aic.690210233

[67] Fomin YD, Brazhkin VV, Ryzhov VN (2012) Transport coefficients of soft sphere fluid at high densities. JETP Letters 95(6):320-325. https://doi.org/10.1134/S0021364012060045

[68] Deegan RD, Leheny RL, Menon N, Nagel SR, Venerus DC (1999) Dynamic shear modulus of tricresyl phosphate and squalane. Journal of Physical Chemistry B 103(20):4066-4070. https://doi.org/10.1021/jp983832g

[69] Comuñas MJP, Paredes X, Gaciño FM, Fernández J, Bazile JP, Boned C, Daridon JL, Galliero G, Pauly J, Harris KR, Assael MJ, Mylona SK (2013) Reference correlation of the viscosity of squalane from 273 to $373 \mathrm{~K}$ at $0.1 \mathrm{MPa}$. Journal of Physical and Chemical Reference Data 42(3):033101. https://doi.org/10.1063/1.4812573

[70] Bair S, Andersson O, Qureshi FS, Schirru MM (2018) New EHL modeling data for the reference liquids squalane and squalane plus polyisoprene. Tribology Transactions 61(2):247-255. https://doi.org/10.1080/10402004.2017.1310339

[71] Outcalt SL, McLinden MO (2007) Automated densimeter for the rapid characterization of industrial fluids. Industrial and Engineering Chemistry Research 46(24):8264-8269. https://doi.org/10.1021/ie070791e

[72] Schaschke CJ, Abid S, Fletcher I, Heslop MJ (2008) Evaluation of a falling sinker-type viscometer at high pressure using edible oil. Journal of Food Engineering 87(1):51-58. https://doi.org/10.1016/j.jfoodeng.2007.09.032

[73] Kishore K, Shobha HK (1992) Thermodynamics of flow and vaporization processes in long-chain liquids. Journal of Physical Chemistry 96(20):8161-8168. https://doi.org/10.1021/j100199a063 


\section{Journal of Research of the National Institute of Standards and Technology}

[74] Fandiño O, García J, Comuñas MJP, López ER, Fernández J (2006) P $\rho$ T measurements and equation of state (EOS) predictions of ester lubricants up to $45 \mathrm{MPa}$. Industrial and Engineering Chemistry Research 45(3):1172-1182. https://doi.org/10.1021/ie050818z

[75] Laesecke A, Fortin TJ, Splett JD (2012) Density, speed of sound, and viscosity measurements of reference materials for biofuels. Energy Fuels 26(3):1844-1861. https://doi.org/10.1021/ef201645r

[76] Fortin TJ, Laesecke A, Widegren JA (2016) Measurement and correlation of densities and dynamic viscosities of perfluoropolyether oils. Industrial and Engineering Chemistry Research 55(30):8460-8471. https://doi.org/10.1021/acs.iecr.6b01921

[77] Widegren JA, Laesecke A, Magee JW (2005) The effect of dissolved water on the viscosities of hydrophobic room-temperature ionic liquids. Chemical Communications 2005(12):1610-1612. https://doi.org/10.1039/B417348A

[78] Hellmann R, Jäger B, Bich E (2017) State-of-the-art ab initio potential energy curve for the xenon atom pair and related spectroscopic and thermophysical properties. Journal of Chemical Physics 147(3):034304. https://doi.org/10.1063/1.4994267

[79] Hellmann R (2017) Intermolecular potential energy surface and thermophysical properties of propane. Journal of Chemical Physics 146(11):114304. https://doi.org/10.1063/1.4978412

[80] Hellmann R (2014) Ab initio potential energy surface for the carbon dioxide molecule pair and thermophysical properties of dilute carbon dioxide gas. Chemical Physics Letters 613:133-138. https://doi.org/10.1016/j.cplett.2014.08.057

[81] Laesecke A (2002) Through measurement to knowledge: The inaugural lecture of Heike Kamerlingh Onnes (1882). Journal of Research of the National Institute of Standards and Technology 107(3):261-277. https://doi.org/10.6028/jres.107.021

About the authors: Arno Laesecke was a guest researcher, contractor, and staff member in the Applied Chemicals and Materials Division of NIST from August 1988 until his retirement at the end of March 2018.

Clemens Junker, M.Sc., is a captain in the German Army and a doctoral candidate in the Department of Mechanical Engineering of the Helmut-Schmidt University of the Federal Armed Forces at Hamburg, Germany. He served with the International Security Assistance Force (ISAF) in Afghanistan.

Damian S. Lauria, M.Sc., is a computer scientist and laboratory automation specialist for the Laboratory Automation Group in NIST's Research Services Office. He served with the Peace Corps in Togo, West Africa.

The National Institute of Standards and Technology is an agency of the U.S. Department of Commerce. 